\title{
Seismic performance of Composite Plate Shear Walls
}

\author{
Sandip Dey
}

A Thesis

in

The Department of

Building, Civil \& Environmental Engineering

Presented in Partial Fulfillment of the Requirements

for the Degree of Master of Applied Science (Civil Engineering) at

Concordia University Montreal, Quebec Canada

September, 2014

(C) Sandip Dey, 2014 


\section{CONCORDIA UNIVERSITY School of Graduate Studies}

This is to certify that the thesis prepared

By: $\quad$ Sandip Dey

Entitled: $\quad$ Seismic performance of Composite Plate Shear Walls

and submitted in partial fulfillment of the requirements for the degree of MASc Civil Engineering

complies with the regulations of the University and meets the accepted standards with respect to originality and quality.

Signed by the final examining committee:

Dr. Ashutosh Bagchi Chair

Dr. Muthukumaran Packirisamy Examiner

Dr. Khaled Galal Examiner

Dr. Anjan Bhowmick Supervisor

Approved by

Chair of Department or Graduate Program Director

Dean of Faculty

Date 


\section{ABSTRACT \\ Seismic performance of Composite Plate Shear Walls}

\section{Sandip Dey}

Composite plate shear wall (C-PSW) is a lateral resisting system primarily used to resist wind and earthquake loadings. A composite steel plate shear wall system consists of a steel plate shear wall with reinforced concrete panels attached to one side or both sides of the steel infill plates by bolts or shear studs. Research on composite plate shear walls is still in the initial stage and a significant amount of research is needed before it can be adopted by the Canadian steel design code, CAN/CSA S16-09. This study evaluates performances of one 6-storey and one 4-storey CPSW under spectrum compatible seismic records for Vancouver. A nonlinear finite element model which includes both material and geometric nonlinearities is used for this study. The model is first validated using the results from a quasi-static test. The study describes details of the validation of the finite element model by comparing the results from quasi-static experimental program with finite element analysis results. Excellent correlation between the test results and the finite element analysis results is observed. With the validated finite element model, the performance of 4-storey and 6-storey C-PSWs were studied under spectrum-compatible seismic records. Nonlinear seismic analysis shows that C-PSWs, in high seismic region, behave in a stable and ductile manner. Dynamic analysis showed that major portion of the shear is taken by the steel infill plate, which confirms the intended design philosophy of C-PSWs. 
A series of C-PSWs with different geometry were designed and analysed to estimate the fundamental periods. It is observed that the current code formula predicts periods that are generally shorter than the periods obtained from finite element analysis. In addition, the effectiveness of a simple shear flexure cantilever formulation for determining fundamental periods of C-PSWs was studied.

Shear studs spacing and concrete panel thickness are two important parameters that influence the performance of the composite plate shear wall. Currently there are no guidelines on what would be the minimum or maximum spacing of the shear studs. A rational method based on classical buckling theory of stiffened plate for determining shear stud spacing and thickness for the reinforced concrete panel is presented in this research. 


\section{ACKNOWLEDGEMENTS}

I would like to express my deep gratitude and sincere appreciation to Dr. Anjan Bhowmick for his guidance and encouragement throughout the course of my graduate studies.

Funding for this research project is provided by the Faculty of Engineering and Computer Science, Concordia University, Montreal, Canada and the Natural Sciences and Engineering Research Council of Canada. Their support is gratefully acknowledged.

Thanks to all my seniors, colleagues and friends especially Arghya Chatterjee, Mona Raissi, Moon Moon Dhar, Amit Chanda and Mrinmoy Nath for making my graduate studies so memorable. Wish you all the best in your future endeavors. Hope to stay in touch with you all and derive help as always.

I would also like to thank my family for their support and encouragement during my studies. 


\section{TABLE OF CONTENTS}

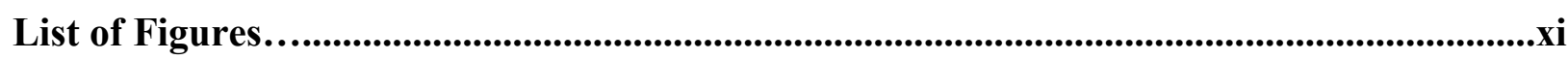

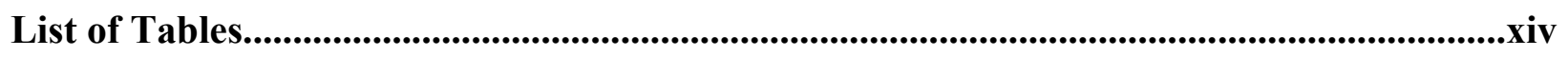

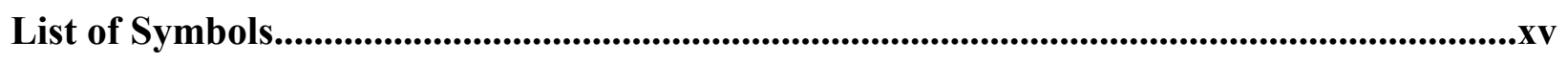

Chapter 1. Introduction......................................................................1

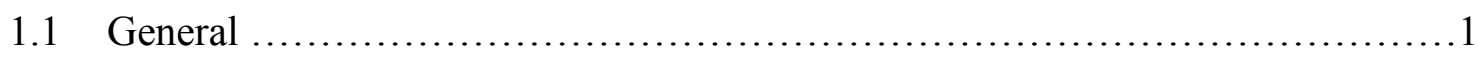

1.2 Objective and Scope...............................................

1.3 Organization of the thesis..............................................

Chapter 2. Literature Review...............................................................7

2.1 General overview..................................................

2.2 Selected works on Steel Plate Shear Walls.................................

2.2.1 Thorburn, Kulak and Montgomery (1983) .............................................. 8

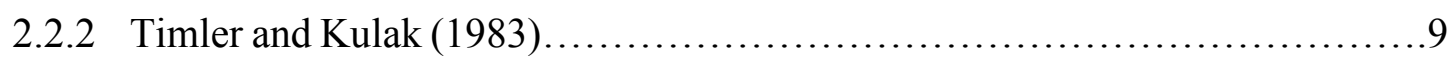

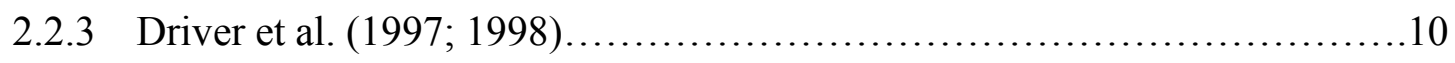

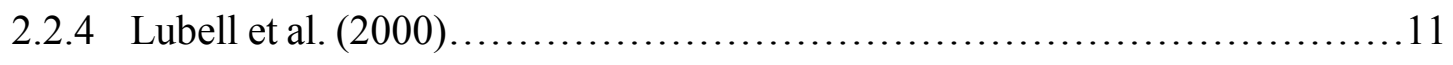

2.2.5 Berman and Bruneau (2008) ....................................... 
2.3 Works on Composite Shear Walls

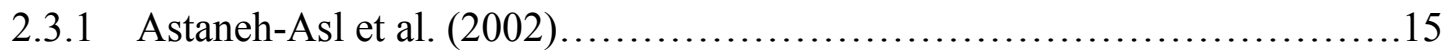

2.3.2 A.Rahai and F. Hatami (2009) .........................................18

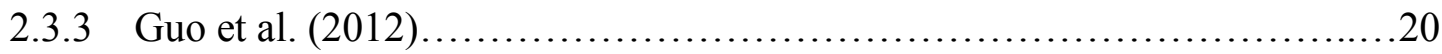

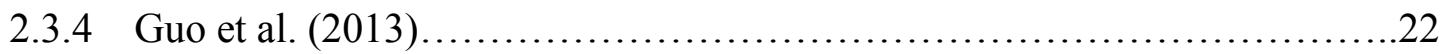

2.4 Works on constitutive concrete models.....................................25

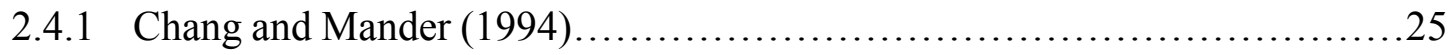

2.4.2 Belarbi and Hsu (1994)...................................................

2.4.3 Hsu and Hsu (1994) .................................................

Chapter 3. Finite Element Analysis of Composite Plate Shear Walls (C-PSWs)..............33

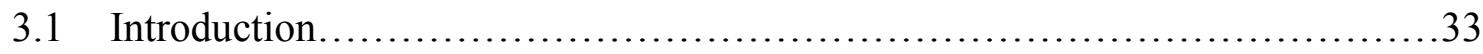

3.2 Selection of finite element analysis technique...............................33

3.3 Characteristics of finite element model.......................................34

3.3.1 Initial conditions and assumptions.........................................

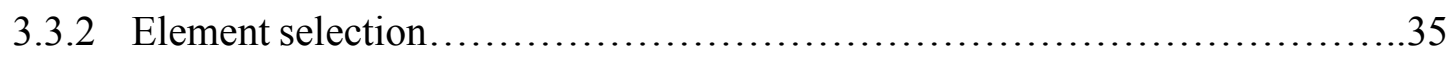

3.3.3 Steel material properties....................................................

3.3.4 Concrete material properties............................................... 
3.3.5 ABAQUS Concrete damage plasticity model.

3.3.6 Concrete constitutive model in tension 43

3.3.7 Concrete constitutive model in compression. .46

3.3.8 Other concrete damage plasticity parameters. 49

3.4 Displacement control analysis. 51

3.5 Validation of the finite element model..... .51

3.5.1 Pushover analysis and results of Astaneh-Asl (2002) specimen .52

3.5.2 Comparison of hierarchical order of failure modes .54

3.6 Comparison of pushover curves for C-PSW and SPSW .55

3.7 Conclusion. .56

Chapter 4. Seismic Performance of C-PSWs..............................................57

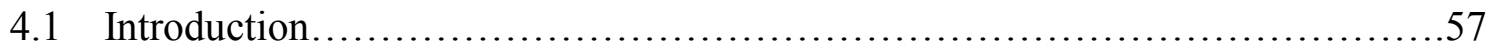

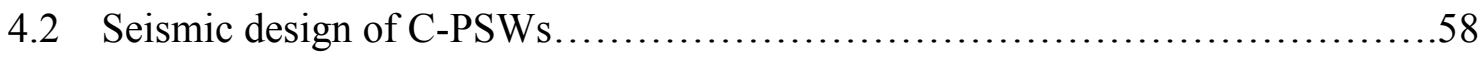

4.3 Selection of C-PSW system...............................................63

4.4 Finite element model of 4-storey and 6-storey C-PSWs.......................67

4.5 Non-linear dynamic seismic analyses of C-PSWs............................68

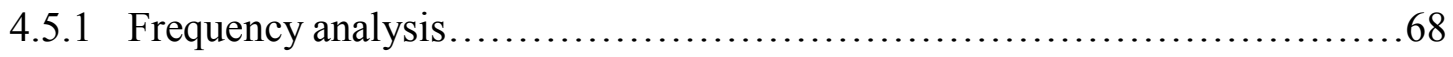


4.5.2 Ground motion time histories

4.5.3 Seismic response of C-PSWs .76

4.6 Conclusions.

Chapter 5. Fundamental Periods of C-PSWs using equivalent shear-flexure cantilever beam model..............................................................................92

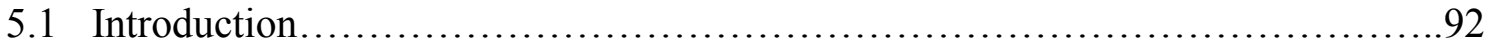

5.2 Selection of C-PSWs for evaluationof code-based period formula................92

5.3 Evaluation of code period formula for C-PSWs............................98

5.4 Equivalent shear-flexure cantilever beam model for C-PSWs................. 104

5.5 Bending and shear stiffness of equivalent shear-flexure cantilever beam model...105

5.5.1 Bending rigidity of equivalent shear-flexure cantilever beam model......106

5.5.2 Shear rigidity of equivalent shear-flexure cantilever beam model.........107

5.6 Fundamental periods of C-PSWs using cantilever beam model.................110

5.7 Conclusion...................................................... 112

Chapter 6. Rational method for determination of stud spacing and concrete panel thickness

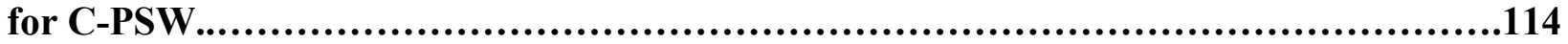

6.1 Introduction....................................................... 114

6.2 Buckling of composite plate shear wall.................................114

6.2.1 Local buckling mode for spacing of shear studs........................115 
6.2.2 Reinforced concrete panel thickness requirements......................118

6.3 Conclusion..............................................................

Chapter 7. Summary and conclusions.....................................................121

7.1 Summary........................................................... 121

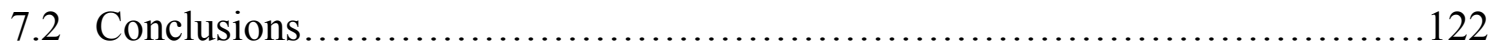

7.3 Scope of future work............................................. 123

Reference..........................................................................................125 


\section{List of Figures}

Figure 1.1 : Components of a Composite Plate Shear Wall.................................

Figure 2.1 : $\quad$ Strip model (Thorburn et al. 1983) ......................................... 9

Figure 2.2 : Four storey experimental specimen (Driver et al. 1997).......................11

Figure 2.3 : Single storey experimental specimen (Lubell et al. 1997).....................13

Figure 2.4 : Boundary Column free body diagram (Berman and Bruneau, 2008)..............14

Figure 2.5 : Composite Plate Shear wall specimen (Astaneh-Asl et al., 2002)...............16

Figure 2.6 : Composite Plate Shear wall specimen (A. Rahai and F. Hatami, 2009)..........19

Figure 2.7 : Composite Shear wall in composite frame specimen (Guo et al., 2012).........21

Figure 2.8 : CSPSW connected with frame beams only (Guo et al., 2013).................24

Figure 3.1 : Parameters for tension stiffening model of concrete (ABAQUS Manual, 2011)...42

Figure 3.2 : Parameters for compression hardening model of concrete....................42

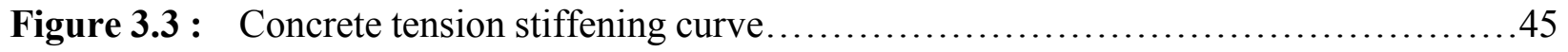

Figure 3.4 : Concrete tension damage curve.....................................45

Figure 3.5 : Concrete compression hardening curve................................48

Figure 3.6 : Concrete compression damage curve.....................................48

Figure 3.7 : Finite element mesh of Astaneh et al. (2002) 'innovative' specimen..............51

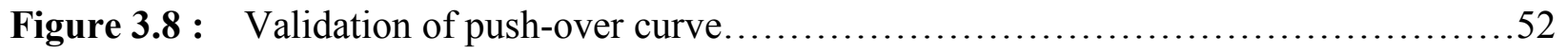

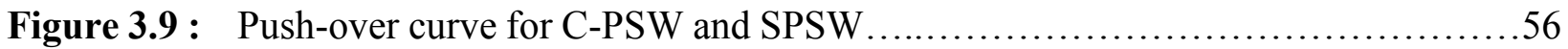

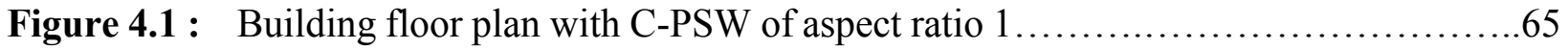




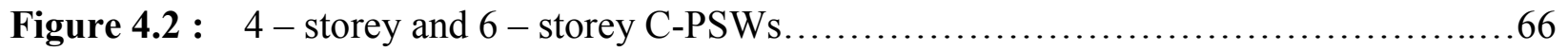

Figure 4.3 : Scaled accelerograms for 6 - storey C-PSW ................................ 72

Figure 4.4 : Scaled accelerograms for 4 - storey C-PSW ............................... 73

Figure 4.5 : Acceleration spectra for accelerograms and design spectra for Vancouver.......74

Figure 4.6 : Acceleration spectra for accelerograms and design spectra for Vancouver.........75

Figure 4.7 : Peak storey shear contribution for different components of 4 - storey C-PSW.....79

Figure 4.8 : Peak storey shear contribution for different components of 4 - storey C-PSW ....80

Figure 4.9 : Peak storey shear contribution for different components of 6 - storey C-PSW....81

Figure 4.10 : Peak storey shear contribution for different components of 6 - storey C-PSW...82

Figure 4.11 : Right column axial force and moment of 4 - storey C-PSW .................83

Figure 4.12 : Left column axial force and moment of 4 - storey C-PSW ...................84

Figure 4.13 : Right column axial force and moment of 6 - storey C-PSW ................85

Figure 4.14 : Left column axial force and moment of 6 - storey C-PSW .................86

Figure 4.15 : Storey displacements at instant of peak top storey displacement...............87

Figure 4.16 : Inter-storey drift ratio at instant of peak top storey displacement ..............88

Figure 4.17 : Inter-storey drift ratio at instant of peak top storey displacement ..............89

Figure 4.18 : Yield pattern of 6-storey (left) and 4-storey (right) C-PSW at peak base shear

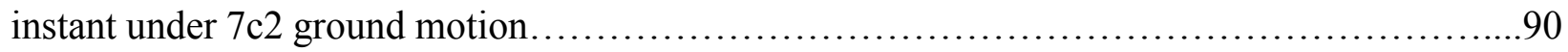

Figure 5.1 : Floor plan of buildings with C-PSW of aspect ratio $1.5 \ldots \ldots \ldots \ldots \ldots \ldots \ldots \ldots . \ldots 9$

Figure 5.2 : 1 -Storey specimen of 1 aspect ratio and 1.5 aspect ratio......................95

Figure 5.3 : 2-Storey specimen of 1 aspect ratio and 1.5 aspect ratio.....................95 
Figure 5.4 : 4-Storey specimen of 1 aspect ratio and 1.5 aspect ratio.....................96

Figure 5.5 : 6-Storey specimen of 1 aspect ratio and 1.5 aspect ratio.....................97

Figure 5.6 : Computed and code based periods for C-PSWs.............................99

Figure 5.7 : Fundamental mode shape of 1 storey 1 aspect ratio C-PSW...................100

Figure 5.8 : Fundamental mode shape of 1 storey 1.5 aspect ratio C-PSW..................100

Figure 5.9 : Fundamental mode shape of 2 storey 1 aspect ratio C-PSW...................101

Figure 5.10 : Fundamental mode shape of 2 storey 1.5 aspect ratio C-PSW ..................101

Figure 5.11 : Fundamental mode shape of 4 storey 1 and 1.5 aspect ratio C-PSWs...........102

Figure 5.12 : Fundamental mode shape of 6 storey 1 and 1.5 aspect ratio C-PSWs..........103

Figure 5.13 : Shear-flexure cantilever idealization of C-PSW ......................... 105

Figure 6.1 : Representation of horizontal and vertical stiffeners in C-PSW ............... 116 


\section{List of Tables}

Table 4.1 : Simulated earthquake records......................................... 70

Table 4.2 : Real earthquake records............................................ 70

Table 5.1 : Input parameter values in simple shear-flexure cantilever beam..................111

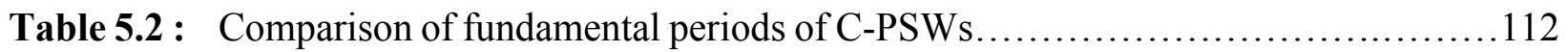




\section{List of Symbols}

$L_{1} \quad$ Width of the panel

$H \quad$ Height

$b, t \quad$ Infill plate thickness

$A_{b} \quad$ Cross sectional area of the beam

$A_{c} \quad$ Cross sectional area of the column

$I_{C} \quad$ Moment of inertia for columns

$f_{c}^{\prime} \quad$ Concrete compressive strength

$\varepsilon_{c}^{\prime} \quad$ Concrete strain at peak stress

$E_{c} \quad$ Initial stiffness of concrete in compression

$x_{c r}^{-} \quad$ Non-dimensional critical strain

$x^{-} \quad$ Non-dimensional strain parameter

$\varepsilon_{c} \quad$ Concrete strain

$x_{s p} \quad$ Non-dimensional spalling strain

$E_{t} \quad$ Initial stiffness of concrete tension

$\varepsilon_{t}^{\prime} \quad$ Strain at peak tensile stress

$x^{+} \quad$ Non-dimensional strain parameter

$x_{c r}^{+} \quad$ Non-dimensional critical strain

$x_{c r k} \quad$ Cracking strain

$\beta_{2} \quad$ Shape function of the curve

$\beta_{1} \quad$ Dilation angle

D Scalar degradation variable; Stud diameter 
$E_{0} \quad$ Initial elastic stiffness

: $\quad$ Tensor product

$\bar{\sigma} \quad$ Effective stress

$G \quad$ Scalar function

$\dot{\lambda} \quad$ Plastic consistency parameter

$f_{c} \quad$ Compressive strength of concrete

$f_{t} \quad$ Tensile strength of concrete

$\bar{\sigma}_{\max } \quad$ Maximum effective principal stress

$\bar{\sigma}_{c}\left(\widetilde{\varepsilon}_{c}^{p l}\right)$ Effective compressive cohesion stress

$\bar{\sigma}_{t}\left(\widetilde{\varepsilon}_{t}^{p l}\right)$ Effective tension cohesion stress

$f_{b o} \quad$ Compressive strength under biaxial loading

$f_{c 0} \quad$ Compressive strength under uniaxial loading

$\varepsilon_{t}^{c k} \quad$ Cracking strain

$\varepsilon_{t} \quad$ Total concrete tensile strain

$\varepsilon_{e l} \quad$ Elastic strain corresponding to undamaged concrete material

$\sigma_{t} \quad$ Concrete tensile stress

$\sigma_{C} \quad$ Compressive stress

$d_{t} \quad$ Tension damage parameter

$d_{c} \quad$ Compression damage parameter

$\varepsilon_{t}^{p l} \quad$ Tension plastic strain values

$\dot{\varepsilon}_{v} p \quad$ Volumetric plastic strain

$\dot{\varepsilon}_{1} p \quad$ Axial plastic strain 
$\varepsilon_{C}{ }^{p l} \quad$ Compression plastic strain values

$M_{V} \quad$ Amplification factor

$I_{E} \quad$ Importance factor for the structure

$R_{d} \quad$ Force modification factor of the structure related to ductility

$R_{0} \quad$ Over-strength related force modification factor of the structure

$F_{y p} \quad$ Yield strength

$t_{w i} \quad$ Steel infill thickness

$\alpha \quad$ Angle of tension field

$w_{y c i} \quad$ Vertical distributed force applicable to the columns

$w_{x c i} \quad$ Horizontal distributed force applicable to the columns

$w_{y b i} \quad$ Vertical distributed load applicable to the beams

$w_{x b i} \quad$ Horizontal distributed load applicable to the beams

$w \quad$ Infill plate thickness

$h_{s} \quad$ Storey height

$L \quad$ Bay width; Cantilever beam length

$I_{C} \quad$ Moment of inertia of the column cross-section

$I_{b} \quad$ Moment of inertia of the top beam cross-section

$A_{s p} \quad$ Horizontal area of the stiffened steel plate

$V_{n s} \quad$ Nominal shear force

$h_{n} \quad$ Height of the building in meters

$T \quad$ Fundamental time period of the structure

$\Delta \quad$ Deflection at the tip 


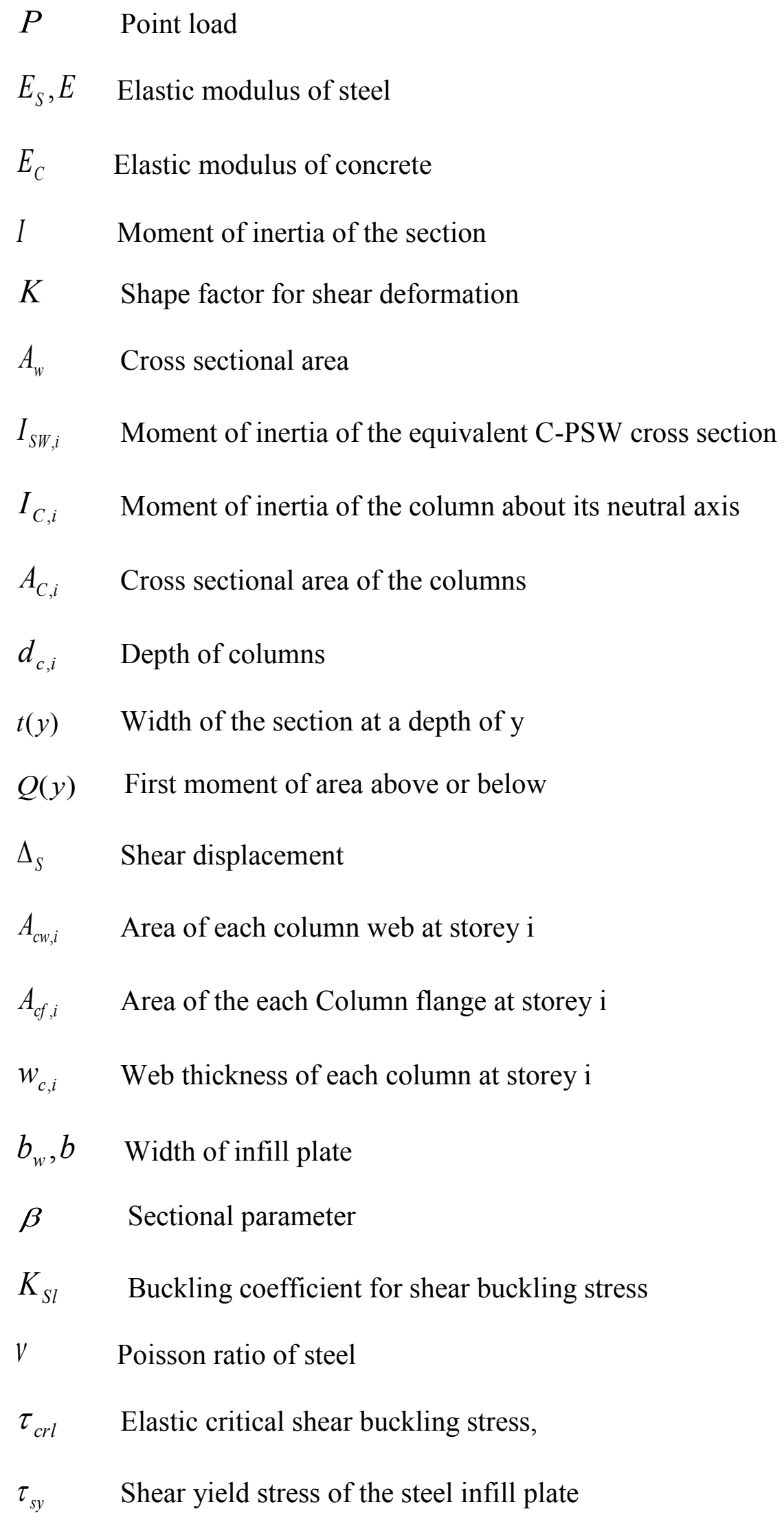


c Spacing of vertical and horizontal stiffeners

$K_{S g} \quad$ Global buckling factor

$D_{y} \quad$ Flexural stiffness for bending about y-axis

$D_{x} \quad$ Flexural stiffness for bending about $\mathrm{x}$-axis

$\tau_{c l} \quad$ Critical shear buckling stress 


\section{INTRODUCTION}

\subsection{General}

Shear walls have been long used as lateral load resisting systems. Some of the most commonly used shear walls in multistoried buildings are reinforced concrete shear walls (RC walls) and steel plate shear walls (SPSWs). Composite Plate Shear Walls (C-PSWs) incorporate components of a steel plate shear wall as well as a reinforced concrete shear wall. C-PSWs can be used as lateral load resisting systems which can resist both wind and earthquake forces.

Shear walls are one of the most common lateral load resisting systems used in high rise buildings. Steel plate shear walls (SPSW) have been extensively used as lateral load resisting systems in the past few decades. The most important characteristic of SPSW is in its ability to dissipate high energy and provide ductility in cases of extreme load events. SPSWs in their conventional form consist of a thin steel plate, two steel columns in the vertical direction and two horizontal floor beams surrounding the plate. It acts as a vertical plate girder with the columns acting as the flanges and the steel plate acting as the web. The horizontal floor beams add lateral stiffness to the system. The wall stiffness is provided by the diagonal tension field generated in the steel plate and by the yielding action of the steel frame. If design demands, these plates can be further stiffened to increase the overall stiffness of the system. The post-bucking strength is significant to be considered in the analysis and design. However there are some disadvantages regarding the overall buckling of the steel plates that can cause the reduction in the shear strength, stiffness and energy dissipation capacity (Zhao, 2004). Moreover, in steel shear walls, due to large 
inelastic deformations of the steel plate, the connections of the boundary columns and beams can undergo large cyclic rotations and inter-storey drifts (Allen, 1980). On the other hand, Concrete Shear Walls has its own disadvantages. During large cyclic displacements, they can develop tension cracks and localized crushing. In addition, when used in tall buildings, they develop relatively larger shear forces during earth quake due to high lateral stiffness. Construction efficiency is also poor for Concrete Shear Walls. Composite Plate Shear Walls (C-PSWs) can combine the advantages of steel and concrete shear walls. In C-PSWs, a layer of pre-cast or cast-in-situ reinforced concrete layer is connected to the steel plate from one or both sides to improve the shear capacity and also to safeguard against fire, explosions etc. The concrete panels also help to prevent the buckling of the steel counterparts before yielding thereby resisting storey shears by yielding in shears (Astaneh, 2002). When compared to Concrete shear walls, C-PSWs with the same shear strength are lighter in weight and smaller in thickness. Construction efficiency is also good since pre-cast concrete panels can be bolted to their steel counter parts at any convenient time during construction. There have been very limited research (Zhao, 2004) available on C-PSWs. Currently no seismic guidelines are available for this innovative C-PSW system in Canadian steel design standard CAN/CSA S16-09. Also, to date C-PSWs have never been studied under real seismic loadings and, thus, there is a need for seismic evaluation of this innovative shear wall system before it can be adopted in the Canadian design standard.

The current design codes and standards need accurate and credible assessment of inelastic structural response. The methods of analyzing a C-PSW for obtaining complete structural response curve would require sophisticated finite element analysis or to obtain reasonable approximation of the complete structural response, elastic analyses might be used supplemented with time 
consuming hand calculations. While, powerful and sophisticated software are used for research purposes, they are not common in industry. Design engineers need the ability to assess inelastic structural response using conventional analysis software that is commonly available and relatively simple and expeditious to use. Most software used by design engineers are elastic analysis programs using inelastic methods, using suitable approximations. So, an equivalent shear-flexure cantilever beam model for C-PSWs have been proposed to find out its fundamental periods considering stiffness from both the SPSW component and the RC panels.

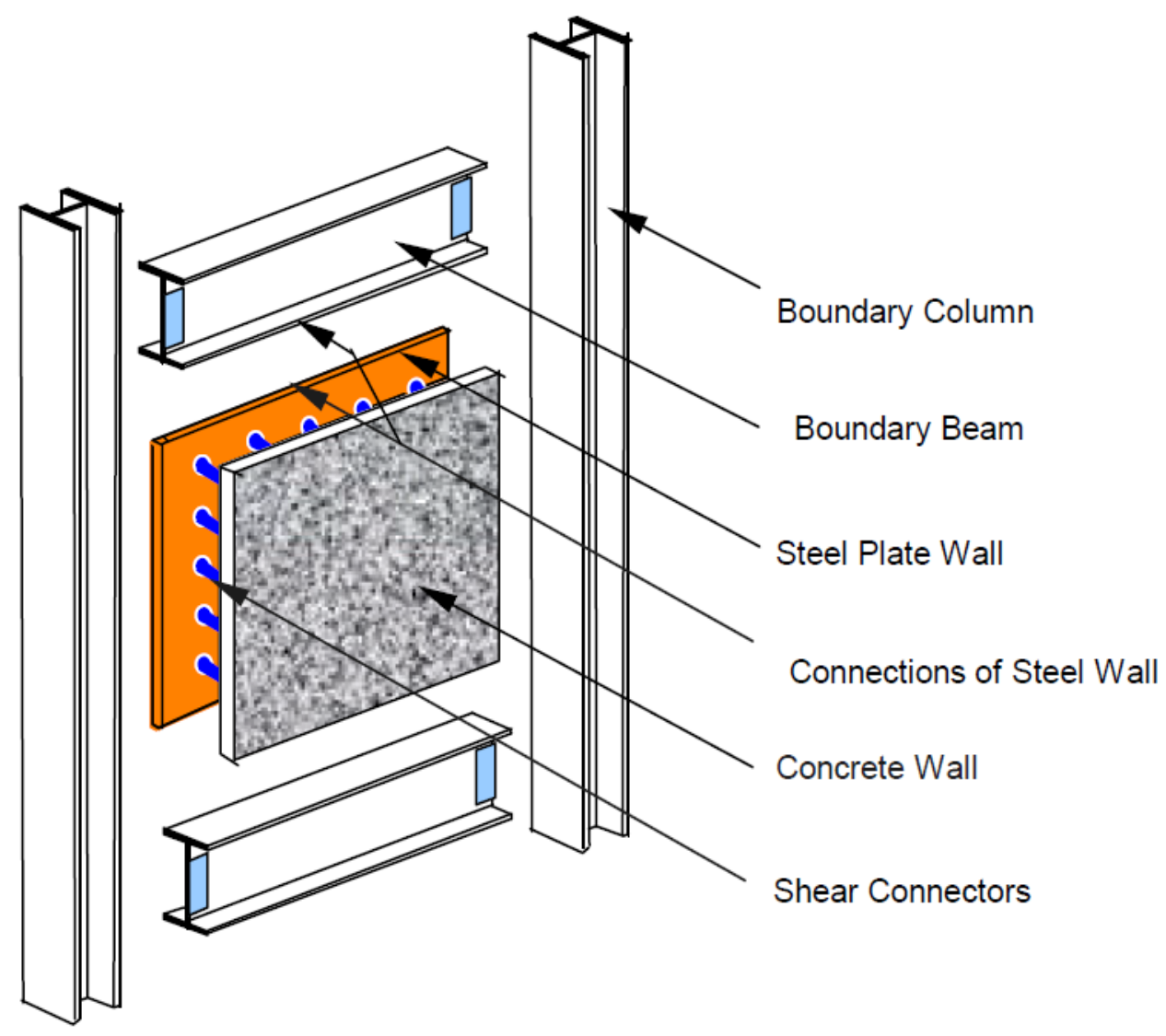

Figure 1.1: Components of a Composite plate shear wall (Astaneh, 2002) 
Current building code (NBCC 2010) provide the same period formula for seismic design of both reinforced concrete shear walls and SPSWs, which are known to have different dynamic properties. This empirical period formula needs to be evaluated.

\subsection{Objective and Scope}

Currently, no design guidelines exist for the design of C-PSWs in the Canadian steel design standard CAN/CSA S16-09. More research is required before a distinct set of guidelines can be prescribed for the design of C-PSWs. As mentioned earlier, a few experimental and analytical studies have been carried out in different countries on different forms of composite shear walls; comprising of different dimensions and aimed at studying cyclic behaviour of these structures and also the effect of parameters like aspect ratio, distance between shear studs, the nature of frame holding the composite plates, etc. It was noticed that, there is till now no published document on the behaviour of C-PSWs under spectrum compatible dynamic seismic loads. Thus one of the objectives of this research is to evaluate of the seismic performance of C-PSWs. A non-linear finite element model is developed to study the behaviour of C-PSWs. The research provides a detailed account of the finite element model validation. Some of the critical aspects of the detailed finite element model include modelling of the reinforced concrete panels, the proper modelling of the bolts connecting the steel infill plate with the RC panel and precision modelling of the various geometries of the C-PSWs. The validated FE model is used to conduct non-linear seismic analysis and frequency analysis of C-PSWs. 
Another important objective of this research is to develop a simple shear-flexure cantilever model to estimate fundamental periods of C-PSWs. This is done by conducting frequency analyses of C-PSWs with different geometry and then comparing the results with the results from detailed FE model. This research presents theoretical formulations for combining the bending and shear rigidities of the various components of the C-PSWs like the steel infill, steel columns, RC panels and then incorporate them in a simple equivalent shear-flexure cantilever beam model.

\subsection{Organization of the thesis}

The present chapter provides an introduction to the C-PSW systems along with a brief background and aim of this present study.

Chapter 2 presents a literature review of previous work done on C-PSWs and SPSWs. This includes several experimental work as well as analytical work on the above topics. The chapter also contains review of some concrete constitutive models proposed relevant to the present study.

Chapter 3 describes details of the development and validation of a finite element model by comparing the results from quasi-static experimental program with finite element analysis results.

Chapter 4 deals with the non-linear seismic analysis of one 4-storey and one 6-storey C-PSW under spectrum compatible seismic records for Vancouver. Critical aspects like shear contribution 
by infill plate, reinforced concrete panel, columns; column axial forces, column moments, inter storey drift, base reaction and damage pattern of various elements of the C-PSWs were studied.

Chapter 5 illustrates the theoretical formulations relating to the development of an equivalent shear-flexure cantilever beam model to represent C-PSWs for determining fundamental frequencies. It explains the modeling of the shear-flexure cantilever beam and its validation to predict fundamental frequencies of C-PSWs.

Chapter 6 presents a rational method for determination of stud spacing and reinforced concrete panel thickness for composite plate shear walls.

Finally, chapter 7 provides a summary of the research conducted and presents conclusions from all aspects of the research. It also recommends future scope of study for C-PSWs. 


\section{LITERATURE REVIEW}

\subsection{General Overview}

C-PSWs incorporate components of both SPSWs as well as reinforced concrete walls. This section provides information on selected related research on Steel Plate Shear Walls (SPSWs), Composite Plate Shear Walls (C-PSWs), and Composite Steel Plate Shear Walls (CSPSWs) in composite frame, CSPSWs with only frame beams. The chapter also includes certain constitutive models of concrete studied in due course of this research for modelling the concrete material model.

\subsection{Selected works on Steel Plate Shear Walls}

This section presents an account of selected researches on SPSWs. They are accepted widely as effective lateral resistant system in the last decades. In the early years, the common practice was to stiffen the infill plate. These SPSWs performed as strong and stiff structures with spindle shaped hysteresis loops lacking pinching effects. In the year 1983, Canadian researchers for the first time introduced SPSWs with thin infill plate devoid of stiffeners and established as a possible acceptable system. This system was then subsequently followed up by researchers all around the globe to study it both experimentally as well as numerically. The following selected works provides an account of the development of the research in this field. 


\subsubsection{Thorburn, Kulak and Montgomery (1983)}

Thorburn et al. (1983) developed a couple of analytical models to represent unstiffened thin steel infill panels based on the theory of diagonal tension field actions first proposed by Wagner (1931). The model was based on load resisting mechanism of infill plates solely by virtue of diagonal tension field formation after buckling along the opposite diagonal; completely ignoring the strength of the plate in shear yielding or from compressive stresses. It was assumed that the plate buckles under low load and displacement levels. Other assumptions included that the columns were continuously running through the whole height of the wall and that the beams were connected to the columns using pin connection. The models included an equivalent brace model to represent the steel infill plate with suitable expressions for the brace area. The other model, called 'the strip model' involved representation of the steel infill plates with several pin ended parallel tension strips aligned along the principal tension stress direction in the infill plates as shown in Fig 2.1. The study came up with suitable angle of inclination and cross sectional area expression for the strips. The study also consisted of a parametric study. The strip model has been adopted in the Canadian steel design code CAN/CSA S16-09. The expression representing the angle of inclination for the tension field is as follows:

$$
\tan \alpha=\sqrt[4]{\frac{1+\frac{L_{1} b}{2 A_{c}}}{1+\frac{H b}{A_{b}}}}
$$

Where, ' $L_{1}$ ' is the width of the panel, ' $H$ ' denotes the height, ' $b$ ' is the infill plate thickness and ' $A_{c}$ ' and ' $A_{b}$ ' are the cross sectional area of the beam and column respectively. 


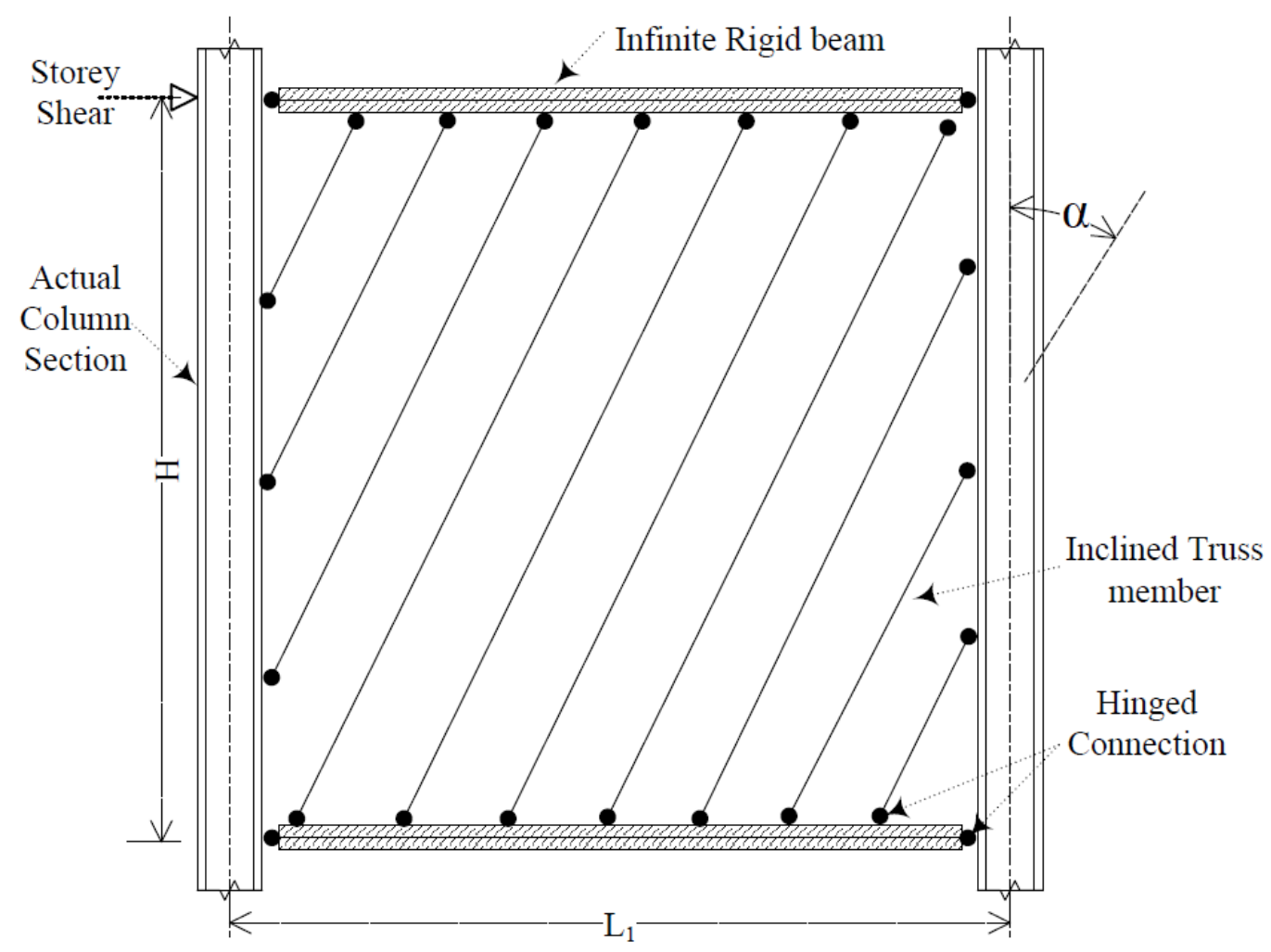

Figure 2.1: Strip model (Thorburn et al. 1983)

\subsubsection{Timler and Kulak (1983)}

Their study was based on experimentation of single storey SPSW designed according to 'strip model'. The experiment included loading under both service and ultimate conditions. The purpose was to verify Thorburn et al. s 'strip model' experimentally. The specimen behaved as predicted. Timler and Kulak (1983) modified the expression of angle of inclination as proposed by Thorburn et al. (1983) taking into account the column's bending stiffness. This expression was subsequently adopted in the Canadian design code CAN/CSA S16-09 and the American design standard AISC 2005. The expression is as follows: 


$$
\tan \alpha=\sqrt[4]{\frac{1+\frac{L_{1} b}{2 A_{C}}}{1+b H\left(\frac{1}{A_{b}}+\frac{H^{3}}{360 L_{1} I_{C}}\right)}}
$$

Where, ' $I_{C}$ ' denotes the moment of the columns and the other parameters are same as that of equation (2.1).

\subsubsection{Driver et al. $(1997 ; 1998)$}

Driver et al. performed experimental as well as analytical studies to evaluate performance of steel plate shear walls. They experimented with a four storey half scale SPSW as shown in Fig.2.2 under cyclic loads. Gravity loads were applied at the top of columns and equivalent cyclic lateral loads were applied at each floor level. The specimen included rigid connections and unstiffened steel infill plates. The results of the experiment indicated high initial stiffness, excellent ductility and high energy dissipation capacity of the SPSW. The SPSW was observed to attain ultimate strength of about $3020 \mathrm{kN}$ at drift ratio of 2.2 percent at the lowest storey, which was about five times the yield deflection. Beyond that, the strength decreased gradually with increase in drift. The maximum deflection attained after which the structure failed was at a drift ratio of 4 percent at the lowest storey, which was about nine times the yield deflection. Driver et al. also developed a finite element model to analytically study their specimens. Overall, the analytical results matched quite well with that of the experiments. The analytical model was successful in capturing the cyclic performance quite well, except for the pinching effect which was observed during the experiment. The model was also successful in capturing the ultimate strength but the initial stiffness varied slightly with that of the experiment. 


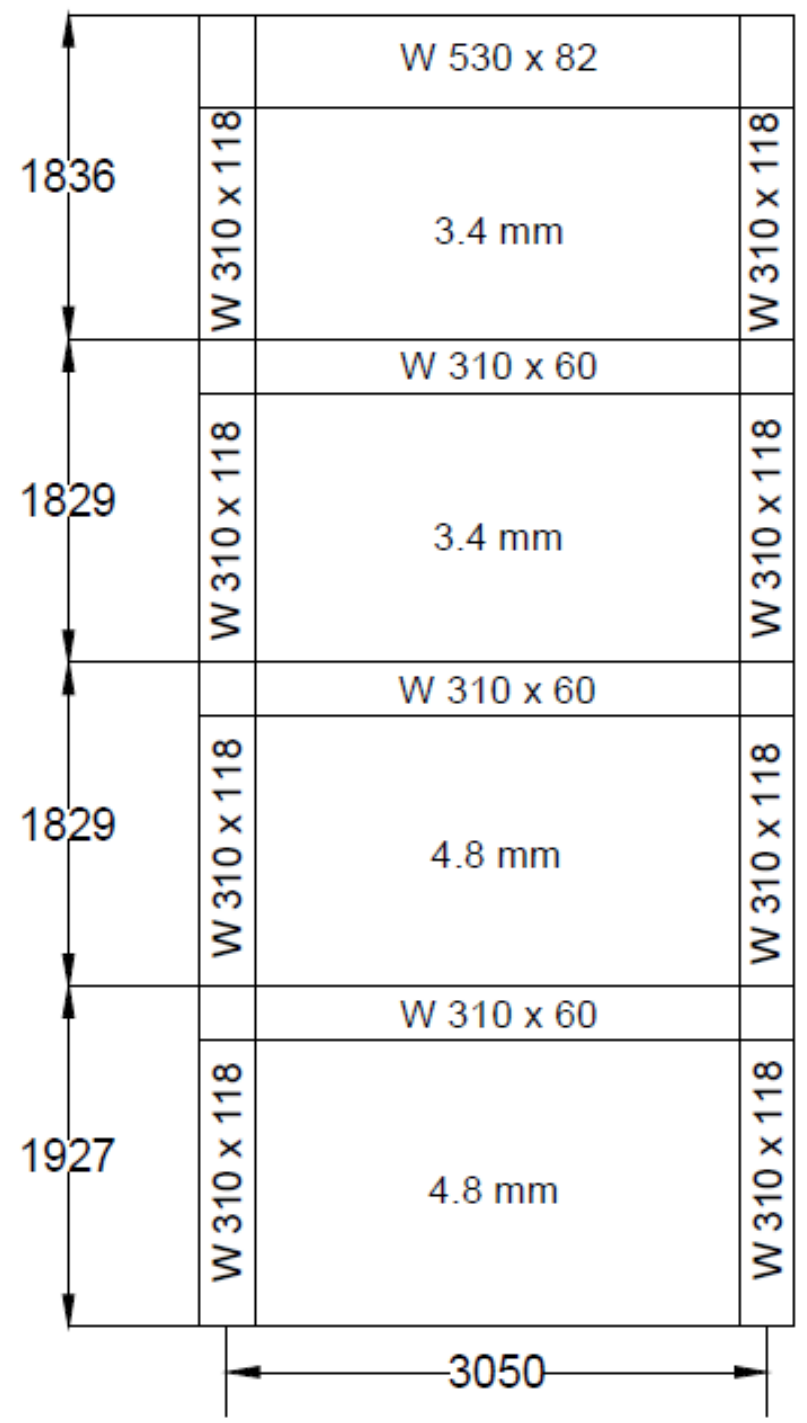

Figure 2.2: Four storey experimental specimen (Driver et al. 1997)

\subsubsection{Lubell et al. (2000)}

Lubell et al. performed experimental cyclic studies to evaluate performance of SPSWs. They experimented with three specimens; two of them single storey (SPSW-1 and SPSW-2) as shown in Fig. 2.3 and one four storey (SPSW-4) quarter scale SPSW specimens under cyclic loads. The specimens included rigid connections and unstiffened infill plates. The SWPWs were designed to 
have an aspect ratio of one. The single storey specimens represented the first storey of a four storey specimen. The $\mathrm{S} 75 \times 8$ sections were chosen for boundary members and $1.5 \mathrm{~mm}$ plate thickness was chosen for the infill plate. SPSW-2 varied from SPSW-1 in the way that, it consisted of an additional $\mathrm{S} 75 \times 8$ section top-beam fully welded with the existing top beam. This was done with the intention of better anchoring the diagonal tension field developed in the infill plates. A heavy S200 $\times 34$ section was used as the top beam for SPSW-4 specimen for the same purpose. It is to be noted that, SPSW-2 and SPSW-4 had much less imperfections in the infill plates compared to that of SPSW-1. The single storey specimens were loaded cyclically at the top of the storey, whereas the four storey specimen was loaded cyclically at the storey levels. Gravity loads were also applied, while loading the specimen cyclically.

The results showed stable hysteresis load vs. displacement curves. The single storey specimens performed well with sufficient initial stiffness and good displacement ductility. However, the performance of the 4 - storey specimen was not in the desirable manner. In the single storey specimens, the yielding sequence of the members was ideal, with the infill plates yielding first, followed by yielding in the boundary elements. The SPSW-4 however showed yielding in the boundary members first, which was undesirable. Incomplete tension field in the infill plates were also reported. The results indicated that the boundary members lacked sufficient strength in this set of experiments. Thus, this experiment highlighted the importance of sufficient strength of boundary elements for desirable performance of the SPSWs. It was also concluded that the columns in the four storey specimen failed due to high axial forces, as a result of higher overturning moments as compared to the single storey specimens. So, the study showed that SPSWs should be analyzed as a whole to properly study its behaviour instead of studying individual storey panels. 
Their study also included a numerical analysis of the experimental test specimens which was successful in predicting the performances of the test specimens quite well with some differences in the initial elastic stiffness.
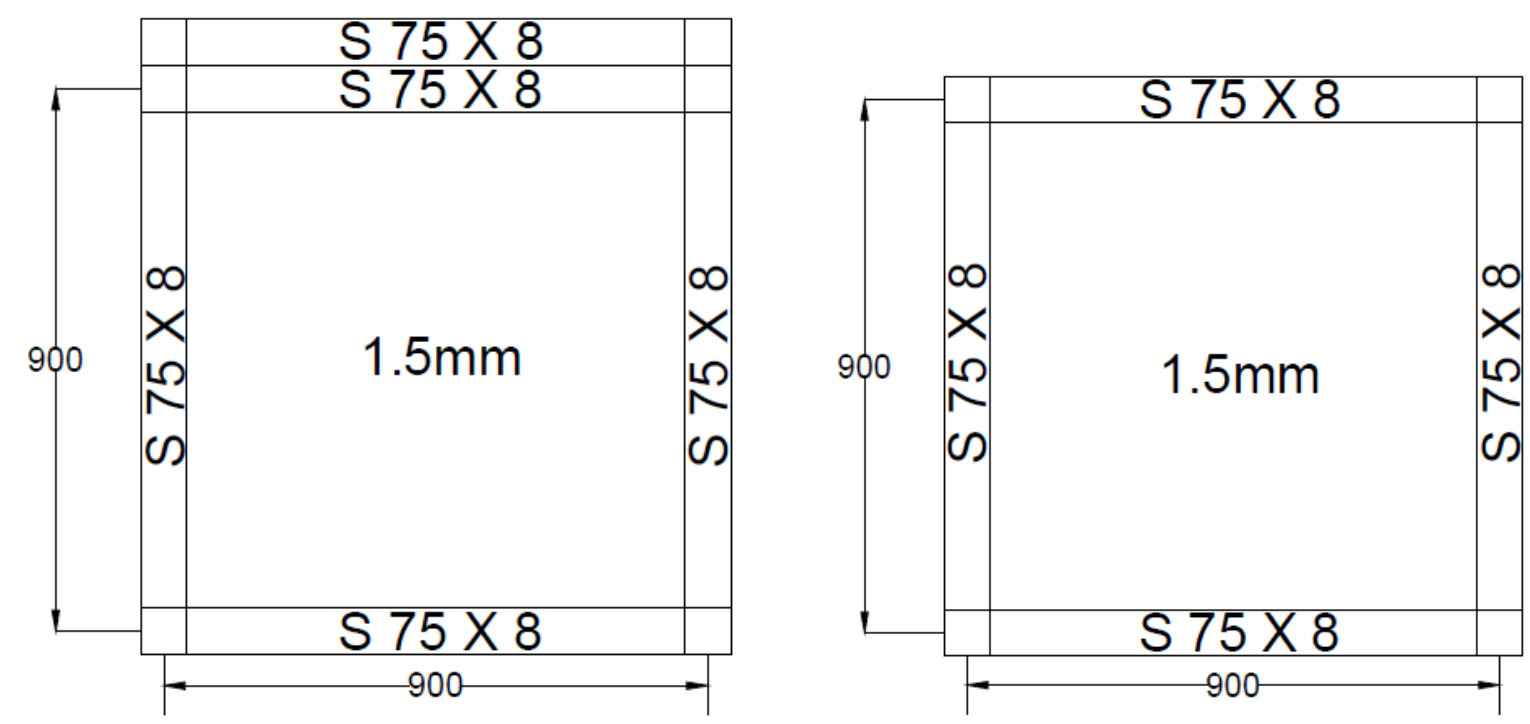

Figure 2.3: Single storey experimental specimen (Lubell et al. 1997)

\subsubsection{Berman and Bruneau (2008)}

Berman and Bruneau (2008) proposed capacity based design procedures for the design of vertical boundary members in SPSWs. The objective of the work was to find out a simple and effective way in determining the load demands in the vertical boundary elements when the infill plates yield completely. Their method involves a linear model as well as a plastic analysis. Axial forces in the beams were determined based on a model of the vertical boundary elements (columns) on elastic supports. To find out the lateral seismic loads, for full yielding in the infill plates and plastic hinge formation at the ends of the horizontal boundary elements (beams), a plastic collapse mechanism by Berman and Bruneau (2003) is used. It the end, the design axial forces and moments in the vertical boundary elements (columns) can be found out from the free body diagram of the 
columns. The forces participating in the free body diagram included uniformly distributed loads from the infill plate yielding, moment capacities from plastic hinging at beam ends, axial forces from the beams, applied lateral seismic loads and base reactions as shown in Fig. 2.4. The procedures to find out each of these forces were explained by the researchers.

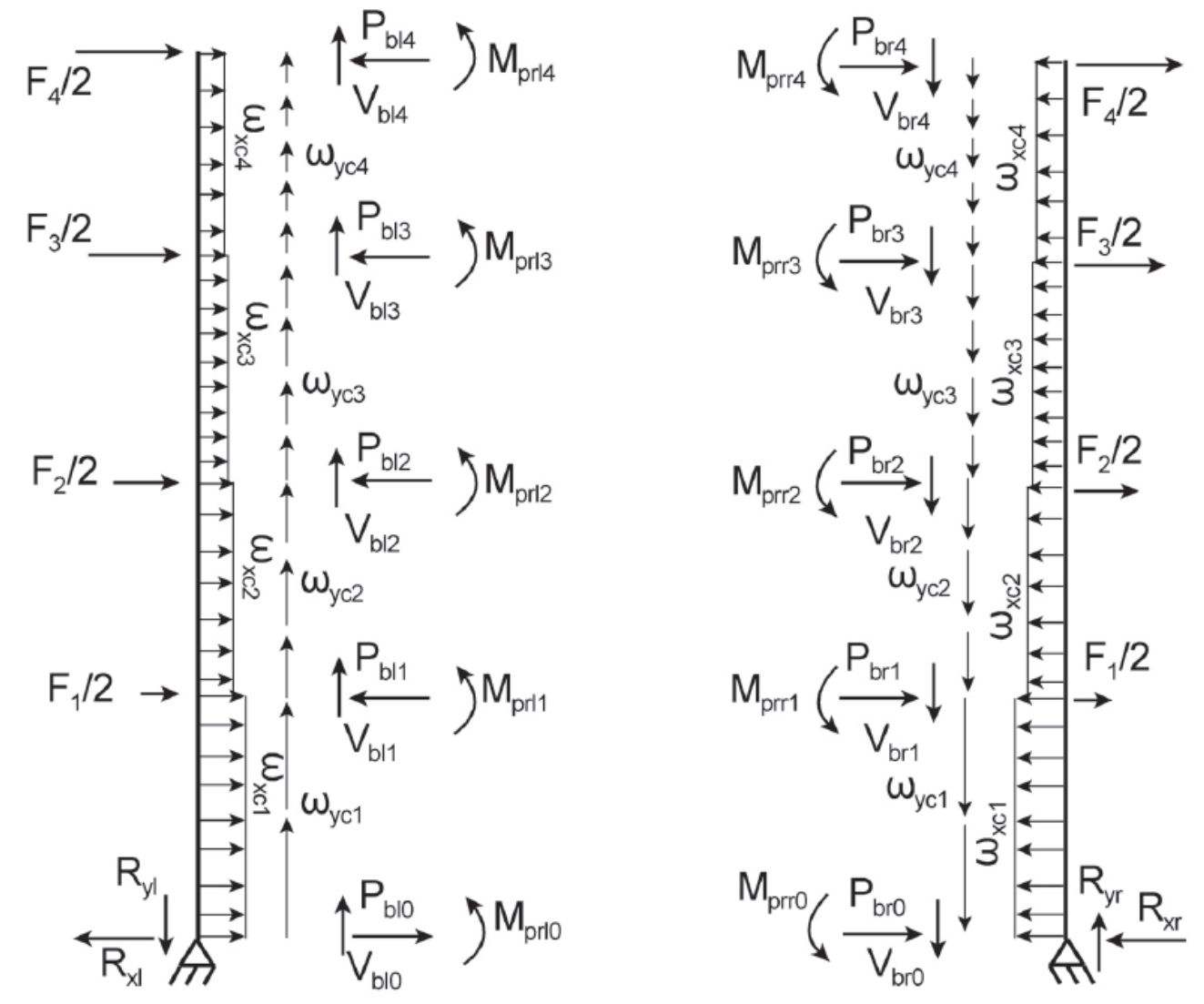

Figure 2.4: Boundary Column free body diagram (Berman and Bruneau, 2008)

Their study also included examples to design SPSWs based on this approach as well as preexisting capacity design methods and then comparing them by nonlinear static analysis. The preexisting capacity design approaches included that of the Indirect Capacity Design (ICD) approach and the Combined Linear Elastic Computer Programs and Capacity Design Concept (LE+CD) as given in AISC 2005. The results were very much in the favor of the proposed concept by Berman 
and Bruneau, which produced column moments and axial force design values much closer to the non-linear static pushover analysis as compared to the existing methods. It was stated that the proposed procedure ensures that the infill plate yields before plastic hinging in the columns, unlike the other two existing methods.

\subsection{Works on Composite Shear Walls}

This section presents a consolidated account of some of the significant works published on composite shear walls. These works are based on composite shear walls of various forms. Firstly, the C-PSW which mainly consists of a SPSW with the steel infill connected with RC panels on one or both sides by virtue of shear studs or bolts. Secondly, the CSPSW in composite frame, unlike the C-PSW; the column here is a steel-concrete composite column. Finally, there is another kind of composite shear wall researched named as the CSPSW in frame beams only. A brief account of these research and the findings are presented in the following sections.

\subsubsection{Astaneh-Asl et al. (2002)}

Astaneh-Asl et al. (2002) undertook a project to study the performance of composite plate shear walls under cyclic loads. The objective of their work was to investigate the behaviour of composite plate shear wall under cyclic load displacements and suggest suitable guidelines for the design of composite shear walls. Their specimen consisted of a type of composite plate shear wall, which included steel boundary elements surrounding the steel infill plates. The steel infill plates were stiffened with reinforced concrete panels on one side of the plate with shear studs placed at 
regular intervals throughout the surface of the plate. This experimental specimen had two variants, namely the 'innovative' C-PSW and the 'traditional' C-PSW. The 'innovative' specimen had a gap of $32 \mathrm{~mm}$ between the periphery of the concrete panel and the steel boundary elements. On the other hand, the 'traditional' specimen lacked any such gap and the concrete panel periphery flushed directly with the surrounding boundary steel members. The yield strength of the steel for the boundary elements and the infill plates were $350 \mathrm{MPa}$ and $248 \mathrm{MPa}$ respectively. The concrete had a compressive resistance of $28 \mathrm{MPa}$. The specimens were half scale, three storey, one-bay structures as shown in Fig. 2.5. The out of plane movement of the C-PSWs as a unit was restricted using suitable arrangements and cyclic displacements were applied at the top level. The bases were fixed to reaction blocks.
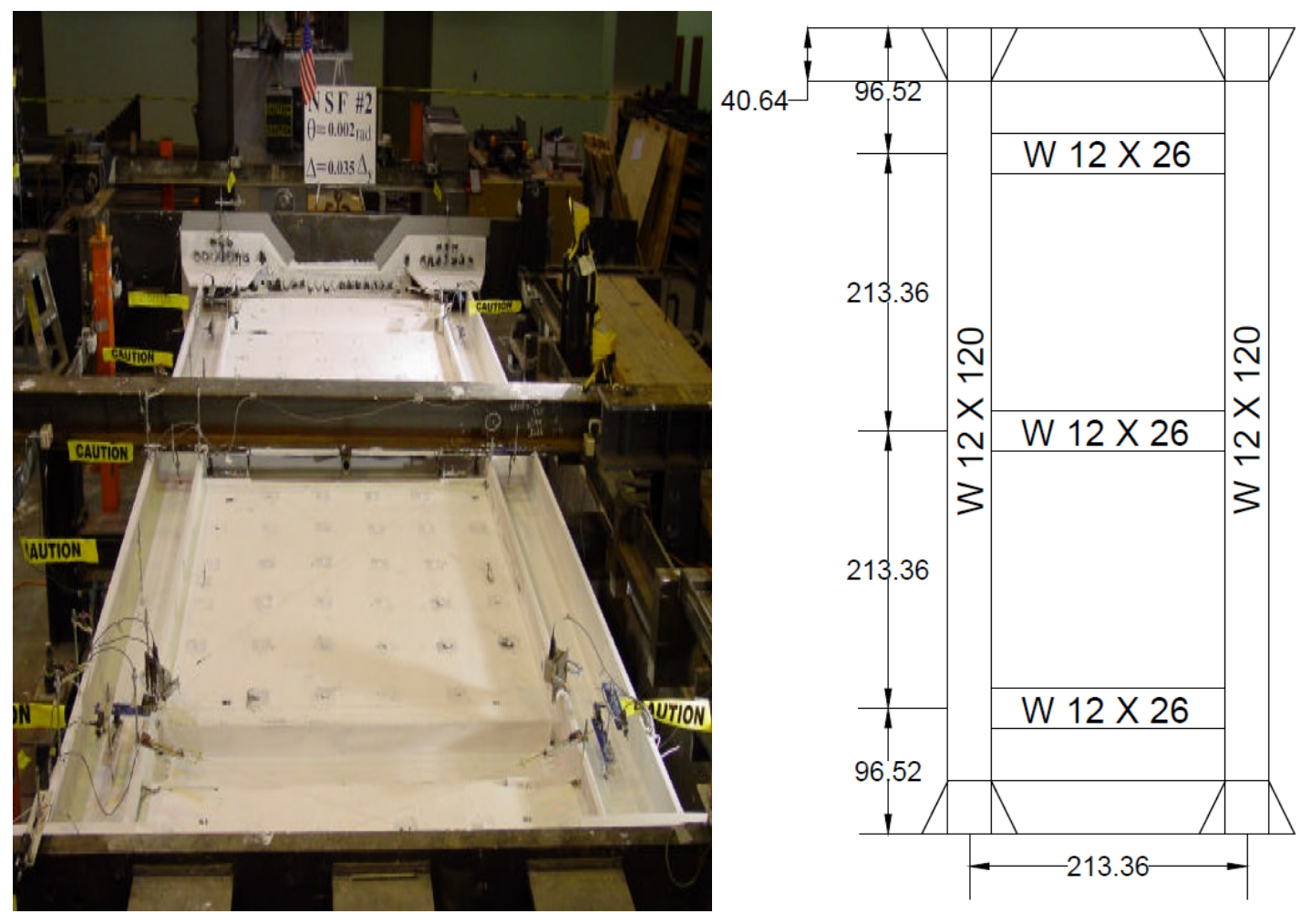

Figure 2.5: Composite Plate Shear wall specimen (Astaneh-Asl et al., 2002) 
The results showed that these systems performed quite well as lateral load resisting systems. They were capable in exceeding very high inter storey drift value of about $4 \%$ without significant reduction of shear strength. The reinforced concrete cover was successful in preventing overall out-of-plane buckling of the infill plates before yielding; thus allowing the infill plates to fail in shear rather than by forming diagonal tension fields. The reinforced concrete cover was undamaged up to higher drift limits in the 'innovative' specimen when compared to the 'traditional' specimen. The 'traditional' specimen was found to offer slightly higher strength as compared to the 'innovative' specimen. The initial stiffness of the 'traditional' specimen was also determined to be marginally higher than the 'innovative' one. The significant difference between the performances of the two specimens as reported, was the degree of damage in the RC panel. The 'traditional' specimen was reported to have developed cracks and crushed regions along the entire edge of the wall during the early cycles. During higher drift levels, the entire RC panel was found to be destroyed in the 'traditional' specimen. However, in the 'innovative' specimen, the degree of damage to the RC panel was limited.

Based on this study, Astaneh et al. proposed some seismic design recommendations for composite shear walls. Based on past literature reviews and experimental results, the authors identified possible failure modes of different components of composite shear walls. The failure modes were then arranged in hierarchical order and classified under 'ductile' and 'brittle' failure modes. Ductile failure modes included slippage of bolts, shear yielding of steel, yielding of beams. Brittle failure modes grossly included plastic hinges in columns, failure of concrete wall, fracture of beam moment connections, fracture of columns in tension etc. It was recommended to design the C-PSW in a way, to facilitate ductile modes of failure precede the brittle ones. 


\subsubsection{A. Rahai and F. Hatami (2009)}

This study included both experimentation and numerical analysis. Their study was aimed at finding out the effects of the distance between the shear studs on the overall behaviour on the CPSWs. The numerical study included modeling previously experimented C-PSWs and SPSWs to validate their model including the one by Astaneh et al. Although, the researchers claim to have modeled the specimen carefully, the cyclic curve of the numerical finite element model analysis didn't quite match with that of the experimental cyclic curves of Astaneh et al. (2002). After that, they went on to analyze 42 finite element model specimens with different geometries. An additional, 5 models of C-PSWs and SPSWs were studied both numerically and experimentally under cyclic loads. 3D BEAM elements with six degrees of freedom and the capability of warping being incorporated as the seventh degree of freedom were used to model the shear studs in the analytical model. To model the steel infill, steel columns and beams, 3D SHELL elements comprising of four nodes and 6 degrees of freedom per node were chosen. The RC panel was modelled using 3D SOLID elements. The solid elements consisted of three degrees of freedom per node for translation. The reinforcement bars were assumed to be spread in the SOLID elements with appropriate volume.

A total of 42 numerical models were modelled with $6.5 \mathrm{~m}$ width and $3 \mathrm{~m}$ height as shown in Fig. 2.6 to study the effect of distance between shear studs on the overall performance of the CPSWs. The boundary members, steel infill and concrete layer were designed so as to initiate yield in the steel infill, followed by beams and finally columns. The compressive strength of the concrete was assumed to be $45 \mathrm{MPa}$ and the steel yield strength was assumed to be $235 \mathrm{MPa}$. 


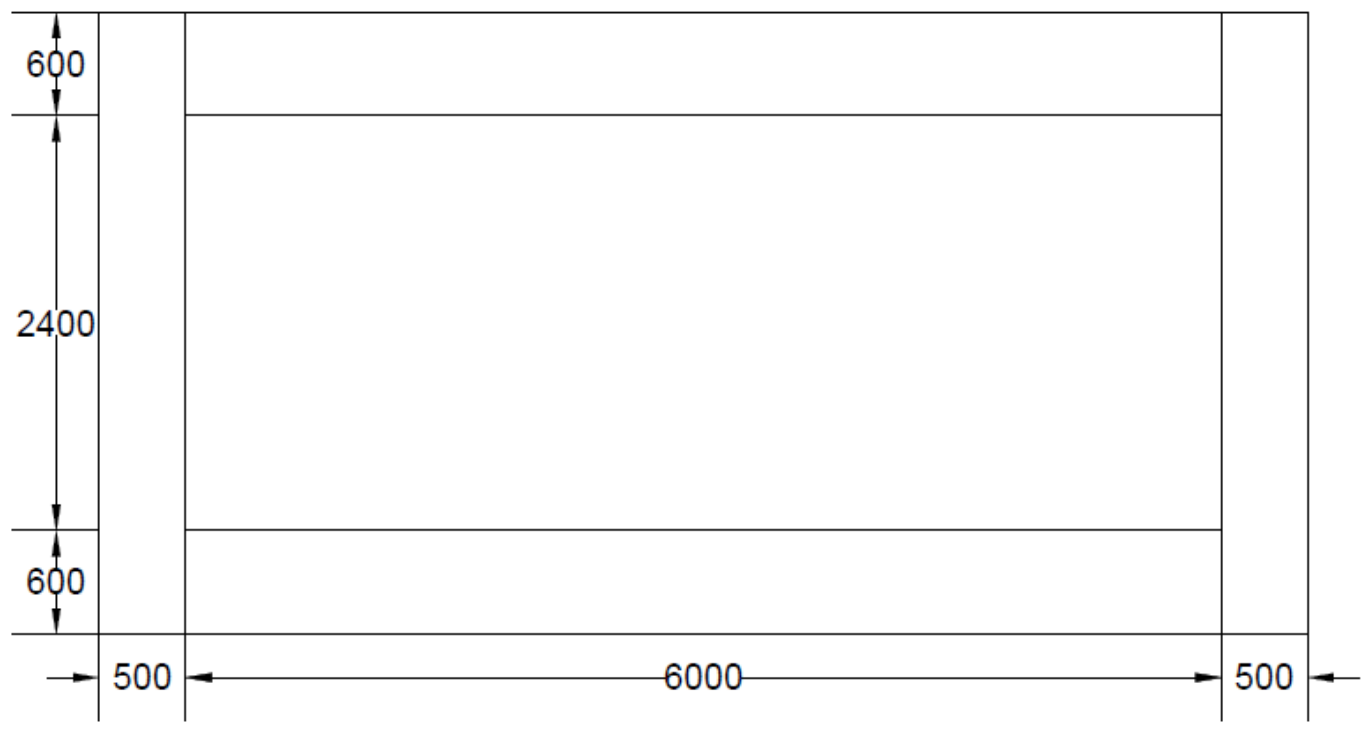

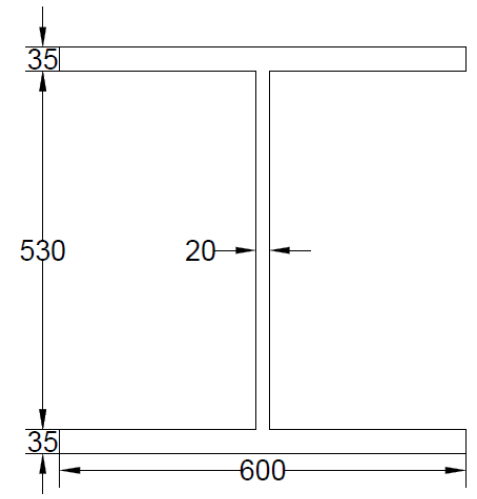

Beam section

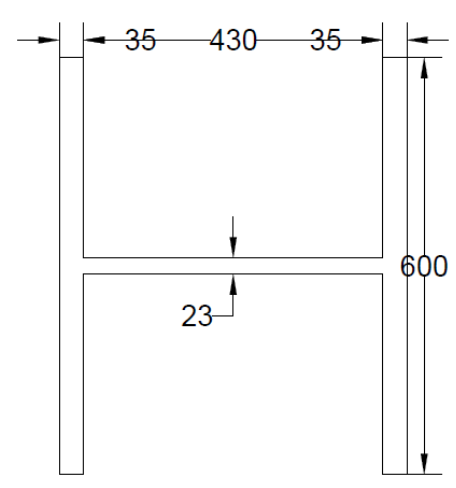

Column section

Figure 2.6: Composite Plate Shear wall specimen (A. Rahai and F. Hatami, 2009)

It is to be noted that the analytical model neglected the friction between the steel infill plate and the RC concrete panels and the only contact between the RC panels with that of the steel infill was through the shear studs. Steel material was considered to possess bilinear behaviour throughout the model. A gap of $35 \mathrm{~mm}$ was maintained between the RC panel edge and the surrounding boundary frame. The experimental program consisted of three types of specimens; a single steel shear wall, three steel reinforced concrete composites and one steel flexible frame. A 
total of 5 specimens were analyzed and experimented. The specimens were designed to undergo ductile failure modes of failure first followed by the brittle ones. Accordingly, the wall was designed to fail first followed by the top and bottom beams and finally the boundary columns. The numerical specimens and experimental tests showed good agreement with respect to loaddisplacement curves. The results of these analyses indicate that with the increase in distance between the shear studs, the amount of energy absorbed increases, the out of plane displacement of steel decreases and the maximum normal stress on the studs decrease. This trend is followed up to a limiting distance between the studs. With further increase in distance between the studs, there is no significant change in these observations.

\subsubsection{Guo et al. (2012)}

Guo et al. (2012) present experimental work related to steel plate shear wall and composite plate shear wall systems in composite steel-concrete frame. The composite plate wall differed from its counterpart in the way that, it had attached reinforced concrete panels on both sides of the steel infill. The columns here consisted of circular hollow steel members filled with concrete. $1 / 3$-scale specimens of a steel plate shear wall and a composite plate shear wall were designed and fabricated with one bay and two and half stories. The frame mainly comprised of concrete filled hollow steel columns and steel beams. Dimensions of the setup and the specimen can be found out in Fig. 2.7. To connect the steel infill with the $\mathrm{RC}$ panel, $10 \mathrm{~mm}$ diameter bolts were used at regular intervals. The steel yield strength for the steel plates in the SPSWs were $283 \mathrm{~N} / \mathrm{mm}^{2}$, while the yield stress of steel infill plates used in the CSPSWs was $230 \mathrm{~N} / \mathrm{mm}^{2}$. The average compressive strength of concrete used was found as $35.8 \mathrm{~N} / \mathrm{mm}^{2} .50 \mathrm{~mm}$ thickness of RC panels were selected for the tests. 
The reinforcement used were of yield strength $697 \mathrm{~N} / \mathrm{mm}^{2}$. The reinforcement area ratio in both directions were $0.79 \%$. Cyclic loads were applied on the specimens and the resultant observations were presented. The loading mechanism was such that the shear load in the first storey was twice that of the second floor.
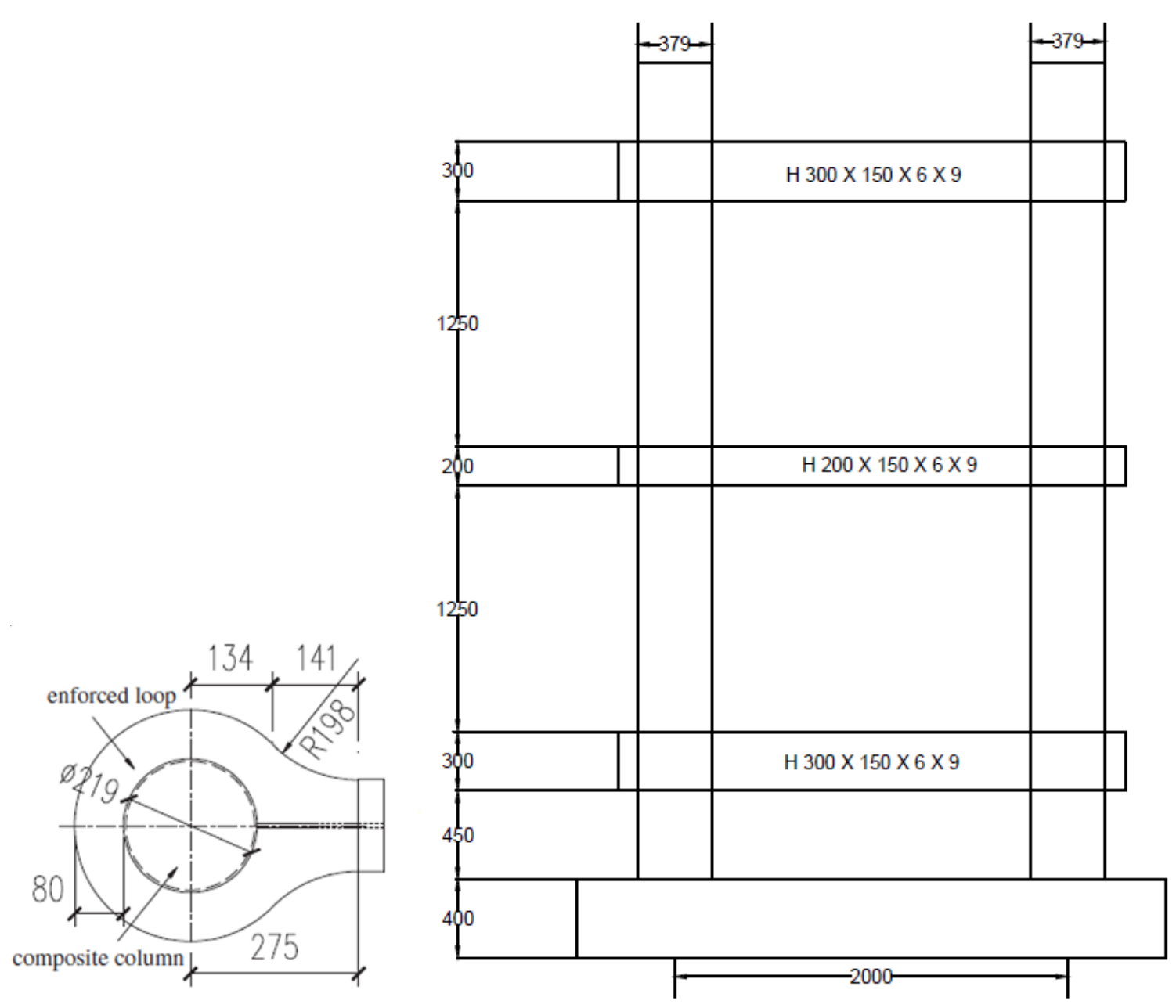

Figure 2.7: Composite Shear wall in composite frame specimen (Guo et al., 2012)

It was reported that most of the failure and damage were concentrated in the first storey. Additionally, it was reported that for drift ratio limiting to $1 / 200$, there was no significant difference on hysteretic curves for SPSW and CSPSW system. The RC panels were reported to 
have an insignificant role until this drift level. Beyond this drift level, the CSPSWs showed higher bearing capacity and energy dissipation compared with that of the SPSWs. The CSPSWs were observed to show an increased load carrying capacity of at least $20 \%$ compared to that of its counterpart. The study concluded that both the steel plate and composite plate shear wall systems in composite frame showed good ductility and energy dissipation capacity during the tests. The steel plate shear wall resisted storey shears by the formation of tension field along its diagonals; while, the composite action in its counterpart provided by the RC panel and steel infill led to the resistance of lateral loads by storey shear.

\subsubsection{Guo et al. (2013)}

The research aimed at studying the behaviour of steel plate and composite plate walls connected only with boundary frame beams. The research included experimental studies as well as analytical studies on the walls. A total of four $1 / 3$ scaled specimens were designed, fabricated and tested; which included three Composite Steel Plate Shear Walls (CSPSWs) and one Steel plate shear wall (SPSW). The specimens considered were all single bay, single storied as shown in Fig. 2.7. The steel infill plate was connected to the frame beams by means of four stiffened $125 \mathrm{~mm} \times$ $125 \mathrm{~mm} \times 10 \mathrm{~mm}$ web angles. High strength bolts of $20 \mathrm{~mm}$ diameter were used to connect the steel plate and the web angles as well as the web angles and frame beams. The dimension of the steel plate are $1200 \mathrm{~mm} \times 1100 \mathrm{~mm} .10 \mathrm{~mm}$ diameter bolts were drilled in the steel plate to connect the steel plate with the concrete panels on both sides. While designing the CSPSWs, due consideration was given to the ANSI/AISC 341-05 for selecting the thickness of the RC panel and the ACI 318 Section 14.3 (ACI, 2008) for meeting or exceeding the minimum reinforcement area 
percentage. For convenient construction, a RC panel thickness of $60 \mathrm{~mm}$ was chosen. The reinforcement ratio was chosen as $0.785 \%$ along the horizontal and vertical directions. The distance between the bolt locations in the concrete panel was $200 \mathrm{~mm}$. The average compressive strength of the concrete was $33.0 \mathrm{~N} / \mathrm{mm}^{2}$. The analytical study was based on creating a moderately simple finite element model of the specimens and comparing the analytical results with that of the experimental ones to validate the model. Beam elements were used to represent the frame members and shell elements were used to represent the steel infill plate and the RC panels. The steel material model was a bilinear one and the concrete material model was based on the cross sectional moment vs. rotation relations of the $\mathrm{RC}$ panel. The concrete material model assumes that the concrete moment stays constant once it reaches the cracked moment value. So, the concrete material relation is also essentially a bilinear one. To represent the bolts, the respective locations at the steel infill plate and RC panel were coupled to make the out-of-plane deformations same.

The analytical analysis results complied with that of the experimental ones. It was also reported that, for the CSPSWs, the difference in the results of the analytical and the experimental specimens in the elasto-plastic stage of the load-displacement curve was much larger than that of SPSWs because of bolt slippage and the buckling of unrestrained strips. This analytical simple finite element validated model was used to carry out a parametric study on parameters such as RC panel thickness, height to thickness ratio and aspect ratio. It was found that, an increase in RC panel thickness led to higher load carrying capacity. For a height to thickness ratio of 300 , it was found that $55 \mathrm{~mm}$ of RC panel thickness is capable of restraining out-of-plane buckling of the steel infill in a CSPSW; denoted as the critical thickness of RC panel. Similarly, for a height to thickness ratio of 500, the corresponding critical thickness of $\mathrm{RC}$ panel was $45 \mathrm{~mm}$. The critical thickness 
was found to decreases with the increase of height-to-thickness ratio. It was also observed that, the height-to-thickness ratio of the steel plate as no significant influence on the rigidity and the maximum shear stress. It is to be noted that, throughout the research in the analytical studies, it has been assumed that the CSPSW behaviour is identical to that of a SPSW with the steel infill plate out-of-plate displacement being restrained. The study concluded that both the steel and composite shear walls connected with only frame beams exhibited good ductility and high energy dissipation capacity. The load carrying capacity and energy dissipation capacity was found to be better for the composite shear walls connected only with frame beams. Additionally, it concluded that the aspect ratio influenced the load carrying capacity of the system. Finally, a simplified Xbrace model was proposed to represent composite shear wall systems based on the assumption that there is no overall buckling in the steel infill plate and treating it as a SPSW.
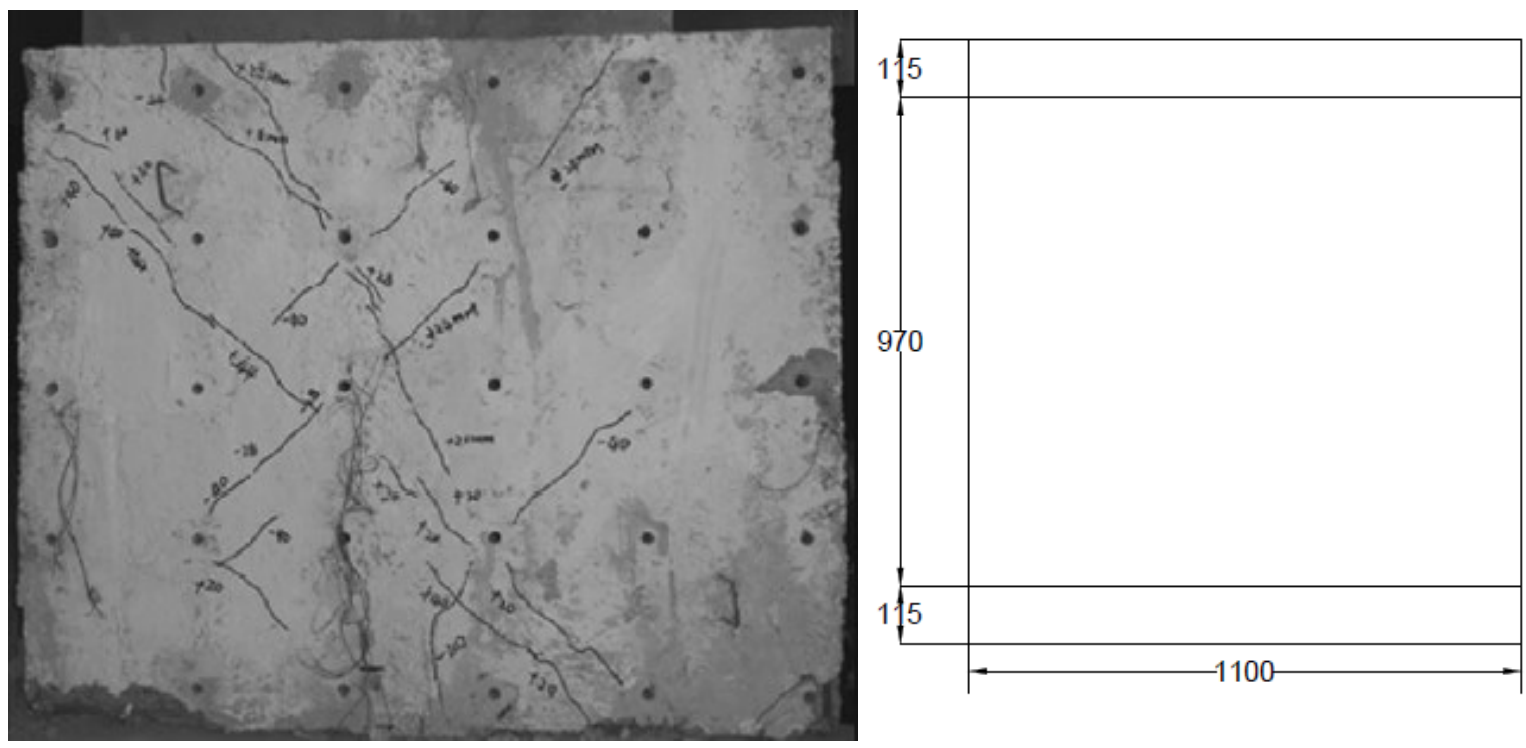

Figure 2.8: CSPSW connected with frame beams only (Guo et al., 2013) 


\subsection{Works on constitutive concrete models}

For the purpose of modeling the concrete behaviour in a finite element model, it's necessary to have an effective concrete constitutive model in tension and compression. The model should be able to capture important behaviours like progressive degradation of stiffness, tension stiffening and damage in the concrete with progressive loading and at the same time it should be simple enough to be incorporated into the damage plasticity model of concrete chosen in ABAQUS finite element software. The following research works were studied for incorporating a sound concrete material model in the C-PSW finite element model.

\subsubsection{Chang and Mander (1994)}

The constitutive model proposed by Chang and Mander is an advanced, generalized concrete constitutive model that provides hysteretic stress-strain relation for concrete in both cyclic compression and tension. This model incorporates specific behavioural changes for both confined and unconfined concrete. The monotonic curves for tension and compression comprise the envelope for the hysteretic stress-strain relation. This model allows for controlling the slopes of concrete stress-strain curves at different parts of the stress-strain curve. The shapes can therefore be controlled keeping the peak stress and the corresponding strain fixed; thereby allowing a provision for calibration while modeling. Chang and Mander adopted the tension and compression envelopes from Tsai's equation; Tsai (1998). Tsai's equation was in turn based on the equation by Popovics (1973). 
The compression envelope curve was defined based on material parameters such as the concrete compressive strength ' $f_{c}$ ', , the concrete strain at peak stress ' $\varepsilon_{c}$ ', , together representing the peak of the curve, the concrete modulus of rigidity ' $E_{C}$ ' representing the initial slope, the parameter ' $r$ ' from Tsai's equation (1988) defining the shape of the envelope and the nondimensional critical strain ' $x_{c r}{ }^{-}$' where the envelope starts a constant negative slope, finally defining the spalling strain where it intersects the strain axis. Empirical expressions for all these parameters were provided by the researchers. However, all these parameters are free to be controlled and manipulated based on specific experimental results for accurately calibrating the compression curves. Based on analysis of previous research, empirical relations for ' $E_{C}$ ', ' $\varepsilon_{C}$ ', and ' $r$ ' were proposed as follows:

$$
\begin{aligned}
& E_{C}=8200 f_{c}^{\prime} M P a \\
& \varepsilon_{C}^{\prime}=\frac{\left(f_{c}^{\prime}\right)^{1 / 4}}{28} \\
& r=\frac{f_{c}^{\prime}}{5.2}-1.9
\end{aligned}
$$

The functions $\mathrm{y}(\mathrm{x})$ and $\mathrm{z}(\mathrm{x})$ are defined as follows:

$$
\begin{aligned}
& y(x)=\frac{n x}{D(x)} \\
& z(x)=\frac{\left(1-x^{r}\right)}{[D(x)]^{2}}
\end{aligned}
$$




$$
\begin{array}{ll}
D(x)=1+\left(n-\frac{r}{r-1}\right) x+\frac{x^{r}}{r-1} & (\mathrm{r} \neq 1) \\
D(x)=1+(n-1+\ln x) x & (\mathrm{r}=1)
\end{array}
$$

The parameters ' $\mathrm{n}$ ' and ' $\mathrm{x}$ ' for compression are defined as follows. The negative sign indicates compression.

$$
\begin{aligned}
& x^{-}=\left|\begin{array}{l}
\varepsilon_{c} \\
\varepsilon_{c}^{\prime}
\end{array}\right| \\
& n^{-}=\left|\frac{E_{C} \varepsilon_{C}^{\prime}}{f_{c}^{\prime}}\right| \\
& x_{s p}=\left(x_{c r}{ }^{-}\right)-\frac{y\left(x_{c r}{ }^{-}\right)}{n^{-} z\left(x_{c r}{ }^{-}\right)}
\end{aligned}
$$

Here, ' $\varepsilon_{c}$ ' denotes the concrete strain, ' $x^{-}$' is the non-dimensional strain parameter on the compression envelope, ' $x_{c r}{ }^{-}$, is the non-dimensional critical strain parameter used to define a change in the nature of the compression envelope and also a tangent line up to the spalling strain; it's the point where the curve starts following a straight line until the spalling strain and finally ' $x_{s p}$ ' is the non-dimensional spalling strain. The compressive stress ' $f_{c}$ ' and tangent modulus ' $E_{t}$ ' for a particular strain at any instant is as follows:

$$
\begin{aligned}
& f_{c}=f_{c}^{-}\left(x^{-}\right) \\
& E_{t}=E_{t}^{-}\left(x^{-}\right)
\end{aligned}
$$


Where, ' $f_{c}^{-}$' and ' $E_{t}^{-}$' can be defined as follows:

If, $x^{-}<x_{c r}^{-}$

$$
\begin{aligned}
& f_{c}^{-}=f_{c}^{\prime} y\left(x^{-}\right) \\
& E_{t}^{-}=E_{c} z\left(x^{-}\right)
\end{aligned}
$$

If, $x_{c r}{ }^{-} \leq x^{-} \leq x_{s p}$

$$
\begin{aligned}
& f_{c}^{-}=f_{c}^{\prime}\left[y\left(x_{c r}{ }^{-}\right)+n^{-} z\left(x_{c r}{ }^{-}\right)\left(x^{-}-x_{c r}{ }^{-}\right)\right] \\
& E_{t}^{-}=E_{c} z\left(x_{c r}{ }^{-}\right)
\end{aligned}
$$

When, $x^{-}>x_{s p}$

$$
f_{c}^{-}=E_{t}^{-}=0
$$

After the spall strain is reached, the concrete is considered to have zero stress. The tension envelope curve was also of the same shape involving the corresponding parameters for tension, like ' $\varepsilon_{t}^{\prime}$ ', representing strain at peak tensile stress, ' $f_{t}^{\prime}$, , representing the tensile strength, together representing the peak of the tensile curve, ' $x^{+}$, is the non-dimensional strain parameter on the tension envelope, the concrete modulus of rigidity ' $E_{t}$ ' representing the initial slope, the parameter ' $r$ ' from Tsai's equation (1988) defining the shape of the envelope, the non-dimensional critical strain ' $x_{\mathrm{cr}}{ }^{+}$, where the envelope starts a constant positive slope is free to be calibrated from experimental results, finally defining the cracking strain ' $x_{c r k}$ ' where it intersects the strain axis. 
The positive sign indicating tension. The non-dimensional parameters for the concrete tension envelope curve are as follows:

$$
\begin{aligned}
& x^{+}=\mid \begin{array}{l}
\frac{\varepsilon_{c}}{\varepsilon_{t}^{\prime}} \\
\varepsilon_{t}
\end{array} \\
& n^{+}=\left|\frac{E_{c} \varepsilon_{t}^{\prime}}{f_{t}^{\prime}}\right| \\
& x_{c r k}=\left(x_{c r}{ }^{+}\right)-\frac{y\left(x_{c r}{ }^{+}\right)}{n^{+} z\left(x_{c r}{ }^{+}\right)}
\end{aligned}
$$

The tensile stress ' $f_{c}$ ' and tangent modulus ' $E_{t}$ ' for a particular strain at any instant is as follows:

$$
\begin{aligned}
& f_{c}=f_{c}^{+}\left(x^{+}\right) \\
& E_{t}=E_{t}^{+}\left(x^{+}\right)
\end{aligned}
$$

Where, ' $f_{c}^{+}$' and ' $E_{t}^{+}$' are as follows:

$$
\begin{aligned}
& \text { If, } x^{+}<x_{c r}{ }^{+} \\
& f_{c}^{+}=f_{t}^{\prime} y\left(x^{+}\right) \\
& E_{t}^{+}=E_{c} z\left(x^{+}\right) \\
& \text {If, } x_{c r}{ }^{+} \leq x^{+} \leq x_{c r k}
\end{aligned}
$$




$$
\begin{aligned}
& f_{c}^{+}=f_{t}^{\prime}\left[y\left(x_{c r}^{+}\right)+n^{+} z\left(x_{c r}^{+}\right)\left(x^{+}-x_{c r}^{+}\right)\right] \\
& E_{t}^{+}=E_{c} z\left(x_{c r}^{+}\right)
\end{aligned}
$$

When, $x^{+}>x_{c r k}$

$$
f_{c}^{+}=E_{t}^{+}=0
$$

When the tensile strain reaches the cracking strain, the concrete can be considered to have zero tensile stress. Concrete experiencing tension stiffening can be considered not to have cracked completely as the concrete still carries significant amount of stresses. As mentioned earlier, this model also provides cyclic properties of concrete in tension and compression based on elaborate and extensive statistical analysis on previous experimental database. To summarize, this model is an excellent tool in modeling cyclic stress- strain behaviour of concrete in compression and tension. It allows flexibility to the user to control the parameters for both monotonic as well as hysteretic curves based on specific experimental observations.

\subsubsection{Belarbi and Hsu (1994)}

Belarbi and Hsu (1994) conducted extensive experimental tests on 17 reinforced concrete panels with concrete cylinder compressive strength varying from 36.9Mpa to 47.7Mpa, subjecting them to normal stresses. The results led to the development of a concrete constitutive model to find out average stress-strain relation of concrete under tension and a constitutive model to find out average tensile stress-strain relation of steel reinforcement embedded in concrete. These models have been used and checked positively to model reinforced concrete panels by various 
researchers like Pang and Hsu, (1995); Hsu and Zhang, (1996); Mansour, Lee, and Hsu, (2001); Hsu and Zhu, (2002). The parameters defining the tension curve for the concrete constitutive model involves the initial modulus of rigidity of concrete in tension, the concrete tensile cracking stress and the concrete strain at cracking. Based on a particular concrete compressive strength, the user can compute the values of the above parameters using the empirical expressions provided by the researchers. The results of the above mentioned experimentation fetched a simple constitutive model of steel reinforcement embedded in concrete, as well. The stress strain relation in tension is represented by two straight lines. Initial slope is ' $E_{s}$ ', which is the steel modulus of elasticity. This straight line is followed by another straight line with a different slope ' $E_{p}$ ', which represents the plastic range of the relation. Empirical relations are provided by the researchers to find out the stress at the discontinuity in slope as well as to find out ' $E_{p}$ '. The relation consists of an ascending straight line up to the peak tensile stress at which instant, micro cracking starts followed by a descending curve to the power of 0.4 after the onset of micro cracking. The above expressions were obtained from the average and best fit curve of numerous experimental reinforced concrete panels.

\subsubsection{Hsu and Hsu (1994)}

Hsu and Hsu (1994) developed a numerical method which has been verified experimentally to propose stress-strain curves of concrete under compression. This model allows defining the concrete compression stress-strain curve based on just the compressive strength of the concrete. The compression relation can be extended to a maximum of stress equivalent to 0.3 times of the maximum compressive strength in the negative sloped arm of the curve. The model can be used in 
its simplest form for concrete compressive strength up to a maximum of $62 \mathrm{MPa}$, beyond which certain modifications need to be made in the procedure. Empirical relations were provided by the researchers to find out the initial stiffness which is represented by the modulus of rigidity, the shape function of the curve ' $\beta_{2}$ ', strain at peak stress and the strain at the final stress point of 0.3 times of maximum compressive strength. 


\section{FINITE ELEMENT ANALYSIS OF COMPOSITE PLATE SHEAR WALLS ${ }^{1}$}

\subsection{Introduction}

This chapter presents development of a detailed Finite Element (FE) model to study the behaviour of composite-plate shear walls. ABAQUS (Hibbitt, 2011) finite element software has been used for the purpose of detailed finite element analysis. Several key features of the finite element model, such as modeling process, element definitions, and material definitions, are discussed. The C-PSW finite element model incorporates steel and concrete non-linear material properties as well as geometric non-linearity. The concrete damaged plasticity model used for the purpose of modeling the concrete material is presented in details. The chapter also presents the validation of the finite element model with experimental results by Astaneh et al. (2002).

\subsection{Selection of finite element analysis technique}

ABAQUS/Standard (Hibbitt, 2011) with implicit formulation was used for all analysis purposes. The implicit operator used for time integration of the dynamic problem is defined by Hilber, Huges and Taylor (1978). In ABAQUS, dynamic integration operators are of two types; namely, the 'explicit' and the 'implicit'. The 'explicit' scheme obtains values for dynamic quantities at time instant ' $t+\Delta t$ ' solely based on the corresponding available values at time instant ' $t$ '; where, ' $t$ ' denotes a time instant and ' $\Delta t$ ' denotes the time increment. Moreover, the 'explicit' operator for stress analysis applications is only conditionally stable. The 'implicit' analysis scheme on the other hand is unconditionally stable. It solves for dynamic quantities at

${ }^{\mathrm{A}} \mathrm{A}$ version of the chapter 3 and 4 has been submitted in the journal of Thin Walled Structures 
time instant ' $\mathrm{t}+\Delta \mathrm{t}$ ' based on values at ' $t$ ' as well as ' $t+\Delta t$ '. In structural problems, 'implicit' integration schemes usually give acceptable solutions with appropriate time step adjustments (ABAQUS / Documentation, 2011).

\subsection{Characteristics of finite element model}

\subsubsection{Initial conditions and assumptions}

C-PSW finite element models were modeled to validate experimental specimen, dynamic seismic analysis and validation of equivalent shear-flexure cantilever model for fundamental frequency estimation. The C-PSW finite element model for validation was modeled to closely represent the experimental specimen by Astaneh et al. (2002). The fish plates used in experimental specimens to connect the steel infill plates with the boundary members were ignored in the finite element models. Infill plates were considered to be attached directly with the boundary columns and beams. The C-PSW modelled for validation had a gap of $32 \mathrm{~mm}$ all around the edges of the $\mathrm{RC}$ panel, separating the RC panel edge and the surrounding steel boundary frame in accordance with the 'innovative' test specimen by Astaneh et al. (2002). The mid beam was laterally restrained in the finite element model to bear resemblance with the experimental setup, where the mid beam was braced by two parallel beams, one on either side. The reinforcement was applied as a smeared layer in the concrete shell with appropriate reinforcement percent. The friction between the $\mathrm{RC}$ panels and the steel was neglected in this model and the sole connection between the steel infill and the RC panel was by virtue of regularly spaced bolts. Other researchers, Rahai and Hatami (2009) and Ayazi et al. (2012), did not account the friction between the steel infill and the RC panel for their FE models for C-PSWs. 


\subsubsection{Element Selection}

ABAQUS provides a variety of element selection options form its element library. User defined elements are also available. According to Astaneh-Asl et al. (2002), in the C-PSWs, the steel infill plate is expected to yield before buckling. Moreover, the reinforced concrete panels are also expected to develop tension cracks. So, shell elements can be suitable to model the steel infill plates and the reinforced concrete panels. 4-node doubly curved general purpose shell with reduced integration (ABAQUS shell element S4R) was used here in. These elements possess six degree of freedom at each node; three translation and three rotations defined in its global co-ordinate system. It consists of a single integration point at the mid-surface to form the element internal force vector. The number of integration points through the thickness of the element were chosen to be the default value of 5. Moreover, the S4R elements are compatible with the damaged plasticity model of concrete used here in. So, S4R elements were used to model the steel infill plates, the steel boundary members and the reinforced concrete panels. In order to model the bolted connections between the RC panel and the steel infill plate, (ABAQUS beam element B31) were used. It is a three dimensional (3D) 2-node linear beam element. The element has six degrees of freedom at each node; three translation and three rotations defined in its global co-ordinate system. Researchers such as, Rahai and Hatami (2009), Zhao et al. (2007) and Ayazi et al. (2012) have also used beam elements to model bolts for their analytical studies.

\subsubsection{Steel material properties}

The material property of the C-PSWs consists of two components; namely, the steel and the concrete material models. In order to define steel material model, stress vs. strain data of steel used 
by researchers were incorporated in the finite element material model. Steel stress vs. strain relationships were considered as bi-linear elasto-plastic curves. The von-Mises yield criterion along with the associated flow rule was adopted for these analyses. A non-linear isotropic hardening model was used for pushover analysis, whereas kinematic hardening model was used for seismic analyses. Raleigh proportional damping with a damping ratio of 5\% was incorporated in the material property for the seismic analysis. It is the commonly used value for buildings with partition walls. The material property for the bolt steel were adopted from G.L. Kulak (2005) based on the tension coupon test results for the specific grade of $1 \frac{1}{2}$ inch diameter A325 bolts.

\subsubsection{Concrete material properties}

There are a number of concrete constitutive models available in the literature based on the principles of elasticity, plasticity and continuum damage mechanics. This includes elastic-plastic model by Chen and Chen (1975), hypo-elastic model Kupfer and Grestle (1978), Kotsovos and Newmann (1978 and 1979), anisotropic model by Isobata, (1978), equivalent uniaxial model by Drawin and Peckold, (1977), smear crack model and concrete damage plasticity (Lubliner et al., 1989; Lee and Fenves, 1998). According to Astaneh et al. (2002), the reinforced concrete panel plays a critical role in the C-PSW functioning and is expected to develop diagonal cracks. So, the selection of an appropriate concrete constitutive model is essential which can represent the accurate behaviour of concrete under dynamic loads.

ABAQUS provides a variety of concrete material modeling options; namely, the concrete smeared cracking, cracking model for concrete and concrete damaged plasticity. The concrete smeared cracking model is suitable for concrete under monotonic straining under low confining 
pressures (ABAQUS 2011). The cracking model of concrete is suitable for behaviour dominated by tensile cracking and is accurate for modelling brittle behaviour of concrete. Moreover, it is only available with ABAQUS/Explicit. The concrete damaged plasticity model (Lubliner et al., 1989; Lee and Fenves, 1998) available with ABAQUS/Implicit, was found to be suitable for use where the concrete is subjected to monotonic, cyclic or dynamic loads under low confining pressures. It can also incorporate irreversible damage occurring during fracture process. It is also capable of capturing the highly nonlinear behaviour of concrete, along with the phenomenon of strength degradation, stiffness degradation and recovery of stiffness under load reversals for dynamic loading. The concrete damage plasticity model is capable of incorporating both elastic as well as plastic behaviour of concrete in both the tension and compression region. It is a continuum, plasticity-based damaged model for concrete. It predicts the damage in the concrete based on two failure mechanisms; namely, the tensile cracking and compressive crushing of the concrete material. A number of concrete constitutive material model are available in literature that can be converted to stress-strain curves representing the tension and compression behaviour based on experimentation results. Suitable concrete constitutive material models have been selected and the data are appropriately processed and incorporated in the damaged plasticity material model for concrete in ABAQUS. 


\subsubsection{ABAQUS Concrete damaged plasticity model}

In the concrete damage plasticity model, the strain ' $\varepsilon$ ' is comprised of the elastic strain ' $\varepsilon_{e}$ ' and the plastic strain ' $\varepsilon_{p}$ '.

$$
\varepsilon=\varepsilon_{e}+\varepsilon_{p}
$$

The stress-strain relationship is as follows:

$$
\sigma=(1-D) E_{0}:\left(\varepsilon-\varepsilon_{p}\right) \quad 0<D<1
$$

Where, ' $D$ ' is a scalar degradation variable, ' $E_{0}$ ' is the initial elastic stiffness, ' $:$ ' represents the tensor product. According to continuum damage mechanics, the stress is mapped into effective stress, ' $\bar{\sigma}$ ' by a damage tensor ' $D$ '.

$$
\bar{\sigma}=E_{0}:\left(\varepsilon-\varepsilon_{P}\right)
$$

The plastic strain values are generated based on a non-associative flow rule, generated from a scalar function ' $G$ '. The rate of change of plastic strain is given as follows:

$$
\dot{\varepsilon}_{P}=\dot{\lambda} \frac{\delta G}{\delta \bar{\sigma}}
$$

Where, ' $\dot{\lambda}$ ' is a non-negative function called the plastic consistency parameter and ' $G$ ' is the flow potential function accepted from the Drucker-Prager hyperbolic function expressed as:

$$
G=\sqrt{\bar{q}^{2}+\left(f_{c}-m f_{t} \tan \beta\right)^{2}}-\bar{p} \tan \beta-\sigma
$$


Where, ' $f_{c}$ ' and ' $f_{t}$ ' are uniaxial compressive and tensile strengths of concrete respectively. ' $\beta_{1}$ ' is the dilation angle measured in the $\mathrm{p}$-q plane under high confining pressures, ' $m$ ' is the eccentricity of the plastic potential surface defined as the rate at which the flow approaches asymptote.

The concrete damage plasticity model uses the yield function proposed by Lubliner et al. (1989) and Lee and Fenves (1998) to take in to account different cases of strength evolution under tension and compression. The yield function is as follows:

$$
F=\frac{1}{1-\alpha}\left(\bar{q}-3 \alpha \bar{p}+\theta\left(\widetilde{\varepsilon}^{p l}\right)<\bar{\sigma}_{\max }>-\gamma<-\bar{\sigma}_{\max }>\right)-\bar{\sigma}_{C}\left(\widetilde{\varepsilon}^{p l}{ }_{C}\right)
$$

Where,

$$
\begin{aligned}
& \alpha=\frac{\left(\frac{f_{b 0}}{f_{c 0}}\right)-1}{2\left(\frac{f_{b 0}}{f_{c 0}}\right)-1} \\
& \theta\left(\widetilde{\varepsilon}^{p l}\right)=\frac{\bar{\sigma}_{C}\left(\widetilde{\varepsilon}^{p l}{ }_{c}\right)}{\bar{\sigma}_{t}\left(\widetilde{\varepsilon}^{p l}\right)}(1-\alpha)-(1+\alpha) \\
& \gamma=\frac{3\left(1-K_{C}\right)}{2 K_{C}-1}
\end{aligned}
$$

Where, ' $\bar{\sigma}_{\max }$ 'is the maximum effective principal stress, ' $\bar{\sigma}_{C}\left(\widetilde{\varepsilon}^{p l}{ }_{c}\right)$ ' is the effective compressive cohesion stress, ' $\bar{\sigma}_{t}\left(\widetilde{\varepsilon}_{t}^{p l}\right)$ ' is the effective tension cohesion stress, ' $f_{b 0}$ ' is the 
compressive strength under biaxial loading, ' $f_{C 0}$ ' is the compressive strength under uniaxial loading and the bracket ' $\langle>$ ' is defined by

$$
<x>=\frac{1}{2}(|x|+x)
$$

There are various parameters related with the definition of the concrete damage plasticity model. Mathematical relationships of complete stress-strain curves in tension and compression associated with the respective damage curves are required to be provided. In the concrete damaged plasticity model, the concrete under uniaxial tension follows a linear elastic relationship initially until the peak tensile stress is reached. After this point, micro cracking starts to form in the concrete which is resembled in the macroscopic level with a softening stress-strain relation. This extends until the point where the stress reaches very low values close to zero; where, the concrete can be considered to be failed. Under uniaxial compression, the concrete follows a linear elastic relationship until the initial yield stress ' $\sigma_{C 0}$ '. This is followed by the plastic region where the relationship is characterized by stress hardening followed by strain softening beyond the ultimate stress ' $\sigma_{C u}$ '. In order to simulate the tensile behaviour of reinforced concrete in concrete damaged plasticity model, the input provided were that of the young's modulus ' $E_{t}$ ', the tensile stress ' $\sigma_{t}$ ' vs cracking strain ' $\varepsilon_{t}{ }^{c k}$, relationship and the damage parameter value ' $d_{t}$ ' vs cracking strain ' $\varepsilon_{t}{ }^{c k}$, relationship for the relevant grade and constitutive model of concrete chosen.

$$
\begin{aligned}
& \varepsilon_{t}{ }^{c k}=\varepsilon_{t}-\varepsilon_{e l} \\
& \varepsilon_{e l}=\sigma_{t} / E_{t}
\end{aligned}
$$


Where, ' $\varepsilon_{t}{ }^{c k}$ ' is the cracking strain, ' $\varepsilon_{t}$ ' is the total concrete tensile strain, ' $\varepsilon_{e l}$ ' is the elastic strain corresponding to undamaged concrete material, ' $\sigma_{t}$ ' is the concrete tensile stress. The damage parameter ' $d_{t}$ ' is found out as the ratio of degraded strength to the peak strength. ABAQUS checks for the accuracy of the damage curve using the plastic strain values ' $\varepsilon_{t}{ }^{p l}$, as shown in expression (3.3). It is to be noted that the Fig. - 3.1 depicts ' $E_{t}$ ' as ' $E_{0}$ '. Negative and/or decreasing tensile plastic strain values are indicative of incorrect damage curves which may lead to generate error message before the analysis is performed (ABAQUS Manual, 2011). All these inputs were provided in tandem with the concrete constitutive model chosen to provide a tensile stress-strain relationship similar to Fig.-3.1 accounting for tension stiffening, strain-softening and reinforcement interaction with concrete.

$$
\varepsilon_{t}^{p l}=\varepsilon_{t}^{c k}-\frac{d_{t}}{\left(1-d_{t}\right)} \frac{\sigma_{t}}{E_{t}}
$$

In order to simulate the compressive behaviour of reinforced concrete in concrete damaged plasticity model, the input provided were that of the young's modulus ' $E_{C}$ ', the compressive stress ' $\sigma_{C}$ ' vs inelastic strain ' $\varepsilon_{C}{ }^{\text {in }}$, relationship and the damage parameter value ' $d_{c}$ ' vs inelastic strain ' $\varepsilon_{C}{ }^{i n}$, relationship for the relevant grade and constitutive model of concrete chosen. 


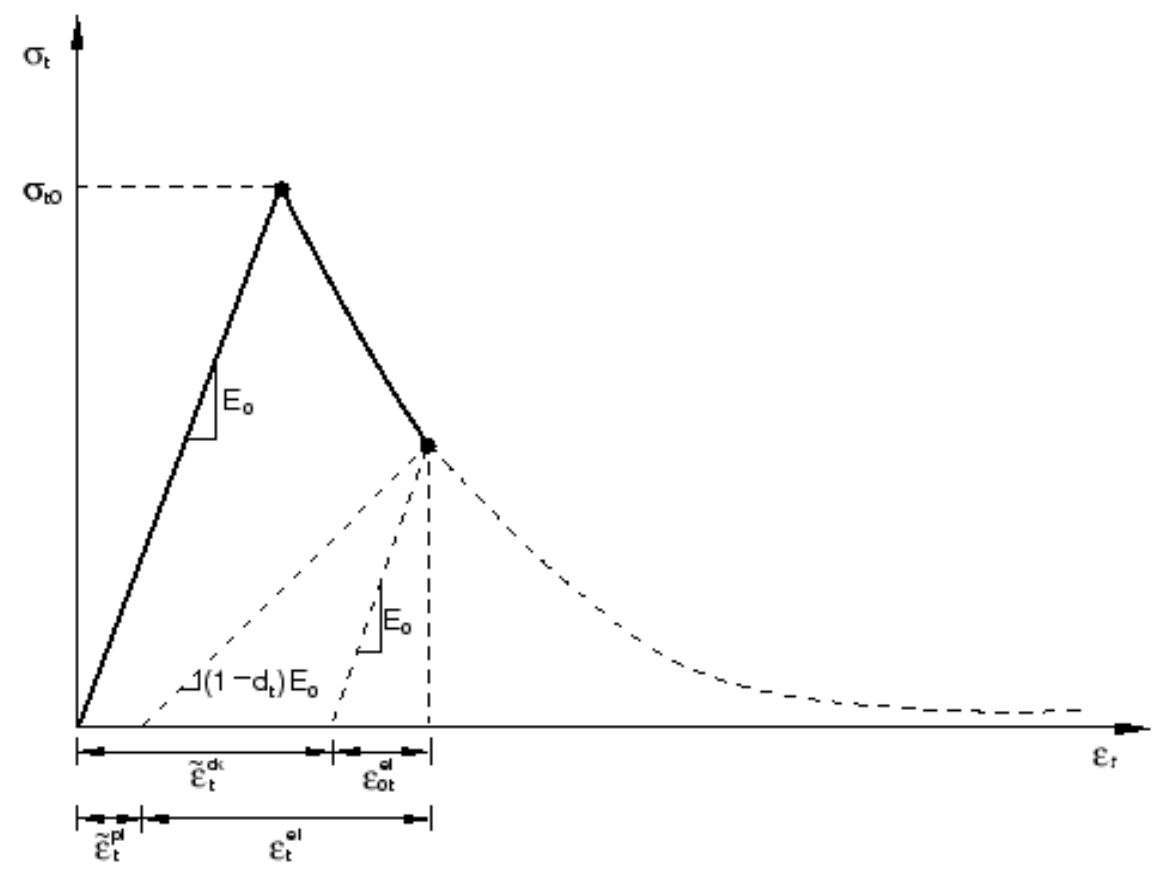

Figure3.1: Parameters for tension stiffening model of concrete (ABAQUS Manual, 2011)

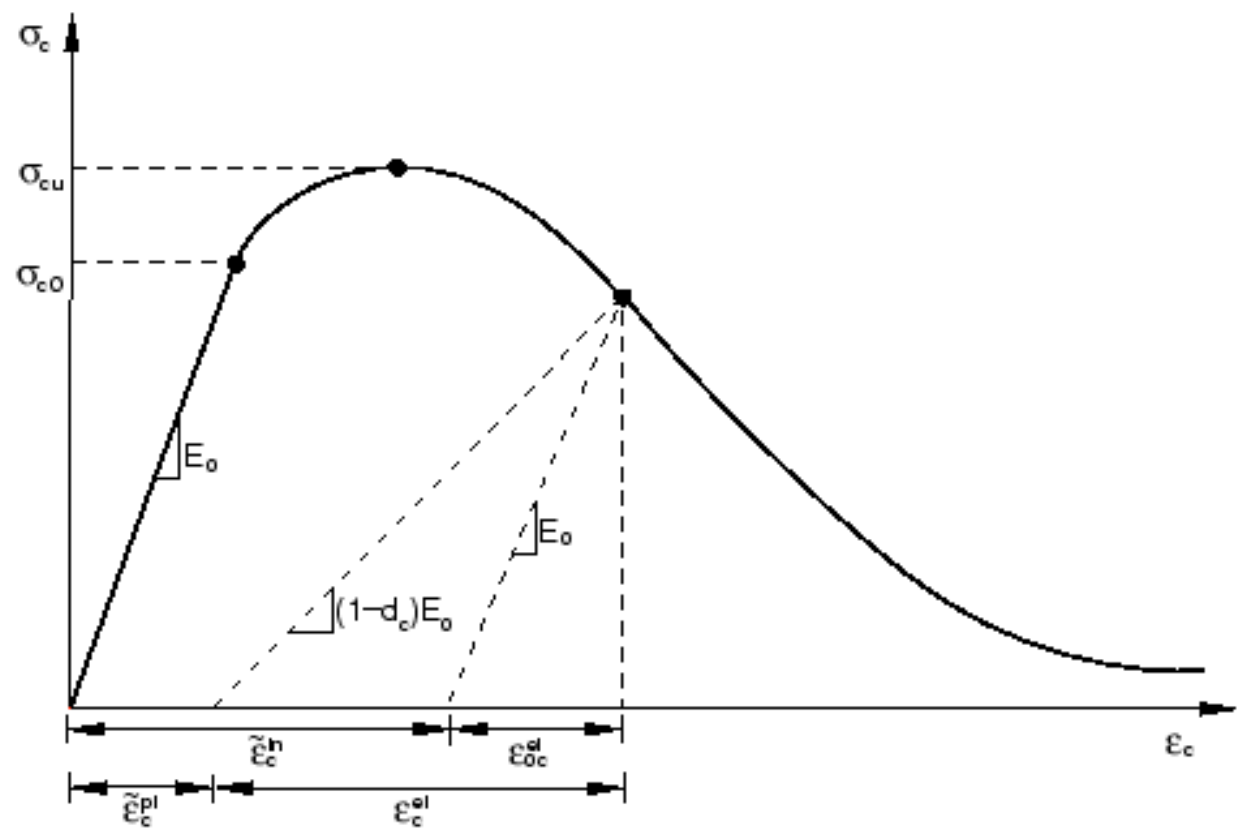

Figure3.2: Parameters for compression hardening model of concrete (ABAQUS Manual, 2011) 


$$
\varepsilon_{C}{ }^{i n}=\varepsilon_{C}-\varepsilon_{e l}
$$

$$
\varepsilon_{e l}=\sigma_{C} / E_{C}
$$

Where, ' $\varepsilon_{C}{ }^{\text {in }}$ ' is the inelastic strain, ' $\varepsilon_{C}$ ' is the total concrete compressive strain, ' $\varepsilon_{e l}$ ' is the elastic strain corresponding to undamaged concrete material, ' $\sigma_{C}$ ' is the concrete compressive stress. The damage parameter ' $d_{c}$ ' is found out as the ratio of the degraded strength to the peak strength. It should be ensured that the plastic strain values ' $\varepsilon_{C}{ }^{p l}$, calculated using expression (3.6) are neither negative, nor decreasing with increasing stresses (ABAQUS Manual, 2011).

$$
\varepsilon_{C}^{p l}=\varepsilon_{C}{ }^{i n}-\frac{d_{C}}{\left(1-d_{C}\right)} \frac{\sigma_{C}}{E_{C}}
$$

In the absence of a damage parameter definition, the model behaves as a plasticity model. In Fig.-3.2, ' $E_{C}$ ' is depicted as ' $E_{0}$ '. All these inputs were provided in tandem with the concrete constitutive model chosen to provide a compressive stress-strain relationship similar to as shown in Fig.-3.2 accounting for compression stress hardening followed by strain softening.

\subsubsection{Concrete constitutive model in tension}

The concrete tensile constitutive model by Belarbi and Hsu (1994) has been adopted herein to define the tensile stress-strain relationship of concrete. Based on extensive experimentation on reinforced concrete panels subjected to normal stresses, Belarbi and Hsu (1994) developed constitutive models for average tensile stress strain relation of concrete and that of the steel 
reinforcing bars stiffened by concrete. The tension stiffening model proposed by Belarbi and Hsu have also been used and validated experimentally in more recent studies relating to model the shear behaviour of reinforced concrete membrane elements (e.g. Pang and Hsu, 1995; Hsu and Zhang, 1996; Mansour, Lee and Hsu, 2001; Hsu and Zhu, 2002). In this study, the average tensile stress strain relation of concrete has been adopted for modelling the concrete tension stiffening model. The tensile stress-strain relation proposed by Belarbi and Hsu (1994) is as follows:

$$
\begin{aligned}
& \text { For } \quad \varepsilon_{C} \leq \varepsilon_{c r}, \quad \sigma_{t}=E_{t} \varepsilon_{C} \\
& \text { For } \quad \varepsilon_{C} \geq \varepsilon_{c r}, \quad \sigma_{t}=f_{c r}\left(\frac{\varepsilon_{c r}}{\varepsilon_{c}}\right)^{0.4} \\
& \text { Where, } \quad E_{t}=3875 \sqrt{f_{c}^{\prime}}(\mathrm{MPa} a) \\
& f_{c r}=0.31 \sqrt{f_{c}^{\prime}}(\mathrm{MPa}) \\
& \varepsilon_{c r}=0.00008
\end{aligned}
$$

In the above expressions, ' $\sigma_{t}$ ' is the average concrete tensile stress, ' $E_{t}$ ' is the initial young's modulus of the average stress-strain relation, ' $f_{c r}$ ' is the peak concrete tensile stress, ' $\mathcal{E}_{c r}$ ' is the strain at the instant of peak tensile stress and ' $f_{c}^{\prime}$ ' is the compressive strength of the concrete. The relation consists of an ascending straight line up to the peak tensile stress at which instant, micro cracking starts followed by a descending curve to the power of 0.4 after the onset of micro cracking. The above expressions were obtained from the average and best fit curve of numerous experimental reinforced concrete panels. The grade of concrete chosen for the finite element models has a compressive strength of $28 \mathrm{MPa}$. The tension stiffening relations and the progressive 


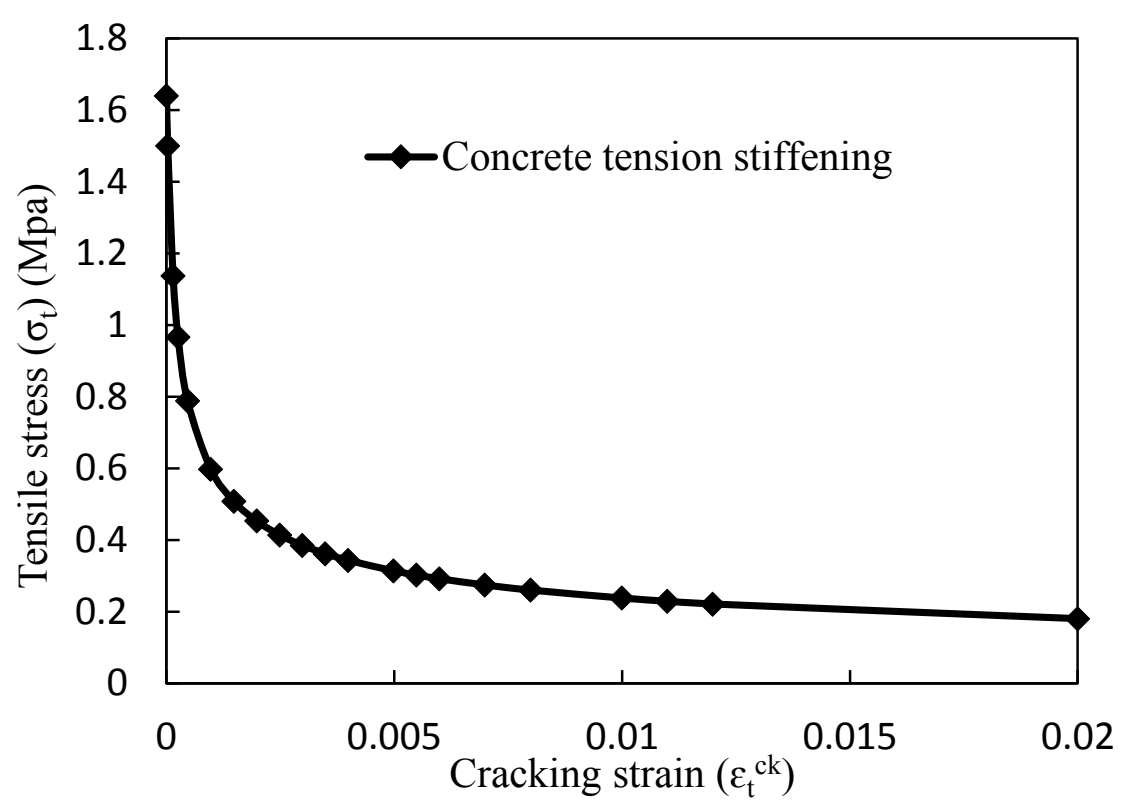

Figure3.3: Concrete tension stiffening curve

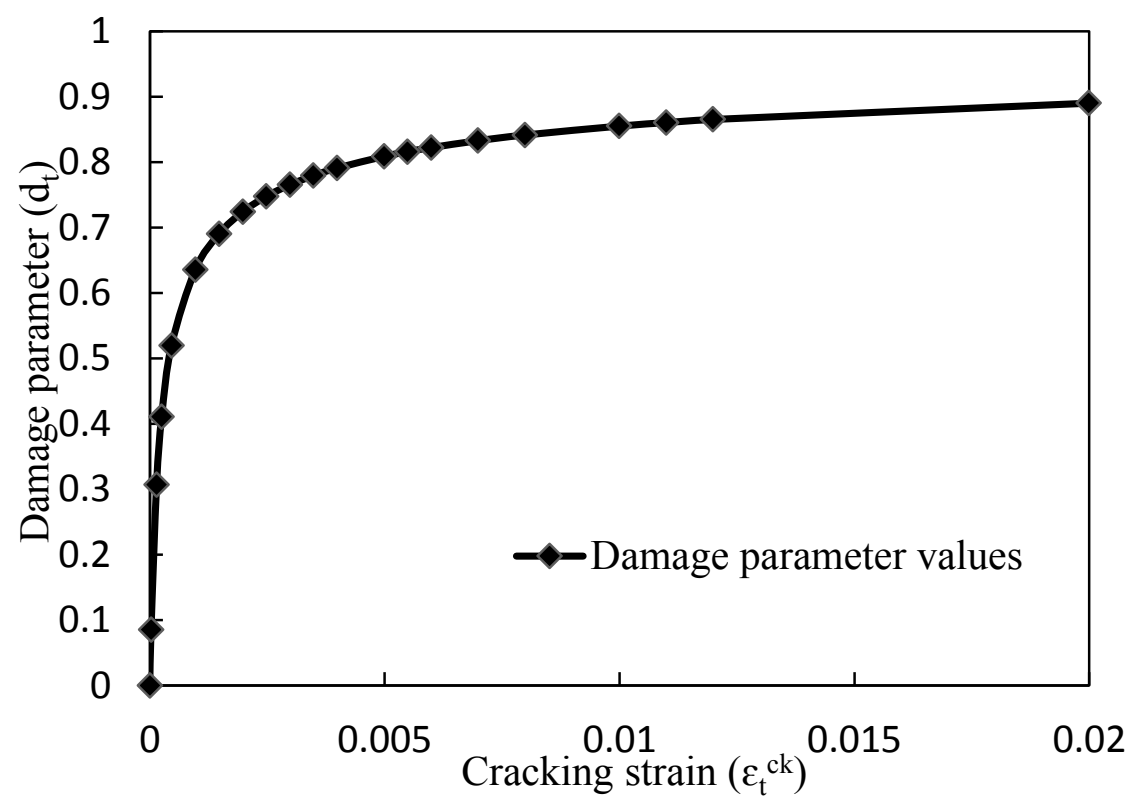

Figure3.4: Concrete tension damage curve

damage relations based on cracking strain values were found out as explained in expression (3.11) and the damage parameter was computed on the lines of Jankowiak and Lodygowski (2005) as the 
ratio of reduction of strength capacity to that of the maximum strength. Figure 3.3 and Figure 3.4 represent the final curves obtained for the tension stiffening and damage parameter values complying with the Belarbi and Hsu (1994) concrete constitutive model in tension for concrete compressive strength of $28 \mathrm{MPa}$. ABAQUS (2011) suggests that a tension stiffening model, where the tensile stress reaches zero at a total strain value of about $10^{-3}$ is reasonable. The Belarbi and Hsu (1994) concrete constitutive model doesn't provide a specific strain value for stress reaching zero under tension. Following the recommendations by ABAQUS (2011), the failure strain for concrete in tension according to Belarbi and Hsu (1994) concrete constitutive model can be calculated as about $10^{-3}$. Based on the Chang and Mander (1994) concrete constitutive model, when the tensile strain reaches the cracking strain, the concrete can be considered to have zero tensile stress; which was found out to be 0.001 for a concrete of maximum compressive strength of $28 \mathrm{MPa}$. In this study, a tensile strain value of 0.001 has been adopted to classify a region of concrete in tension as failed.

\subsubsection{Concrete constitutive model in compression}

The concrete stress-strain relation under compression is defined using the experimentally validated numerical constitutive model by Hsu and Hsu (1994). This concrete constitutive model is suitable in the way that, the entire relationship can be derived based on the concrete compressive

strength ' $f_{c}^{\prime}$ '. The formulations presented herein are suitable for concrete maximum compressive strength of up to $62 \mathrm{MPa}$. For higher grades, suitable modifications need to be made based on Hsu and Hsu (1994). The relationship is defined by an initial linear relation up to 0.5 times of ultimate compressive strength followed by the relationship as depicted in the following expressions: 


$$
\begin{aligned}
& \sigma_{c}=\left(\frac{\beta_{2}\left(\frac{\varepsilon_{c}}{\varepsilon_{0}}\right)}{\beta_{2}-1+\left(\frac{\varepsilon_{c}}{\varepsilon_{0}}\right) \beta_{2}}\right) \sigma_{c u} \\
& \beta_{2}=\frac{1}{1-\left[\frac{\sigma_{c u}}{\varepsilon_{0} E_{c}}\right]} \\
& \varepsilon_{0}=8.9 \times 10^{-5} \sigma_{c u}+2.114 \times 10^{-3} \\
& E_{C}=1.2431 \times 10^{2} \sigma_{c u}+3.28312 \times 10^{3}
\end{aligned}
$$

Where, ' $\sigma_{c}$ ' is the concrete average compressive stress, ' $\sigma_{c u}$ ' is the peak compressive stress, ' $E_{c}$ ' is the young's modulus of concrete in compression in units of kip/in ${ }^{2}$ ' ' $\varepsilon_{0}$ ' is the strain at maximum strength and ' $\varepsilon_{c}$ ' denotes the average compressive strain. The grade of concrete chosen for the finite element models has a compressive strength of $28 \mathrm{MPa}$. The compression hardening relations and the progressive damage relations based on inelastic strain values were found out as explained in expression (3.14) and the damage parameter was computed on the lines of Jankowiak and Lodygowski (2005) as the ratio of reduction of strength capacity to that of the maximum strength. Figures3.3 and 3.4 represents the final curves obtained for the compression hardening and damage parameter values complying with the Hsu and Hsu (1994) concrete constitutive model in compression for concrete compressive strength of $28 \mathrm{MPa}$. 


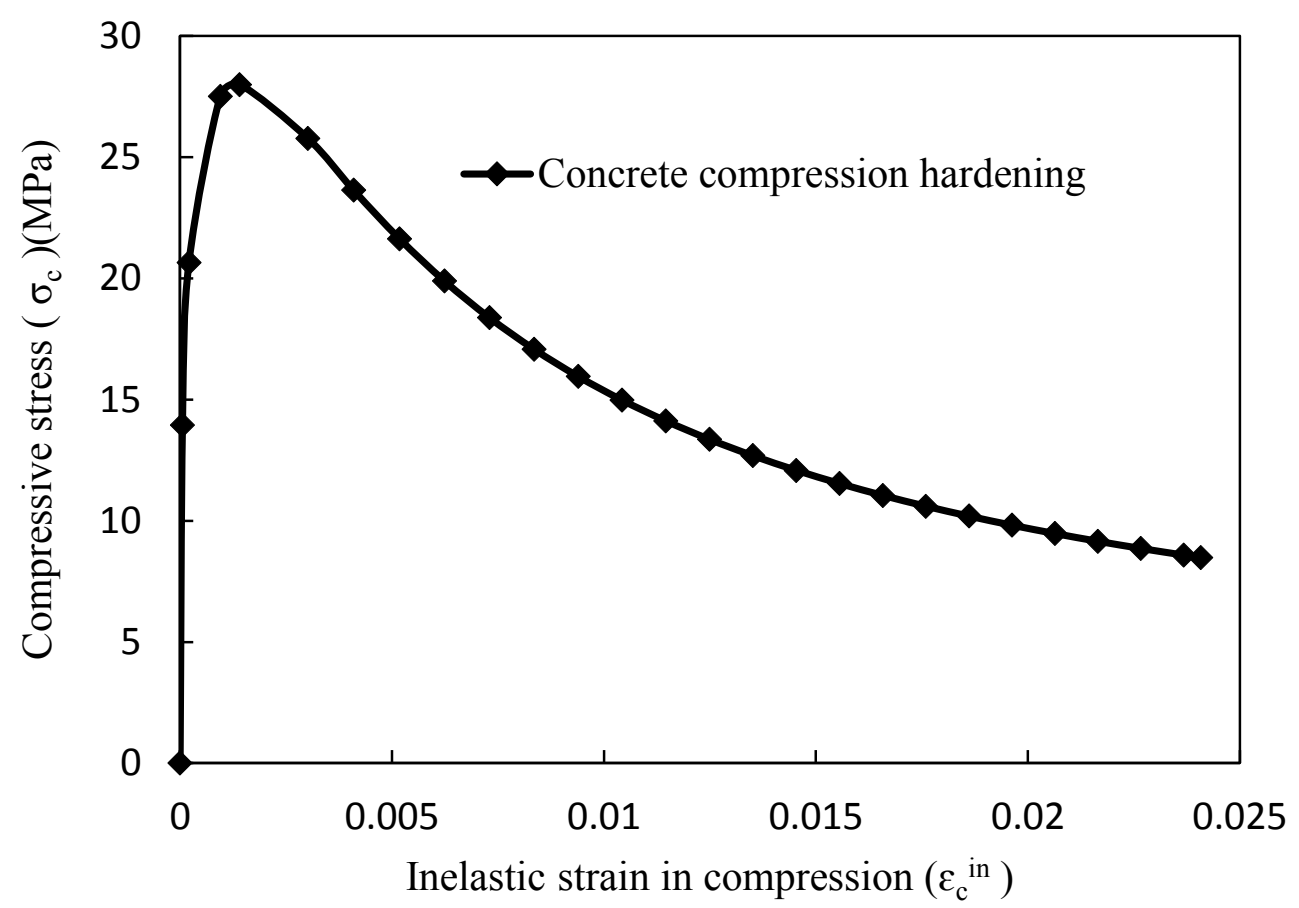

Figure3.5: Concrete compression hardening curve

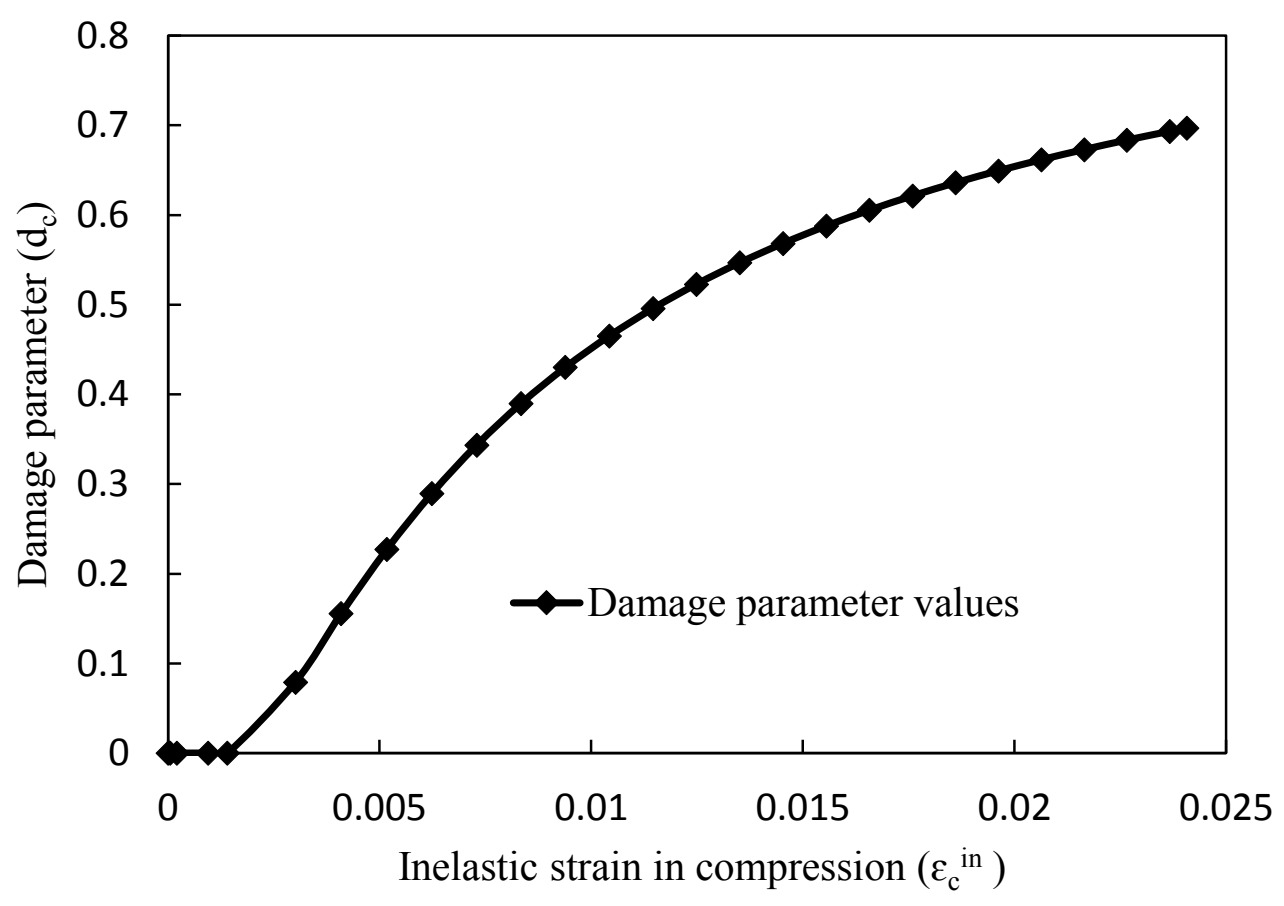

Figure3.6: Concrete compression damage curve 


\subsubsection{Other concrete damage plasticity parameters}

The concrete damage plasticity needs a few additional parameters to be defined in order to completely define the concrete material model. Sufficient studies are missing in order to characterize the tension recovery factor and compression recovery factor based on the grade of the concrete used. Syed (2012) reported from a numerical experimentation that the value of these factors definitely control the size and orientation of the loop of the stress-strain curves. It was also reported that the nature of variation in the loop was dependent on the material type and is not related in any way to the grade of concrete used. So, constant values were chosen for these parameters based on the default values available in ABAQUS in this study. The compressive stiffness recovery factor of ' $w_{c}$ ' of 1 has been used implying full compressive stiffness recovery upon crack closure as loading changes from tension to compression. The tensile stiffness recovery factor of ' $w_{t}$ ' of 0 has been chosen assuming no tension stiffness recovery when the loading changes from compression to tension, once concrete crushing has been initiated.

Dilatancy can be defined as the change in volume resulting from shear distortion of an element in the material. Dilation angle is used to characterize dilation (Hansen, 1958). The dilation angle can be found out from tri-axial compressive test and is defined as the ratio of the plastic volume change over plastic shear strain (Vemeer and deBorst, 1984). The dilation angle is specific to the material concerned and also on its kind of application. Some of the values of dilation angle found are as follows. Brost et al. (1984) used a value of 230; ABAQUS verification manual a value of 150; Armaanidis (2003) values ranging from $27.75-42.87^{0}$ and $23.51-35.40^{\circ}$; ABAQUS example

problem manual a value of $36.31^{0}$; Beckwith et al. (1973) a value of $40^{0}$; Rollins et al. (1997) a 
value of $42^{0}$. Materials like concrete can have dilation angle values varying from zero to its friction angle. Lubliner et al. (1989) suggested typical range of dilation angle of concrete between $8^{0}$ and $15^{0}$. Lee and Fenves (1998) suggested dilation angle values of concrete as $34.6^{0}$. Vemeer and deBorst (1984) based on experimental test results concluded that the dilation angle for concrete is at least $20^{0}$ less than its friction angle (approximately, equal to $37^{\circ}$ ). They proposed an expression to find out the dilation angle given as:

$$
\sin \beta_{1}=\frac{\dot{\varepsilon}_{v} p}{-2 \dot{\varepsilon}_{1} p+\dot{\varepsilon}_{v} p}
$$

Where, ' $\beta_{1}$ ' is the dilation angle, ' $\dot{\varepsilon}_{v} p$ ' and ' $\dot{\varepsilon}_{1} p$ ' are the volumetric and axial plastic strain increments respectively. The above equation has been validated with a numerical experiment more recently by Syed (2012) and the typical range of dilation angle for normal weight concrete was found as $25^{0}-35^{0}$. It was also found out that the values of compressive and tensile strength, strain hardening and softening regions are not affected at the material level for dilation angle varying in the range of $20^{0}-55^{0}$. The shear strength was however found sensitive to different values of dilation angle. It was reported that the variation was not consistent with the typical uncertainty parameters that are found in a concrete material of a specific grade, rather, the variation is more reflective of a change in the type of material. In this study, in the absence of sufficient information on the material properties of concrete used for the experimentation of C-PSWs by Astaneh-Asl et al. (2002) a dilation angle value of $31^{0}$ was chosen. 


\subsection{Displacement control analysis}

Displacement control solution strategy has been used. The desired displacement is applied in steps at the boundary at the loading point. The total base shear is noted as the load. Thus, the total base shear verses the boundary displacement gives the load displacement curve (pushover curve).

\subsection{Validation of the finite element model}

The finite element model (FEM) has been validated by comparing the results of the available test. Very few experimental works have been reported using composite shear walls. In this study the finite element model has been validated against the composite plate shear wall test conducted by Astaneh-Asl et al. (2002).
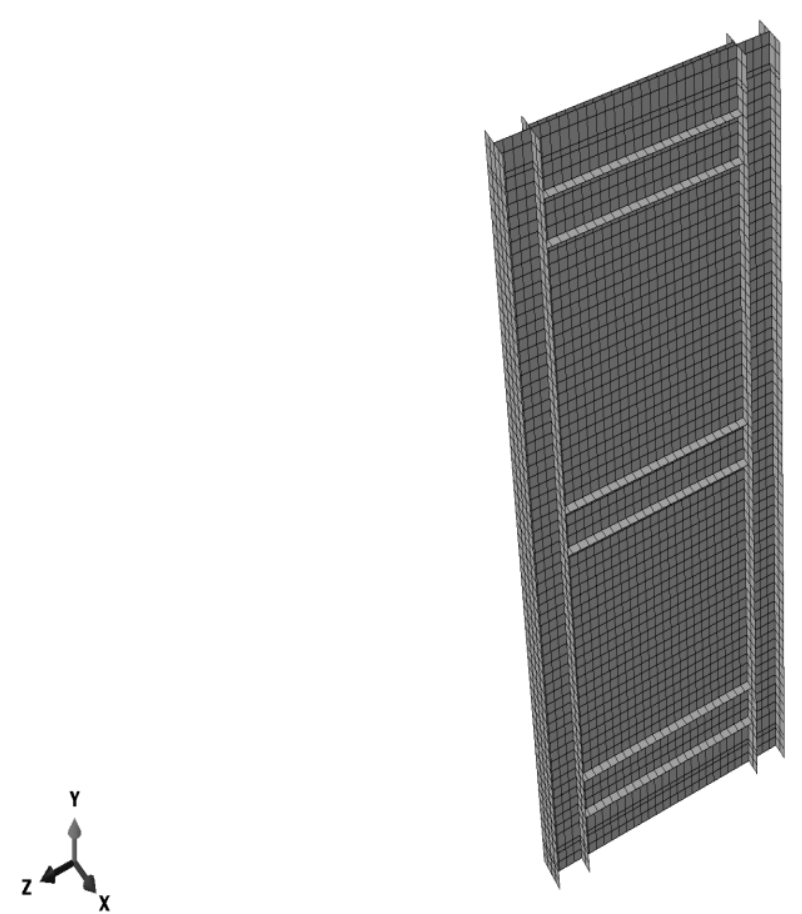

Figure3.7: Finite element mesh of Astaneh et al. (2002) 'innovative' specimen 


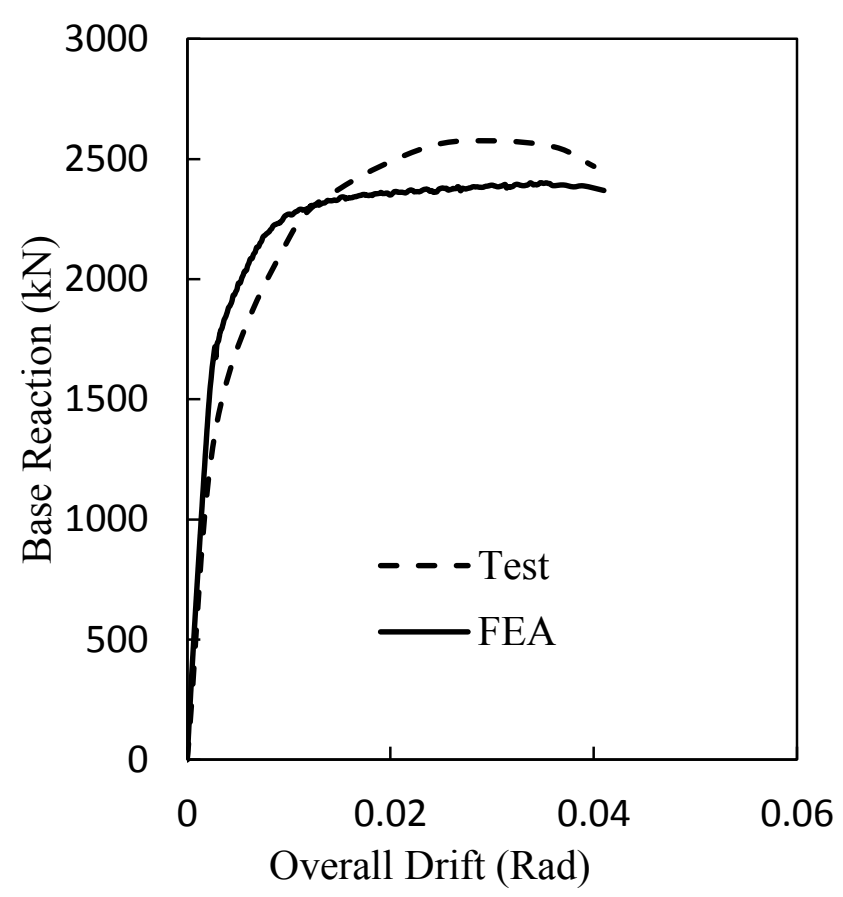

Figure3.8: Validation of push-over curve

\subsubsection{Pushover analysis and results of Astaneh-Asl (2002) specimen}

The composite shear wall project conducted by Astaneh-Asl et al. (2002) dealt with the seismic performance of composite shear walls. The objective of their work was to investigate the behaviour under cyclic load displacements of composite plate shear wall and suggest suitable guidelines for the design of composite shear walls. Their study was concentrated on a type of composite plate shear wall which consisted of a steel boundary frame made of columns and beams and steel plate wall with a reinforced concrete wall attached to it on one side with bolts. Two forms of composite shear walls were studied: 'traditional' and 'innovative'. In the traditional composite plate shear wall, there was no gap between the surrounding boundary frame and the concrete wall edges whereas in the innovative system, there was a $32 \mathrm{~mm}$ gap between the steel boundary frame and the edges of the concrete wall. In the present study, the innovative system specimen was modeled and a pushover analysis was carried out. The material properties were chosen as the one reported 
by the author's work. Thus yield strength of boundary members as $350 \mathrm{MPa}$ and that of the steel infill as $248 \mathrm{MPa}$ were chosen. The concrete compressive strength of $28 \mathrm{MPa}$ was chosen conforming to the grade of concrete used in the experimental work. A reinforcement ratio of $0.92 \%$ was maintained in accordance with the test specimen. $13 \mathrm{~mm}$ diameter A325 bolts were reported to have been used for connecting the reinforced concrete (RC) panels with the steel infill plate. Similarly, in the FE model, the bolts were modelled with appropriate geometry and material properties from push-out tests available in literature.

The system was constrained such that out of plane buckling of the frame does not occur. As in the test, displacement loading has been applied through the center line of the top beam level. The displacement was increased to a maximum value as obtained from the envelope of hysteresis curve of physical test. The element mesh of the composite plate shear wall is shown in Figure 3.7. The measured (as obtained from physical experimentation) and predicted (from FEA) base shear values are plotted against the overall storey drifts in Figure 3.9. The figure indicates that the finite element model predicts the initial stiffness and post-yield response of the shear wall very well. The ultimate capacity of the specimen is under estimated by about $6 \%$. This can be due to the ambiguities in the way of application of displacement in the experiment and the FE model. This can be also due to the small differences in the actual experimental specimen with its associated set up and that of the FE model; like the fish plate used in the actual experiment for connecting the plate with the boundary members has not been considered in the FE model. 


\subsubsection{Comparison of hierarchical order of failure modes}

Zhao and Astaneh-Asl (2004) provides a very clear account of the hierarchical order of failure of the various components of the test innovative C-PSW specimen for incremental drift levels. This section aims to compare the failure levels of the FE model specimen with that of the test specimen under varied drift levels. At an overall drift of 0.002 , the test specimen was reported to behave perfectly elastically which was also the observation from the FE model. At an overall drift of 0.004 , the test specimen was reported to still behave elastically complying with that of the observation for the FE model. This point was named as the proportional limit. The experiment reported the significant yield point at an overall drift of 0.006 when all the three beams and column base showed yielding. The FE model at this overall drift level also showed yield signs in the three beams and yield in the outer flanges of the column base.

The test innovative C-PSW was observed to have its steel infill locally buckled in compression and yielded in tension diagonally at overall drift of 0.012 . Minor damage to RC walls were also observed. Likewise, in the FE model at this drift level the infill steel plate was found to reach its yield strength and local buckling was observed between the bolts along the compression diagonal. Additionally, localized areas of the $\mathrm{RC}$ wall was found to have plastic strain in tension values corresponding to that of failure in concrete; physically resembling localized damage in RC concrete wall. The column flange and web at the column base yielded at overall drift of 0.018 in the experimental test complying with that of the FE model results. Overall drift levels of 0.024 led to the local buckling of middle beam web and bottom beam flange in the test specimen; whereas, local buckling in only the middle beam web and flange were noticed in the FE model. 0.03 of 
overall drift was reported as the point of maximum shear strength in the experimental test. However, no such distinct point of maximum strength was observed for the FE model. Major cracks in the test specimen RC panels and web fracture in the middle beam were observed in the test specimen for an overall drift of 0.036. Identically, in the FE model, significant areas of the RC panel were found to reach tensile plastic strain values corresponding to failure; physically, which can be represented as the formation of cracks. Moreover, plastic hinges were found to have been generated in the middle beam ends and the entire web was found to have yielded. At even higher overall drift values, infill plate fractured in the test C-PSW accompanied with RC wall crushing and spalling and beam flange fracture. Similar symptoms were noticed in the FE model at which instant, the specimen can be considered damaged.

\subsection{Comparison of pushover curves of C-PSW and SPSW}

To evaluate the performance of the C-PSW in comparison to that of ductile plate shear wall, the 'innovative' specimen for validation was analysed and compared for the pushover nature against the same specimen devoid of the RC panels. Figure 3.9 shows the pushover curve for the SPSW vs the C-PSW. Thus, the geometry of the SPSW components of both the specimen were

the same. It is observed from the figure that composite plate shear wall has higher stiffness and strength in comparison to the ductile plate shear wall. 


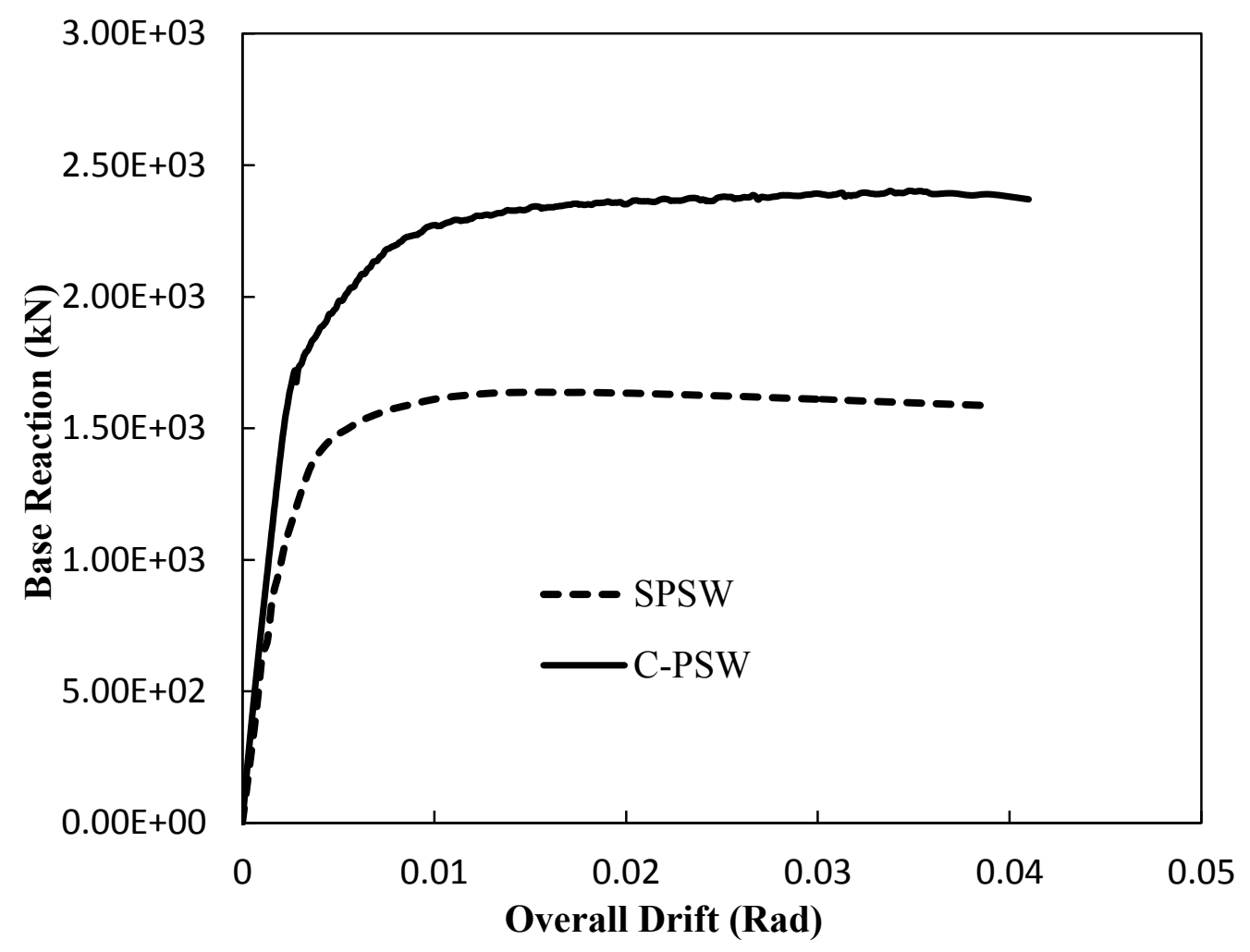

Figure 3.9: Push-over curve for C-PSW and SPSW

\subsection{Conclusion}

A non-linear finite element is developed to study the behaviour of composite plate shear walls. The finite element model developed is able to provide very good predictions for quasi-static pushover analyses of the composite plate shear wall specimen. The model captured all essential features of the test specimens analyzed. Figure 3.8 indicates that the finite element model predicts the initial stiffness and post-yield response of the shear wall very well. The ultimate capacity of the specimen is under estimated by about $6 \%$. The validated FE model is used to investigate seismic performance of composite plate shear walls in Chapter 4 


\section{SEISMIC PERFORMANCE OF COMPOSITE PLATE SHEAR WALLS}

\subsection{Introduction}

Experimental and analytical studies on composite-plate shear walls have been limited to static and quasi-static cyclic loadings till date. C-PSWs have not been studied under real seismic loadings. A finite element model to study the behaviour of C-PSW has been developed in the previous chapter. The finite element model has also been validated with the available experiment data. This chapter presents the seismic performance of a 4-storey and a 6-storey C-PSW under spectrum compatible seismic records for Vancouver. As explained in earlier chapter, the working mechanism of the C-PSW comprises of the reinforced concrete (RC)-panel stiffening the steel infill plate preventing it from overall buckling and thereby ensuring the failure of steel plate in yielding in shear. This expected behaviour of C-PSW is evaluated in this chapter. Shear contributions of different components of the C-PSW like the steel infill, columns, RC panel and other member forces and moments under spectrum compatible seismic forces are presented. Other important seismic parameter presented are the bending moment and axial forces for the boundary columns.

This chapter also describes the methodology used to select the ground motions for the nonlinear time-history analyses. The elastic spectra of the historical and artificial records are computed and scaled to match the design acceleration spectra. 


\subsection{Seismic design of C-PSWs}

In order to design the C-PSWs, the equivalent static force method was employed to find out the storey shear forces at each storey according to NBCC 2010. The design seismic base shear (V) calculated according to NBCC2010 is as follows:

$$
V=\frac{S\left(T_{a}\right) M_{V} I_{E} W}{R_{d} R_{0}} \geq \frac{S(2.0) M_{V} I_{E} W}{R_{d} R_{0}}
$$

Where, ' $S\left(T_{a}\right)$ ' is the spectral acceleration, ' $M_{V}$ ' is an amplification factor accounting for higher mode effects on base shear, ' $I_{E}$ ' is the importance factor for the structure, ' $W$ ' denotes the total dead load in addition to $25 \%$ of the snow load, ' $R_{d}$ ' denotes the force modification factor of the structure related to ductility, ' $R_{0}$ ' denotes the over-strength related force modification factor

of the structure. According to the NBCC 2010, for structures having $R_{d}$ greater than 1.5 the design base shear should assume a maximum value as:

$$
V \leq \frac{2 S(0.2) I_{E} W}{3 R_{d} R_{0}}
$$

The final base shear calculated was distributed at each storey of the structure as:

$$
F_{X}=\left(V-F_{t}\right) \frac{W_{X} h_{X}}{\sum_{i=1}^{i=n} W_{i} h_{i}}
$$

Where, ' $F_{t}$ ' is an extra lateral force component applicable to the top floor, ' $W_{i}$ ' or ' $W_{X}$ ' denotes 
the dead load in addition to $25 \%$ snow load applicable to the storey $i$ or $x$ and ' $h_{x}$ ' or ' $h_{i}$ ' denotes the height from the base to the storey level $i$ or $x$ respectively.

In the absence of proper design guidelines for C-PSWs in the Canadian design standard, the SPSW component was designed according to the capacity design concepts used for conventional ductile SPSWs. Thus, boundary members were designed to develop full capacity of the steel infill plates. The concrete panel was however designed according to the provisions of AISC 341-10, which were selected to be of $200 \mathrm{~mm}$ thickness and reinforcement ratio of 0.0025 was maintained with the bar spacing not exceeding $450 \mathrm{~mm}$ to comply with the minimum requirements. The capacity design of the SPSW component involved designing the structure suitably to facilitate inelasticity accompanied by energy dissipation mostly in the infill plates. The other structural elements like the beams and the columns were designed to have sufficient strength to take the failure force from the infill plate, which acts as the major energy dissipater. The boundary members were protected against failure and were supposed to behave elastically, in general under force levels at par with the failure forces in the infill plates. In a C-PSW, the steel infill are desired to resist the storey shears primarily through yielding in shear; since the concrete panel stiffens the former; thereby restraining the out of plane buckling. However, under extreme load conditions, it is expected that the concrete panel will disintegrate and tension fields will appear in the steel infill plates (Astaneh-Asl, 2002). The boundary members were thus designed to be safe under full tension field yield force from the infill plates. 
The design philosophy for SPSW component followed was that of proposed by Berman and Bruneau (2008) and then checked for CAN/CSA S16-09 strength and stiffness criteria. Accordingly, the infill plate yielding forces were calculated as:

$$
\begin{aligned}
& w_{y c i}=0.5 F_{y p} t_{w i} \sin (2 \alpha) \\
& w_{x c i}=F_{y p} t_{w i}(\sin \alpha)^{2} \\
& w_{y b i}=F_{y p} t_{w i}(\cos \alpha)^{2} \\
& w_{x b i}=0.5 F_{y p} t_{w i} \sin (2 \alpha)
\end{aligned}
$$

Where, ' $F_{y p}$ ' is the yield strength of the infill plate steel, ' $t_{w i}$ ' is the steel infill thickness, ' $\alpha$ ' is the angle of tension field, ' $w_{y c i}$ ' is the vertical distributed force applicable to the columns, ' $w_{x c i}$ ' is the horizontal distributed force applicable to the columns, ' $w_{y b i}$ ' is the vertical distributed load applicable to the beams and ' $w_{x b i}$ ' is the horizontal distributed load applicable to the beams. Based on these yield forces, free body force analysis of the beams and columns leads to the design forces in the boundary members.

CAN/CSA S16-09 provides the following equation to check for the stiffness of columns to develop uniform tension field in the adjacent infill plate:

$$
I_{C} \geq \frac{0.0031 w h_{s}^{4}}{L}
$$


Where, ' $w$ ' is the infill plate thickness, ' $h_{s}$ ' is the storey height, ' $L$ ' is the bay width and ' $I_{C}$ ' is the moment of inertia of the column cross-section.

The following equations are provided to check sufficient uniform tension field formations in the top and bottom infill panel as follows:

$$
I_{b} \geq \frac{w L^{4}}{650 L-\left(\frac{w h_{s}^{4}}{I_{c}}\right)}
$$

Where, ' $I_{b}$ ' is the moment of inertia of the top beam cross-section.

$$
I_{b} \geq \frac{w L^{4}}{267 L-\left(\frac{w h_{s}{ }^{4}}{I_{c}}\right)}
$$

Where, ' $I_{b}$ ' is the moment of inertia of the bottom beam cross-section.

AISC 341-10 recommends adequate stiffening of the steel infill plate by encasement of the steel plate or attachment with a RC panel. The conformance to this requirement is recommended to be demonstrated with an elastic plate buckling analysis ensuring that the composite wall can successfully resist a nominal shear force equal to ' $V_{n s}$ '. AISC 341-10 provides an expression for the nominal shear strength of the steel plate as follows:

$$
V_{n s}=0.6 A_{s p} F_{y}
$$


Where, ' $A_{s p}$ ' is the horizontal area of the stiffened steel plate $\left(\mathrm{mm}^{2}\right)$, ' $F_{y}$ ' is the minimum yield stress of the steel plate (MPa). The design shear strength is given as ' $0.9 V_{n s}$ '. The steelconcrete composite panel was checked for sufficient stiffness against overall buckling according to the provisions of AISC 341-10 using a transformed section stiffness of the wall. It was done so, by transforming the concrete wall to vertical and horizontal equivalent steel stiffeners and then employing the elastic buckling theory of orthotropic plates in order to check for sufficient stiffness against overall buckling of the plate. Orthotropic plates comprise of steel plate stiffened by stiffeners in transverse or longitudinal direction or in both directions. According to Allen and Bulson (1980), simply supported plates containing a large number of longitudinal stiffeners can be considered as 'Orthotropic plates' with different unit flexural rigidities in the longitudinal and transverse direction. Orthotropic plate theory is also applicable for plates containing both vertical and horizontal stiffeners. In here, the composite steel-RC panel plate section has been converted in to an equivalent orthotropic plate prior to check for its elastic buckling under nominal shear strength loads. In order to do so, the RC panel section was converted into equivalent steel stiffeners both in the horizontal and vertical directions. The flexural stiffness of the plate for bending about its y-axis ' $D_{x}$ ', $\mathrm{x}$-axis ' $D_{y}$ ' and the plate torsional rigidity ' $H$ ' were found out as follows:

$$
\begin{aligned}
& D_{x}=\frac{E I_{x}}{c}+\frac{E t^{3}}{12\left(1-v^{2}\right)} \\
& D_{y}=\frac{E I_{y}}{c}+\frac{E t^{3}}{12\left(1-v^{2}\right)} \\
& H=\frac{E t^{3}}{12\left(1-v^{2}\right)}
\end{aligned}
$$


Where, ' $I_{x}$ ' and ' $I_{y}$ ' are the section moment of inertia of the vertical and horizontal stiffeners respectively, ' $c_{1}$ ' and ' $c_{2}$ ' represents the spacing between the vertical and horizontal stiffeners respectively, ' $t$ ' denotes the steel infill plate thickness, ' $E$ ' represents the young's modulus, ' $t$ ' is the plate thickness and ' $v$ ' is the poisons ratio.

To find out the critical shear stress allowable ' $\tau_{c r}$ ' the exact solutions for orthotropic simply supported plates in shear obtained by Seydel E. (1933) were used.

$$
\tau_{c r}=\frac{K_{s} \Pi^{2}}{b^{2} t}\left(D_{x}\right)^{1 / 4}\left(D_{y}\right)^{3 / 4}
$$

Where, ' $K_{s}$ ' is a parameter to be obtained from the solution curves by Seydel E. (1933) for varying values of the parameters ' $\frac{H}{\sqrt{D_{x} D_{y}}}$ ' and ' $\phi\left(\frac{D_{y}}{D_{x}}\right)^{1 / 4}$ '; ' $\phi$ ' is the aspect ratio of the plate. It was checked from the above analysis that the composite panels can successfully resist shear yield stress of steel plate, as provided in equation (4.11). Details of these check can be found in chapter 6 .

\subsection{Selection of C-PSW system}

The buildings considered here for analysis are hypothetical office buildings located at Vancouver having a plan area of $2014 \mathrm{~m}^{2}$. Each of the buildings possess two identical shear walls to resist lateral forces in each direction; thus, each shear wall will resist one half of the design seismic loads as shown in Fig.- 4.1. For simplicity, torsion is neglected. Each C-PSW is $3.8 \mathrm{~m}$ wide, measured from center to center of columns, and has an aspect ratio of 1 (storey height of 3.8 
m). The buildings considered here are one 4-storey and another 6-storey building used to evaluate the performance of C-PSWs under dynamic seismic loads. The 4-storey building has a total height of $15.2 \mathrm{~m}$ and the 6-storey building has a total height of $22.8 \mathrm{~m}$. The building is assumed to be founded on (site class C according to NBCC 2010). A dead load of $4.26 \mathrm{kPa}$ for each floor and $1.12 \mathrm{kPa}$ for the roof were used. The live load on all floors was taken as $2.4 \mathrm{kPa}$. The nominal yield strength of the beams, columns and infill plates was assumed to be $350 \mathrm{MPa}$ and have a young's modulus of 200, $000 \mathrm{MPa}$. NBC 2010 (NRCC 2010) load combination 'D + 0.5L + E' (where, $\mathrm{D}=$ dead load, $\mathrm{L}=$ live load and $\mathrm{E}=$ earthquake load) was considered for floors and for the roof, the load combination ' $\mathrm{D}+0.25 \mathrm{~S}+\mathrm{E}$ ' (where $\mathrm{S}=$ snow load) was considered. A ductility related force modification factor ' $R_{d}$ ' of 5.0 and an over strength force modification factor ' $R_{0}$ ' of 1.6 was used in the design according to the provisions of NBCC 2010 for steel plate shear walls. The equivalent static lateral forces determined based on the NBCC 2010 for the 4- storey C-PSW were $152.5 \mathrm{kN}, 305.1 \mathrm{kN}, 457.7 \mathrm{kN}$ and $206.3 \mathrm{kN}$ for the first storey, second storey, third storey and roof respectively. The lateral forces determined for the 6- storey C-PSW were 104.2 kN, 208.4 $\mathrm{kN}, 312.6 \mathrm{kN}, 416.8 \mathrm{kN}, 521.1 \mathrm{kN}$ and $211.3 \mathrm{kN}$ for the first storey, second storey, third storey, fourth storey, fifth storey and roof respectively. Consistent column section was chosen for the 4storey C-PSW throughout all the floors; whereas, separate column sections were chosen for the bottom two stories and the other top stories for the 6-storey C-PSW as shown in Fig. - 4.2. In order to design the thickness of the steel infill plates of the SPSW, a steel plate thickness of $4.8 \mathrm{~mm}$ was used as the minimum practical thickness based on requirements to be bolted with the reinforced concrete panels and handling issues. $13 \mathrm{~mm}$ diameter A325 bolts were selected for connecting the steel infill plate with the RC panel. The boundary beams and columns were designed according to the Canadian steel design standard CAN/CSA S16-09 satisfying all the required criteria regarding 
strength and stiffness. The design philosophy for the vertical and horizontal boundary members were however, followed that of by Berman and Bruneau (2008) and Qu and Bruneau (2009). Accordingly, the suitable components of the steel infill plate yield forces were transferred to the horizontal beams and vertical columns. The boundary members were then designed as beamcolumn members. The top and bottom steel beams were expected to experience uniformly distributed yield forces from infill plates on one side in addition to axial loads from the columns; whereas, the intermediate beams had the infill plate yield forces cancelled out on two fronts due to use of infill plates of consistent thickness and were designed only on the basis of axial loads from the columns. The columns at each storey were designed to take the reduced plastic moment under axial force of the corresponding beams.

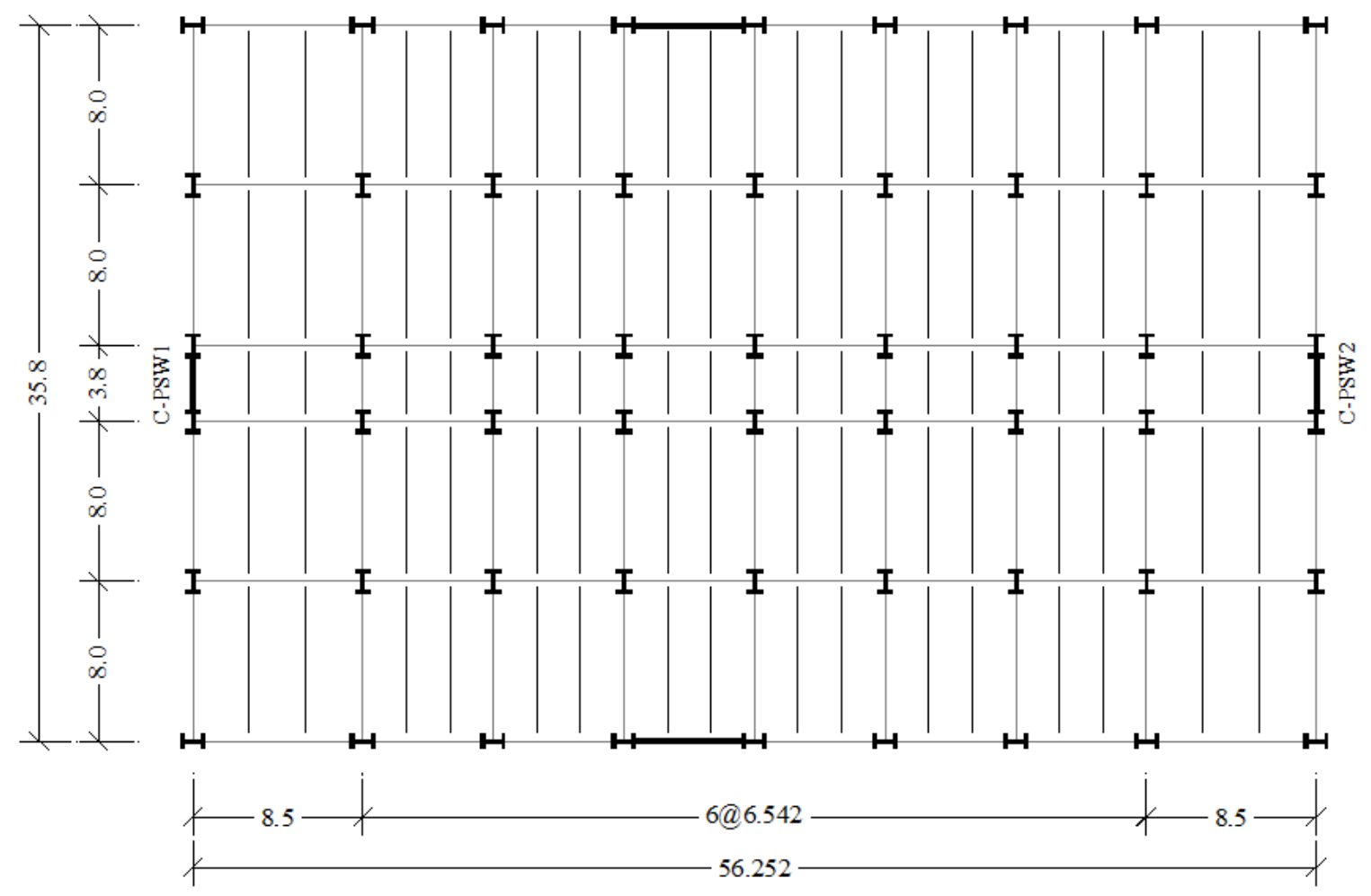

Figure4.1: Building floor plan with C-PSWs of aspect ratio 1 


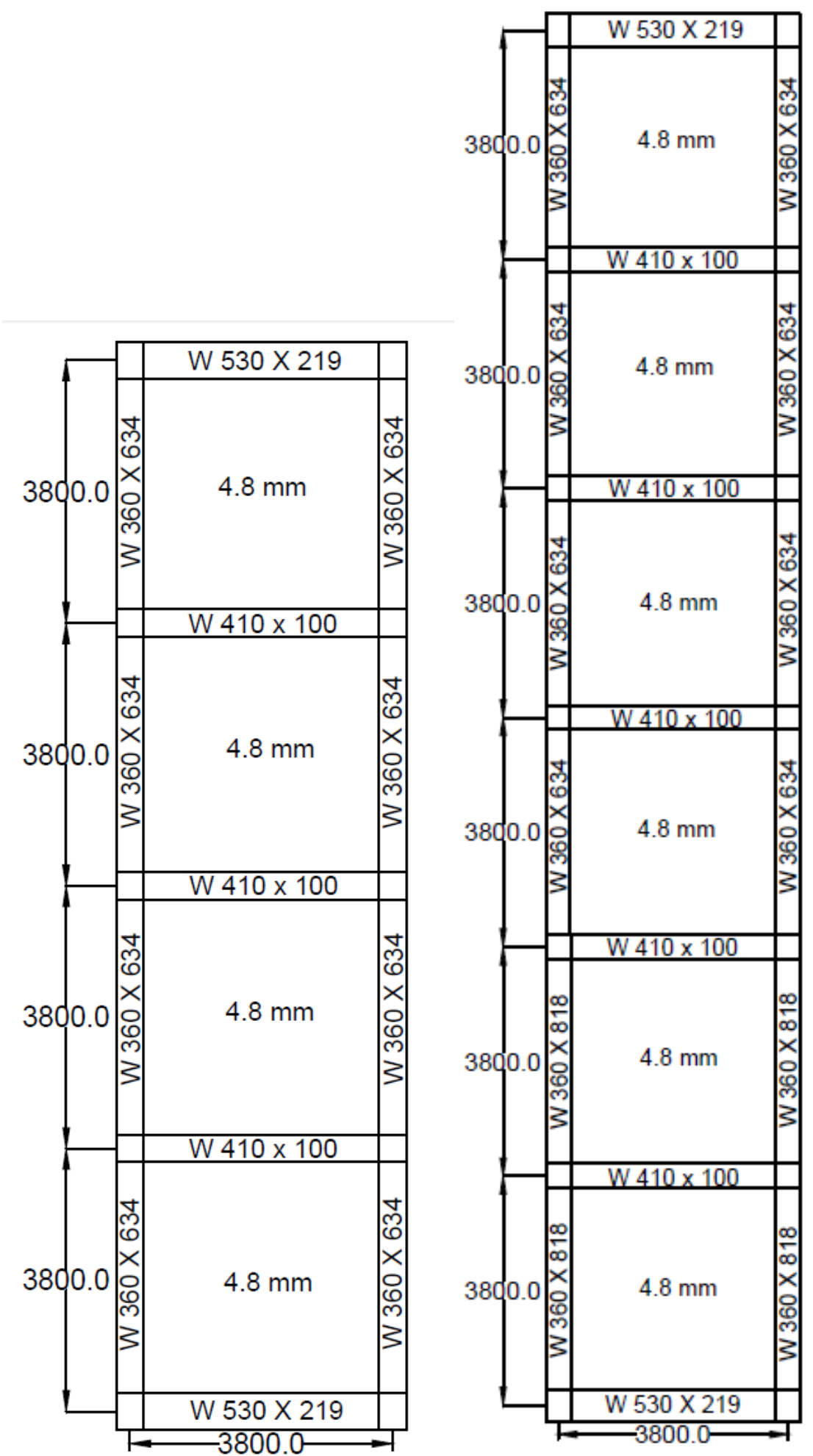

Figure 4.2: 4 - storey and 6 - storey C-PSWs 


\subsection{Finite element model of 4-storey and 6-storey C-PSWs}

The C-PSWs were modeled with 4-node shell elements (ABAQUS S4R) elements. For the seismic analysis, a dummy gravity column is incorporated into the finite element model to take account of $\mathrm{p}-\Delta$ effects. The gravity column is made of 2-node linear 3-D truss (ABAQUS T2D3) elements and is connected with the C-PSW at every floor with connections. The connections were so designed as to constrain the horizontal displacement of the two nodes; one on the gravity column and the other on the C-PSWs at every floor level in accordance with Tremblay et al. (2001). In order to achieve this, pin ended rigid links were used between the concerned nodes in the dummy gravity column and the respective nodes in the C-PSW. The bases of both the dummy gravity column as well as the C-PSWs were pinned to the ground. The mechanism is so designed that the dummy gravity column does not contribute to the lateral stiffness of the structural system. The dummy gravity column carried half of the total remaining mass of the building; since there are two C-PSWs in each mutually perpendicular directions of the building plan. The gravity loads for each storey was applied on the respective storey nodes in the dummy gravity column as point masses. The bolts were modelled using 2-node linear beam element in 3D space (ABAQUS B31). The element is associated with six degrees of freedom at each node; three translation and three rotations defined in its global co-ordinate system. Raleigh proportional damping of 5\% were selected for the analyses. Yield strength of steel infill plates, boundary columns and beams were selected as $350 \mathrm{MPa}$. The concrete was designed to have compressive as well as tensile damage and a compressive strength of $28 \mathrm{MPa}$. 


\subsection{Nonlinear dynamic seismic analyses of C-PSWs}

\subsubsection{Frequency analysis}

A non-linear finite element model for analyzing the C-PSWs were developed. This model was in turn used to perform frequency analysis for the concerned 4-storey and 6-storey C-PSWs prior to the seismic analysis. Frequency analysis for the C-PSWs with the gravity column were carried out to find out the fundamental mode shapes and fundamental frequencies for the 4-storey and 6storey C-PSWs. The intension of such an analysis was twofold. Firstly, the fundamental time period was used to calculate the earthquake time history scale factor to scale the raw accelerogram data suitable for the concerned structure. Secondly, the fundamental frequencies were used to find out the damping factors for the materials in the finite element model based on Raleigh proportional damping of $5 \%$. The fundamental mode shapes were observed to show no abnormality, whatsoever. The NBCC 2010 provides an expression to find out the time period of shear walls:

$$
T=0.05\left(h_{n}\right)^{3 / 4}
$$

Where, ' $h_{n}$ ' is the height of the building in meters.

When compared with the fundamental period estimate from the NBCC 2010, it was found that the NBCC provides conservative estimates of the fundamental period. The fundamental periods of the 4-storey and 6-storey C-PSWs along with the associated gravity column was found out as 0.63 seconds and 1.16 seconds respectively. 


\subsubsection{Ground motion time histories}

NBCC 2010 emphasizes the use of spectrum compatible earthquake records to be used for seismic analysis. The building considered here being located at Vancouver, the uniform hazard spectrum for Vancouver provided in NBCC 2010 has been used in this research. Spectrum compatibility is considered a desirable characteristic where the response spectrum from the selected earthquake records are intended to match with the design site specified response spectrum (uniform hazard spectrum) for a specific period of interest. ASCE7-10 recommends a minimum of three ground motion records for time history analysis, when peak maximum response are considered for component checking and a minimum of seven ground motion records when the average of maximum response are considered for component checking.

In this research, eight ground motion records have been selected and used for time history analysis; four real ground motion records from the strong ground motion database of Pacific Earthquake Engineering Research Center (PEER, 2010) and four simulated earthquake records from Engineering Seismology toolbox website (Atkinson et al., 2009). The four simulated and four real ground motion record included are as shown in Table -4.1 and 4.2 respectively. Fig. -4.3 and Fig. -4.4 represents the scaled simulated and real accelerograms prepared for the $6-$ storey and 4 - storey C-PSWs. The selected real ground motions were chosen to have $\mathrm{A} / \mathrm{V}$ (A, peak acceleration in scale of $g$ and $V$, peak velocity in $\mathrm{m} / \mathrm{s}$, where $g$ is acceleration due to gravity in $\mathrm{m} / \mathrm{s}^{2}$ ) values close to 1 conforming with the $\mathrm{A} / \mathrm{V}$ value for an earthquake expected in Vancouver (Naumoski et al., 2004). Based on past earthquake records during the years 1600-2006, it has been found that more than $60 \%$ of the seismic events occurring in British Colombia and its adjoining offshore areas 
possessed an earth quake magnitude in the range of 6.0-7.0 (Lamontagneet al., 2008). The simulated earthquakes included two different sets of records having magnitude 6.5 and 7.5 respectively for soil class $\mathrm{C}$. Each of the magnitude set consisted of one record for near fault and one for far fault.

The selected ground motions were scaled based on the partial area method of ground motion scaling. According to this method, the area under the acceleration response spectrum curve of the selected ground motion and design response spectrum were compared and made equal by finding out a suitable scaling factor. Area under the acceleration response spectrum curves of ground motion records between $0.2 \mathrm{~T}$ to $1.5 \mathrm{~T}$; where, ' $\mathrm{T}$ ' is the fundamental period of vibration of the building was compared with the area under the design response spectrum of Vancouver in the designated range and made equal by finding out a suitable scaling factor and modifying the concerned accelerogram with that factor. This period range of the excitation motions was assumed to have the largest effects on the structural response. The lower limit of the range can be justified by the participation of higher modes of the structure in the response and the upper limit can be justified as the increase in the fundamental period of the structure due to inelastic action. In both case response spectrum is considered for $5 \%$ of critically damped single degree of freedom system in soil class $\mathrm{C}$. 
Table 4.1: Simulated earthquake records

\begin{tabular}{|c|c|c|c|c|}
\hline $\begin{array}{c}\text { Event } \\
\text { name }\end{array}$ & Magnitude & $\begin{array}{c}\text { Distance } \\
(\mathrm{Km})\end{array}$ & $\begin{array}{c}\text { Scaling factor (4 storey) } \\
\text { Scaling factor (6 storey) }\end{array}$ \\
\hline $6 \mathrm{C} 1$ & 6.5 & 8.8 & 0.71 & 0.76 \\
\hline $6 \mathrm{C} 2$ & 6.5 & 14.6 & 1.31 & 1.44 \\
\hline $7 \mathrm{C} 1$ & 7.5 & 15.2 & 0.79 & 0.89 \\
\hline $7 \mathrm{C} 2$ & 7.5 & 45 & 1.72 & 1.81 \\
\hline
\end{tabular}

Table 4.2: Real earthquake records

\begin{tabular}{|c|c|c|c|c|c|c|}
\hline Event name & Magnitude & PGA & PGV & A/V & Scaling factor & Scaling factor \\
& & $(\mathrm{g})$ & $(\mathrm{m} / \mathrm{s})$ & & $(4$ storey $)$ & (6 storey) \\
\hline Kobe,1995 & 6.6 & 0.143 & 0.147 & 0.973 & 1.84 & 1.60 \\
\hline San Fernando,1972 & 6.61 & 0.188 & 0.179 & 1.05 & 1.65 & 1.53 \\
\hline $\begin{array}{c}\text { Imperial Valley, } \\
1979 \text { (1) }\end{array}$ & 6.53 & 0.3118 & 0.300 & 1.03 & 1.25 & 0.93 \\
\hline $\begin{array}{c}\text { Imperial Valley, } \\
\text { (2) }\end{array}$ & 6.53 & 0.525 & 0.502 & 1.04 & 0.99 & 1.00 \\
\hline
\end{tabular}



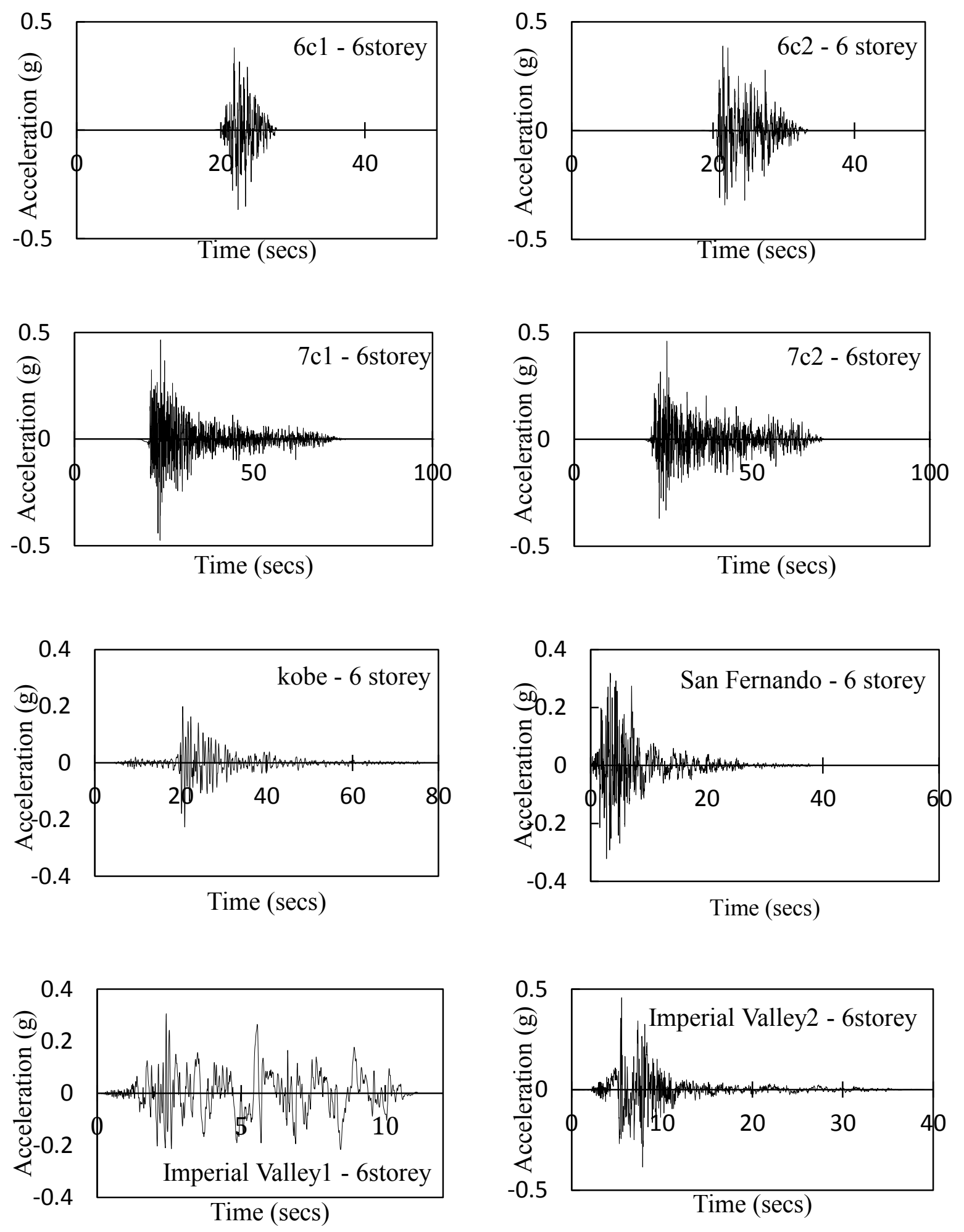

Figure 4.3: Scaled accelerograms for 6 - storey C-PSW 

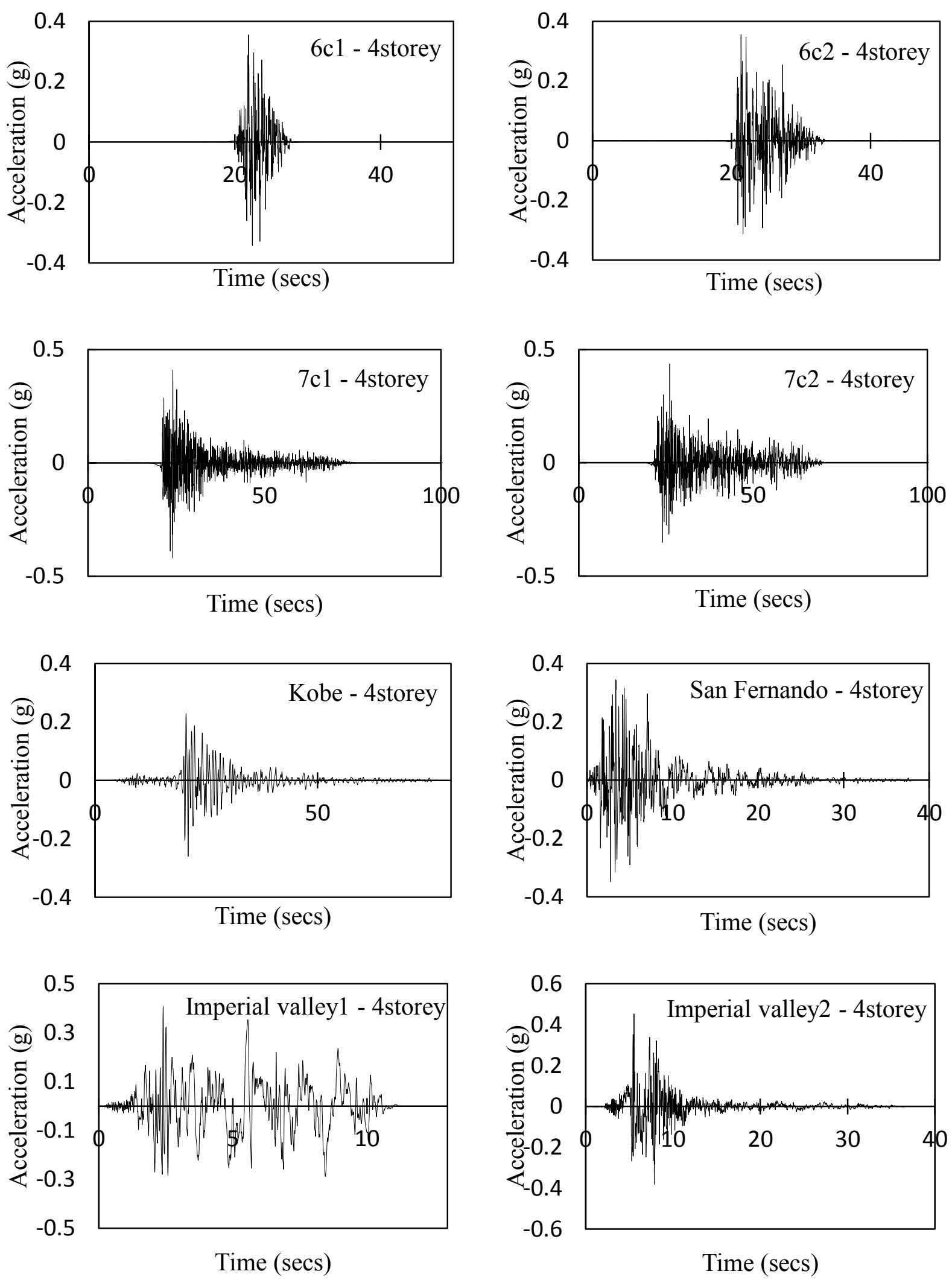

Figure 4.4: Scaled accelerograms for 4 - storey C-PSW 


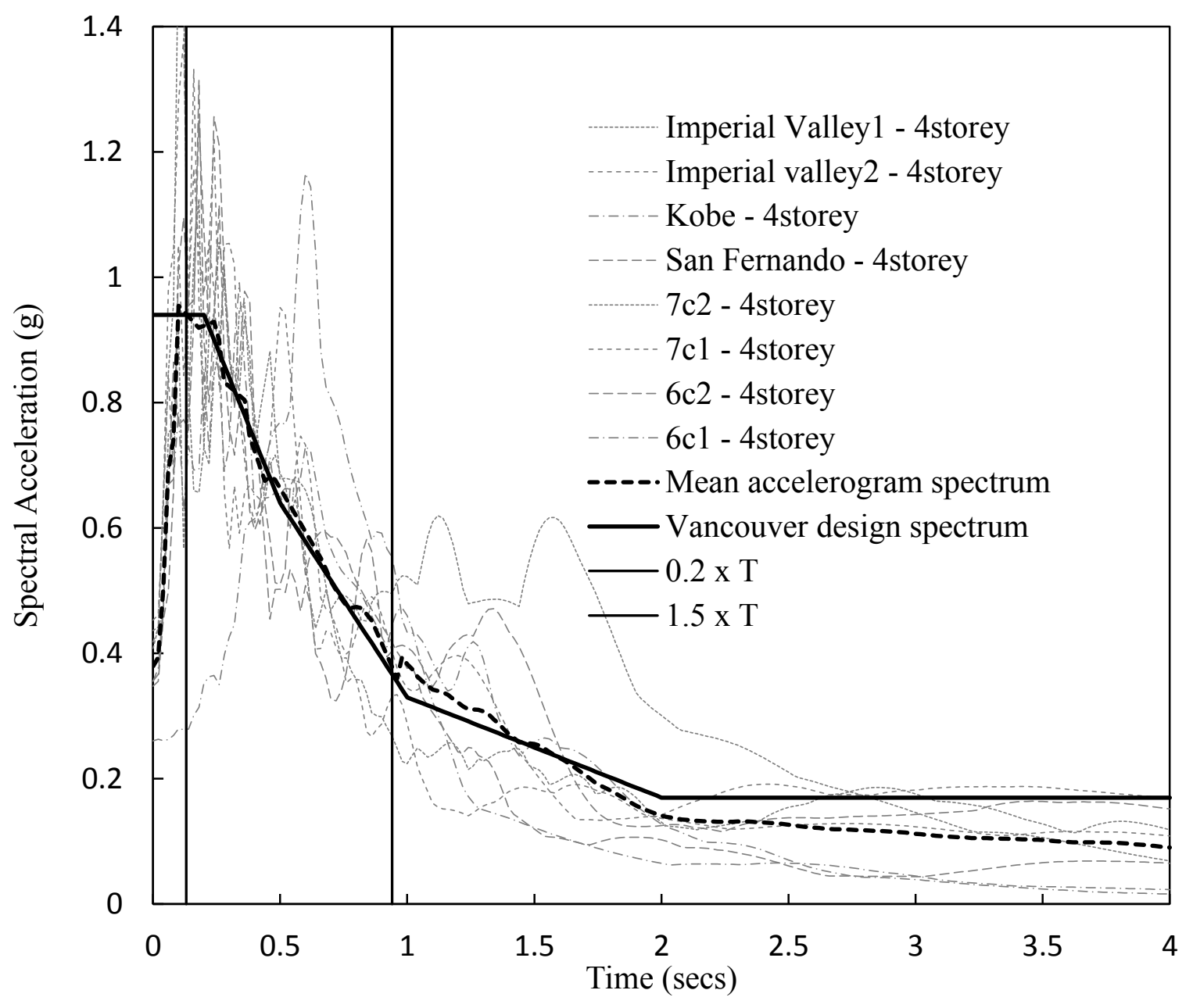

Figure 4.5: Acceleration spectra for selected accelerograms and design spectra for Vancouver 


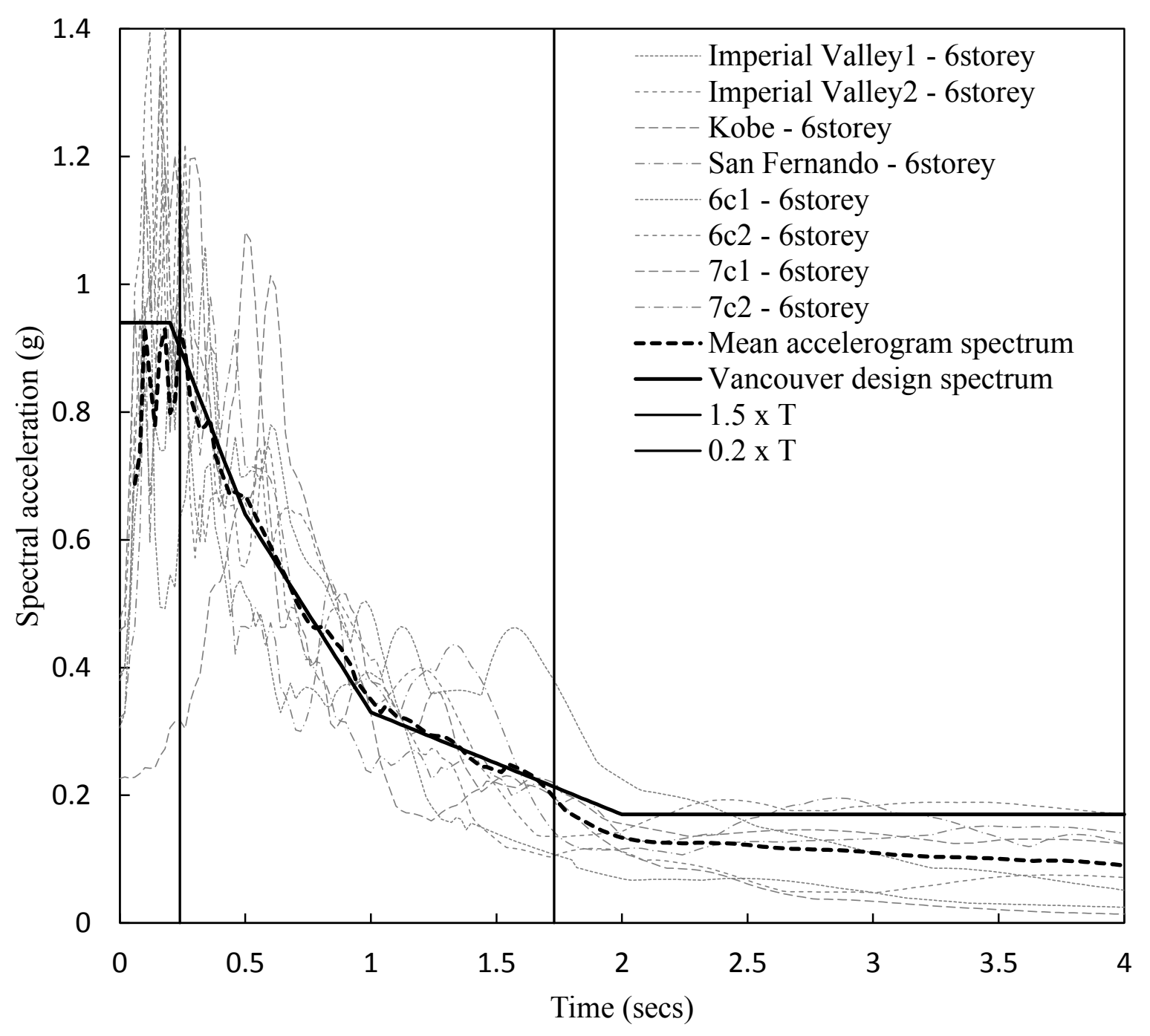

Figure 4.6: Acceleration spectra for selected accelerograms and design spectra for Vancouver 


\subsubsection{Seismic response of C-PSWs}

Non-linear time history analyses were performed in ABAQUS. The maximum base reactions recorded for the 4 - storey C-PSW under simulated earthquakes $6 \mathrm{c} 1,6 \mathrm{c} 2,7 \mathrm{c} 1$ and $7 \mathrm{c} 2$ were 5159 kN, 5394 kN, $4747 \mathrm{kN}$ and $4883 \mathrm{kN}$ respectively. Similarly, base reactions under real records Kobe, San Fernando, Imperial valley 1 and Imperial valley 2 for the 4 - storey C-PSW were found as $4960 \mathrm{kN}, 5040 \mathrm{kN}, 5020 \mathrm{kN}$ and $5170 \mathrm{kN}$ respectively. The maximum base reactions recorded for 6 - storey C-PSW under the simulated earthquakes $6 \mathrm{c} 1,6 \mathrm{c} 2,7 \mathrm{c} 1$ and $7 \mathrm{c} 2$ were $4523 \mathrm{kN}, 4852$ $\mathrm{kN}, 5314 \mathrm{kN}$ and $5232 \mathrm{kN}$ respectively. Base reactions under real records Kobe, San Fernando, Imperial valley 1 and Imperial valley 2 for the 6 - storey C-PSW were found as $4438 \mathrm{kN}, 4656$ $\mathrm{kN}, 4507 \mathrm{kN}$ and $5285 \mathrm{kN}$ respectively. The NBCC 2010 static base and storey shear forces calculated were found to be much lower than those of the dynamic shear distributions. This is due to the over strength in the C-PSWs caused by the use of thicker steel plates than required due to handling and practical requirements. The nominal shear strength of $3427 \mathrm{kN}$ calculated based on equation (4.11) recommended by AISC 341-10 was 36\% lower than the peak dynamic base shear of $5394 \mathrm{kN}$ found out for the 4 - storey C-PSW under the selected ground motions. This is due to the fact that, a portion of the dynamic base shear was found to be carried by the boundary steel columns and also by the reinforced concrete panel; thereby contributing towards greater overall shear strength; compared to the nominal shear strength, where the strength is based only on the steel plate ignoring the steel columns and the RC panel. Similarly, for the 6 - storey C-PSW the nominal shear strength of $3427 \mathrm{kN}$ was $35.5 \%$ lower than the maximum dynamic base shear of $5314 \mathrm{kN}$. From all time history analyses, the peak shear contribution from the steel column members at base was found to be $27 \%$ and the average shear contribution was found as $23 \%$ for the 4 - storey C-PSW. In the 6-storey C-PSW, the average base shear contribution from the 
boundary columns was $22 \%$ and the peak shear contribution was $29 \%$. For all cases, the percentage of storey shear contribution from the RC panels were found to be grossly diminishing with increase in storey level. So, the highest percentage of storey shear contribution by the RC panels was found for the first storey panel. Figures 4.7, 4.8, 4.9 and 4.10 provide a clear understanding of the peak storey shears recorded under the selected group of ground motions and the contributions by the various components of the C-PSWs; namely, the steel infill, boundary column and the RC panel for the 4 -storey and the 6 -storey C-PSWs. The average and peak first storey shear contribution by the RC panel for the 4 - storey C-PSW was $10 \%$ and $11 \%$ respectively. The corresponding values for the 6 - storey C-PSW were $8 \%$ and $10 \%$ respectively. Storey shear percentage contributions by the RC-panels for higher stories were observed to be practically insignificant.

The 4 - storey C-PSW behaved in a ductile manner and showed high strength and stiffness. Steel infill plate for the first and second storey yielded in shear under all the ground motions and third storey infill also yielded for a single case. Yield lines in the first storey beam end were observed for all cases. The RC-panels were capable of successfully restraining out-of-plane motion of the steel infill and was undamaged under all ground motions except for one where minor damage was identified at the first storey RC-panel from the plastic strain in tension (ABAQUS PEEQT) values resembling strain greater than the cracking strain. The 6 - storey C-PSW also behaved in a similar pattern with steel infills yielding in shear as a whole noticed from the first up to the fourth storey for the limiting cases with beam ends of first, second and third storey showing signs of yield. RC-panel was essentially undamaged excepting a couple of cases where the plastic strain in the first storey RC-panel assumed values corresponding to micro-cracking strain in tension. For all cases, stresses were found to be distributed throughout the infill panels and infill plates yielded 
mostly as a whole under shear; unlike the SPSWs where diagonal tension fields are observed under seismic loads and stress distribution is not uniform throughout the panel. Minimum partial yielding were observed in the steel boundary columns, thereby achieving its design objective to sustain the full yield force from the steel infill plates. Figures 4.11, 4.12, 4.13 and 4.14 show the storey column axial force and moments found out for the concerned seismic analyses. It can be observed that the capacity design concept used for designing the vertical boundary elements was essentially successful in maintaining the elastic regime of the columns. The design envelope had higher values than the peak axial force recorded at all times. The bending moment envelope was also above the peak moments noted mostly. Figure 4.15 shows the displacements in every storey obtained from the seismic analyses for the set of ground motions chosen at the instant of peak top storey displacement. It was found that the inter storey drift was within the allowable range from figure -4.16 and 4.17 respectively. The maximum top storey displacements recorded for the 4storey C-PSW were $53 \mathrm{~mm}, 60 \mathrm{~mm}, 51 \mathrm{~mm}$ and $55 \mathrm{~mm}$ for $6 \mathrm{c} 1,6 \mathrm{c} 2,7 \mathrm{c} 1$ and 7c2 earthquake records respectively. The corresponding values for the 4-storey C-PSW under the ground motions Kobe, San Fernando, Imperial valley 1 and Imperial valley 2 were 76 mm, 46 mm, 56 mm and 62 $\mathrm{mm}$ respectively. The maximum top storey displacements recorded for the 6-storey C-PSW were $102 \mathrm{~mm}, 107 \mathrm{~mm}, 88 \mathrm{~mm}$ and $115 \mathrm{~mm}$ for $6 \mathrm{c} 1,6 \mathrm{c} 2,7 \mathrm{c} 1$ and $7 \mathrm{c} 2$ earthquake records and $113 \mathrm{~mm}$, $126 \mathrm{~mm}, 161 \mathrm{~mm}$ and $136 \mathrm{~mm}$ for Kobe, San Fernando, Imperial valley 1 and Imperial valley 2 respectively. Figure 4.18 presents the yield pattern in the C-PSWs under ground motion 7c2 separately for the 4 - storey and the 6 - storey structure. The shear contribution of these yielded panels at the instant of the peak shear was found to assume values close to the nominal shear strength from figures -4.7 and 4.9 respectively. 

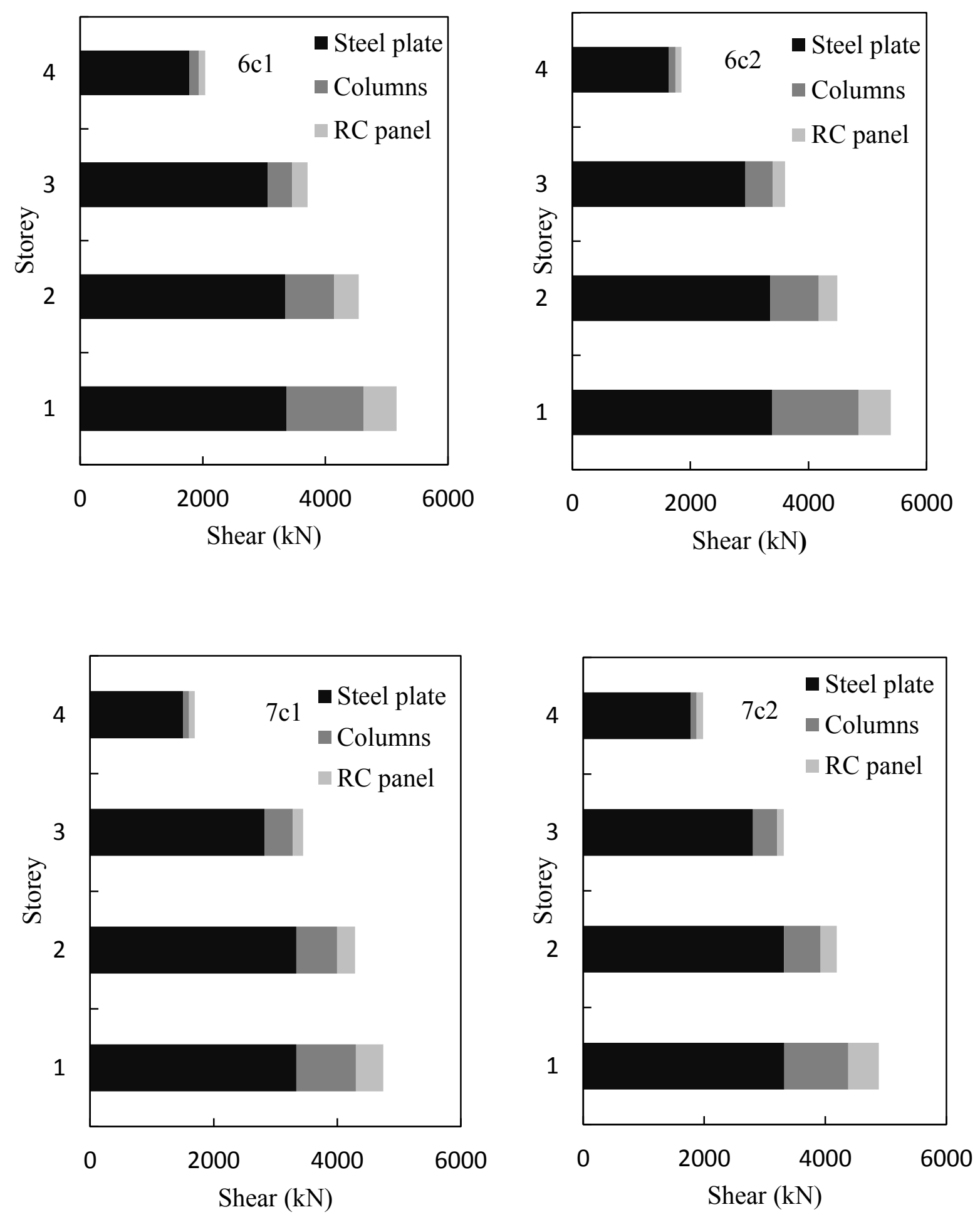

Figure 4.7: Peak storey shear contribution for different components of 4 - storey C-PSW 

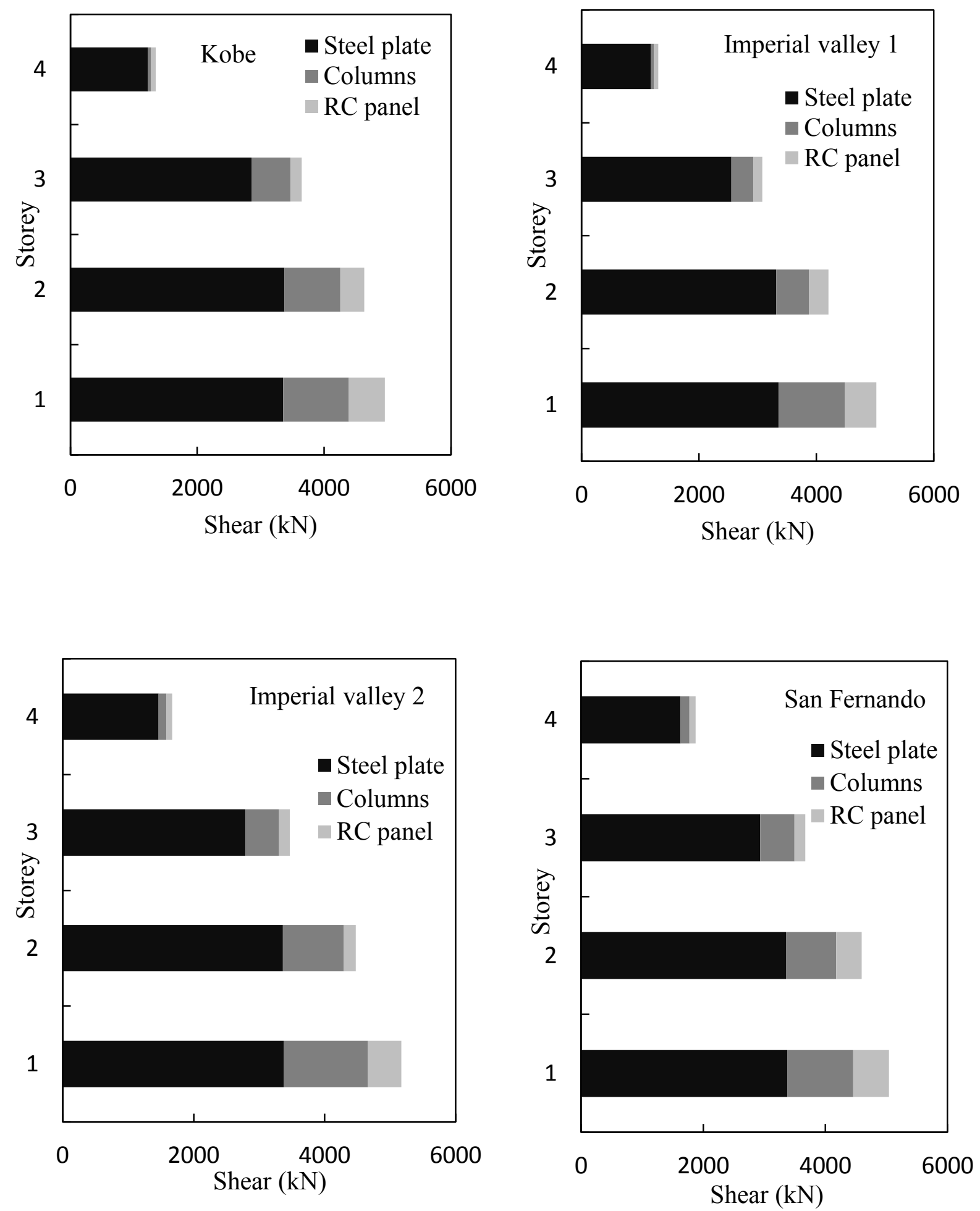

Figure 4.8: Peak storey shear contribution for different components of 4 - storey C-PSW 

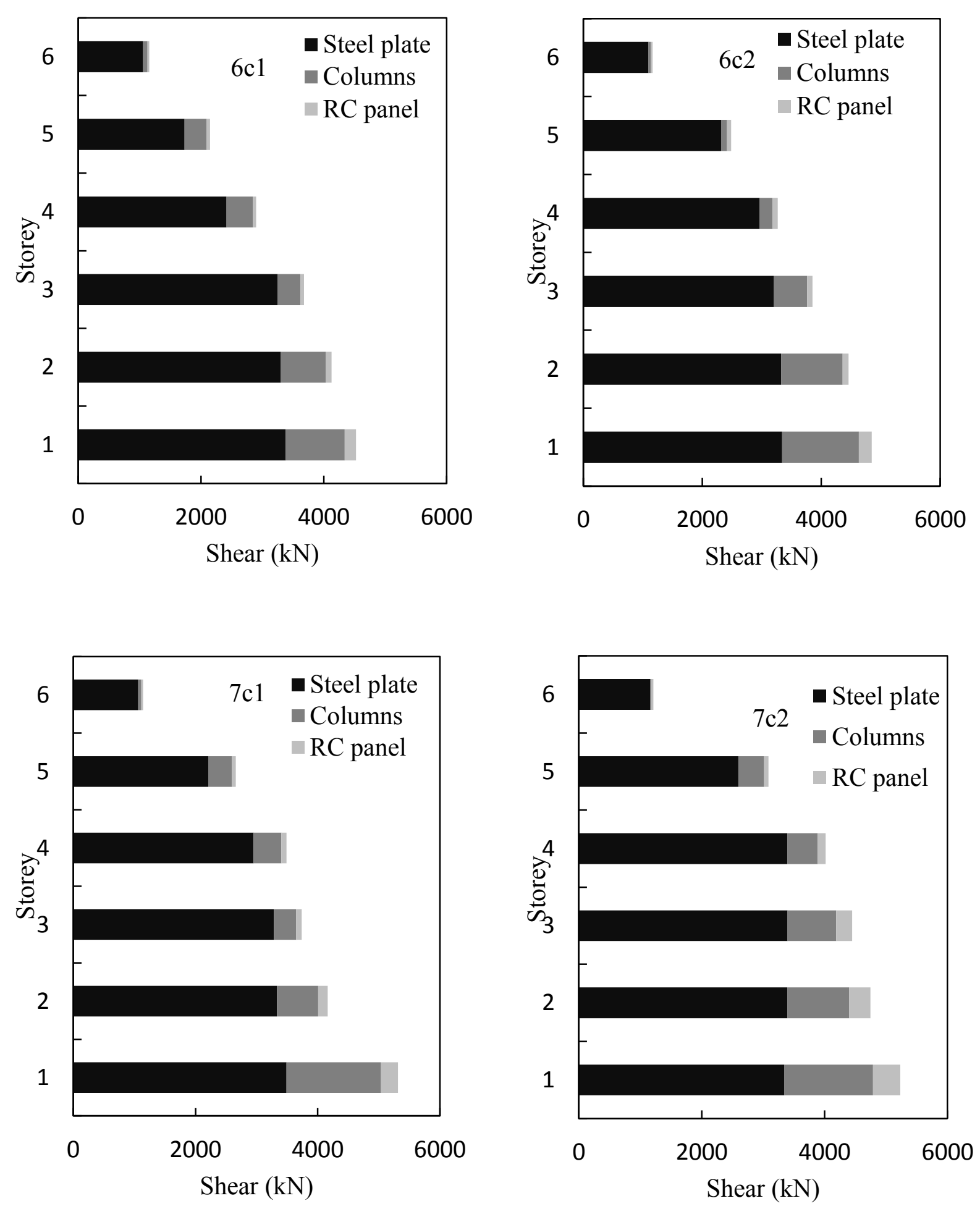

Figure 4.9: Peak storey shear contribution for different components of 6 - storey C-PSW 

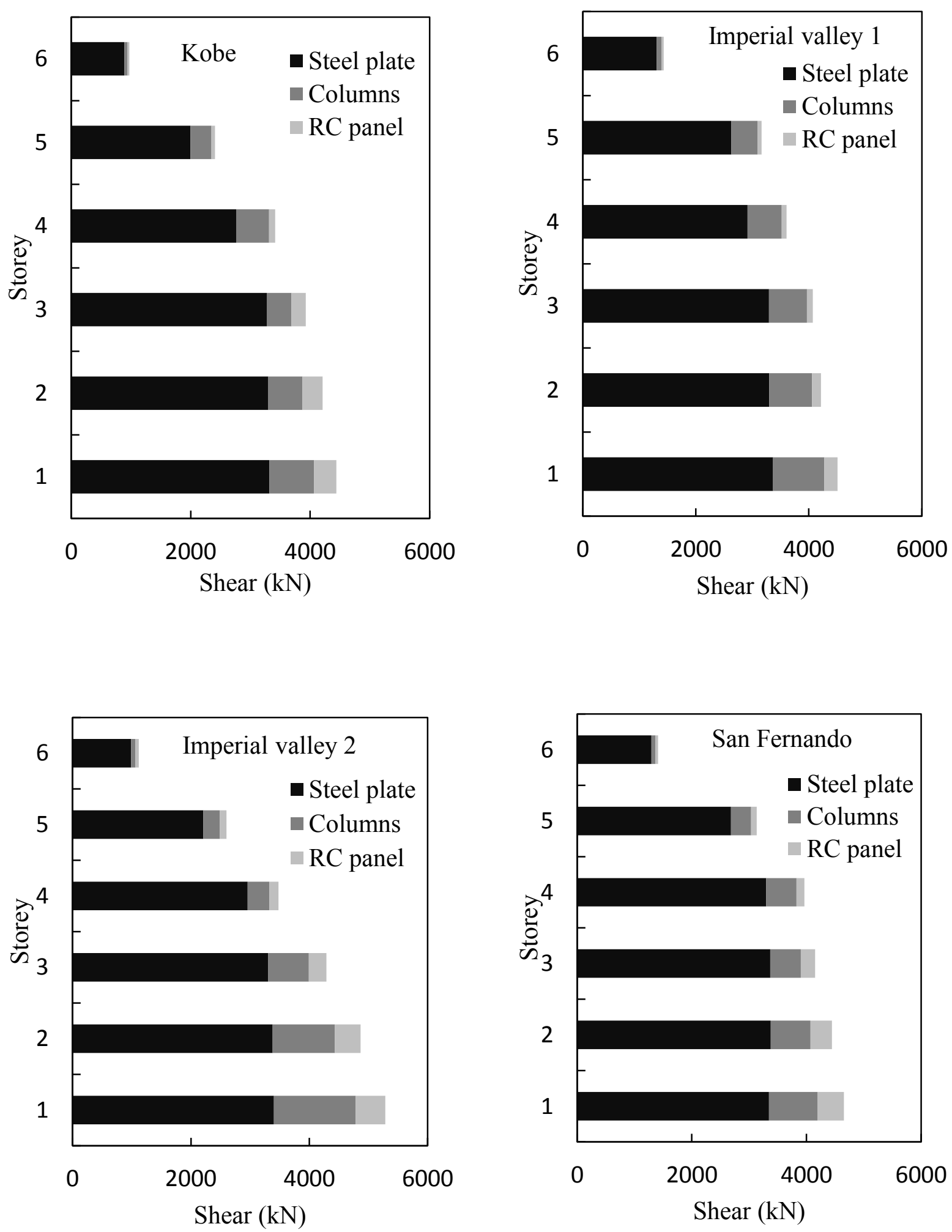

Figure 4.10: Peak storey shear contribution for different components of 6 - storey C-PSW 

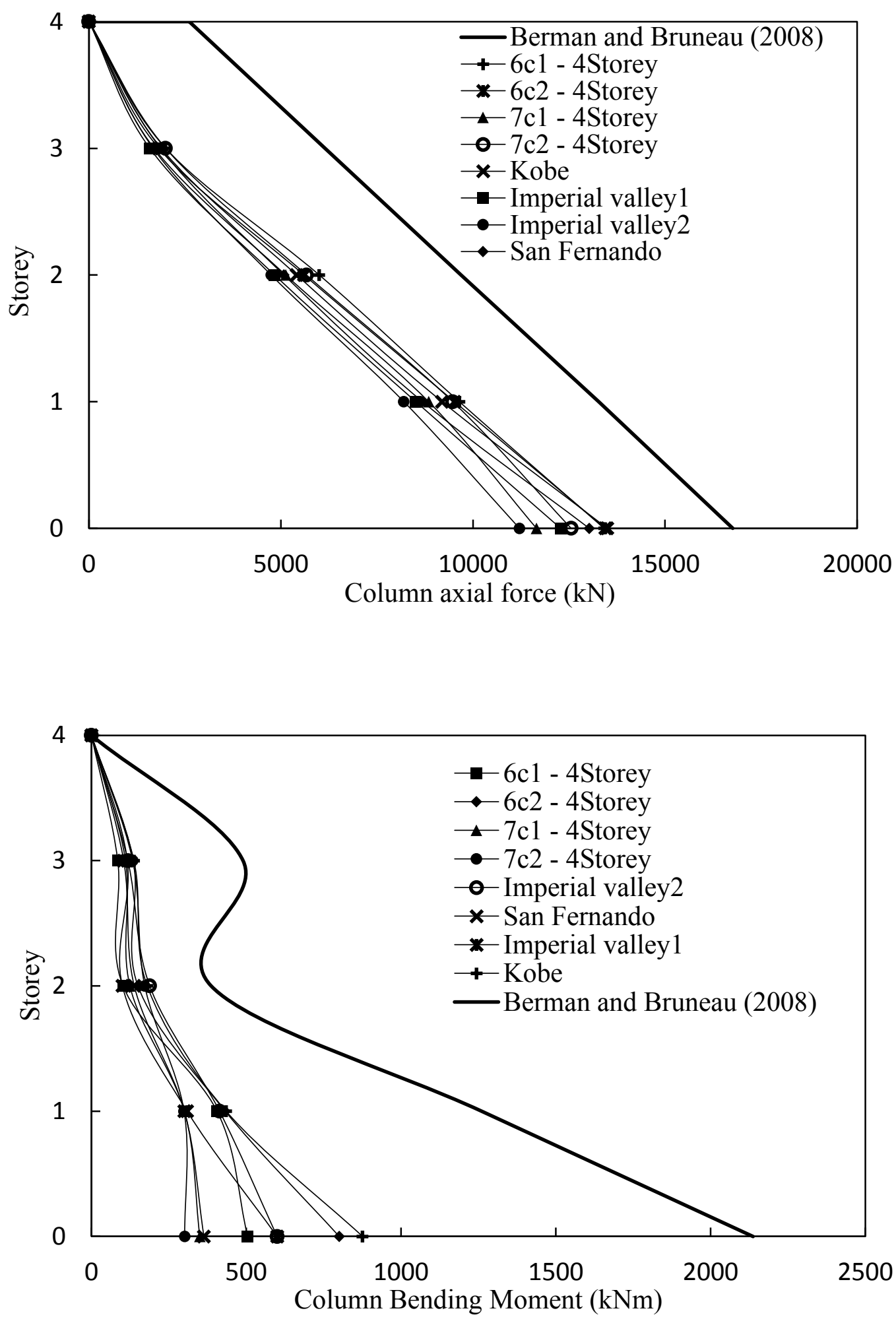

Figure 4.11: Right column axial force and moment of 4 - storey C-PSW 

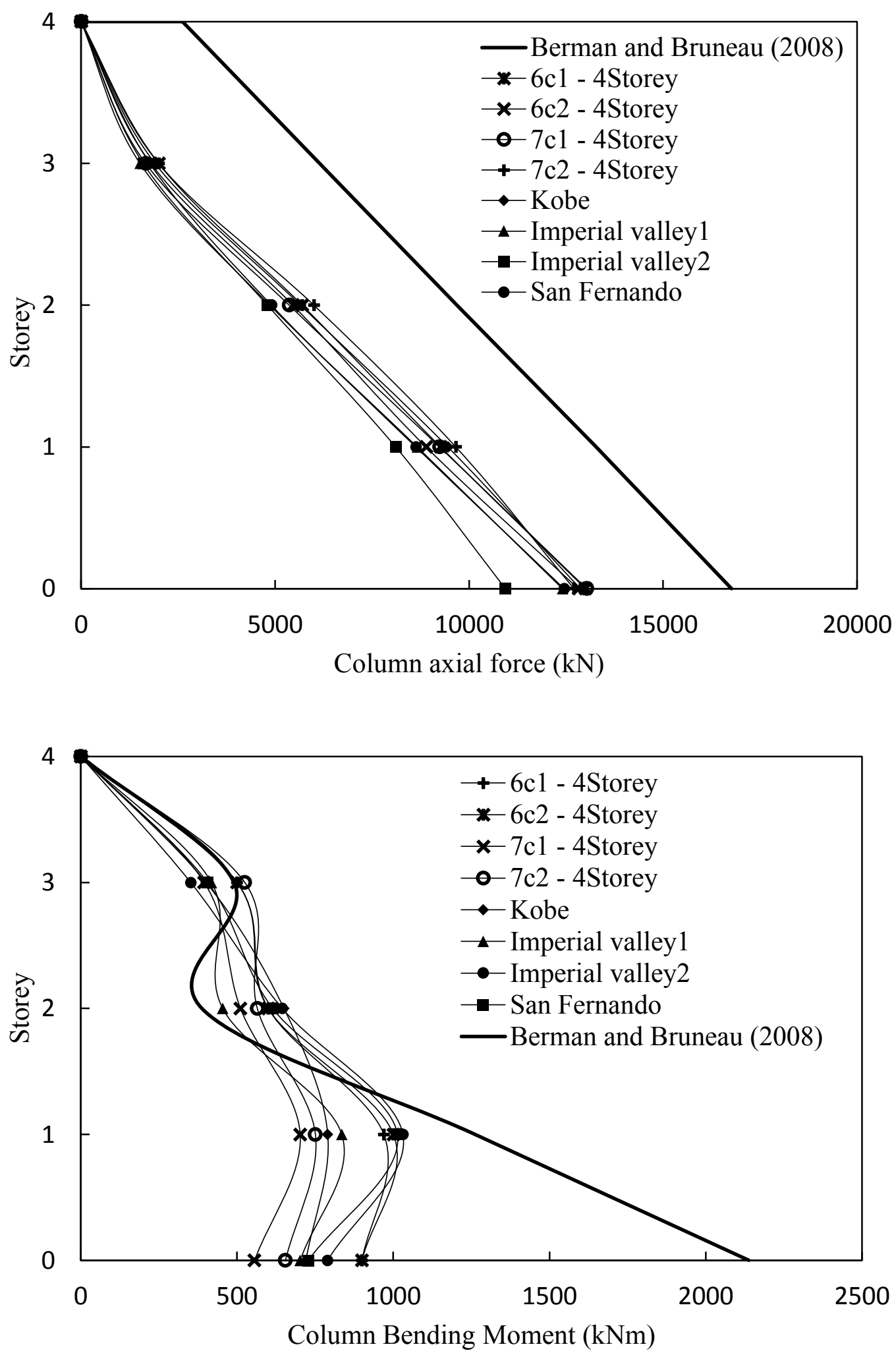

Figure 4.12: Left column axial force and moment of 4 - storey C-PSW 

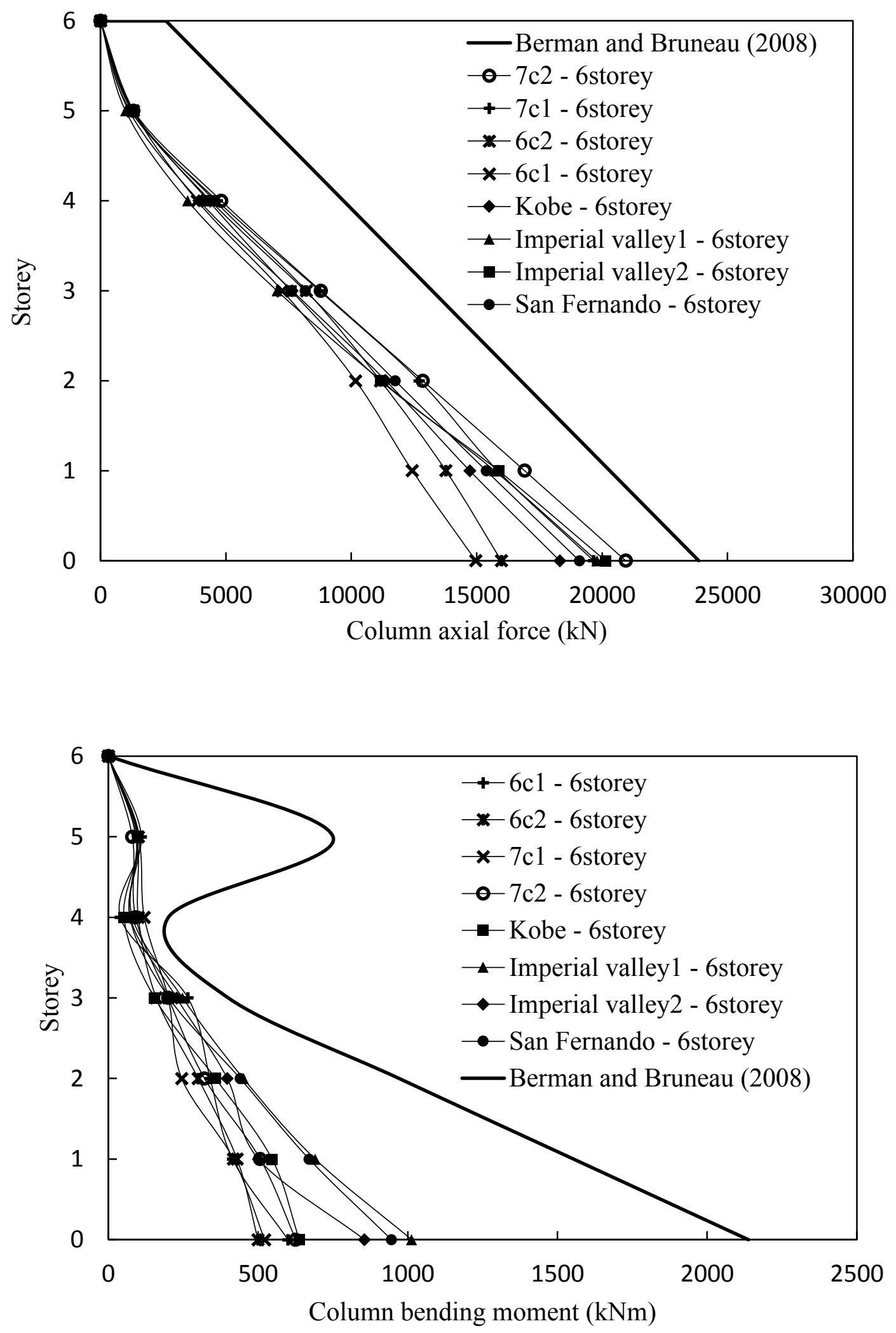

Figure 4.13: Right column axial force and moment of 6 - storey C-PSW 

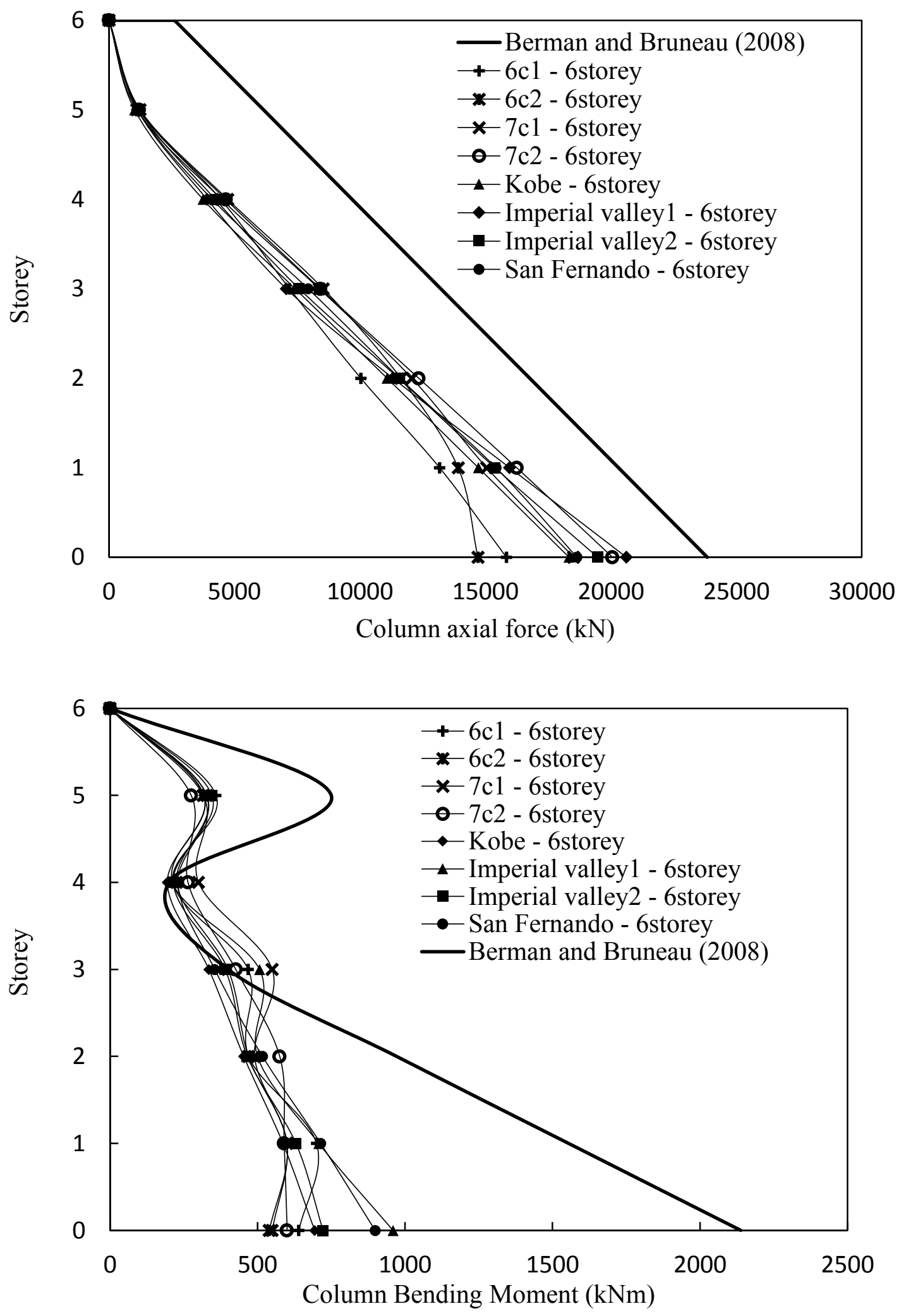

Figure 4.14: Left column axial force and moment of 6 - storey C-PSW 

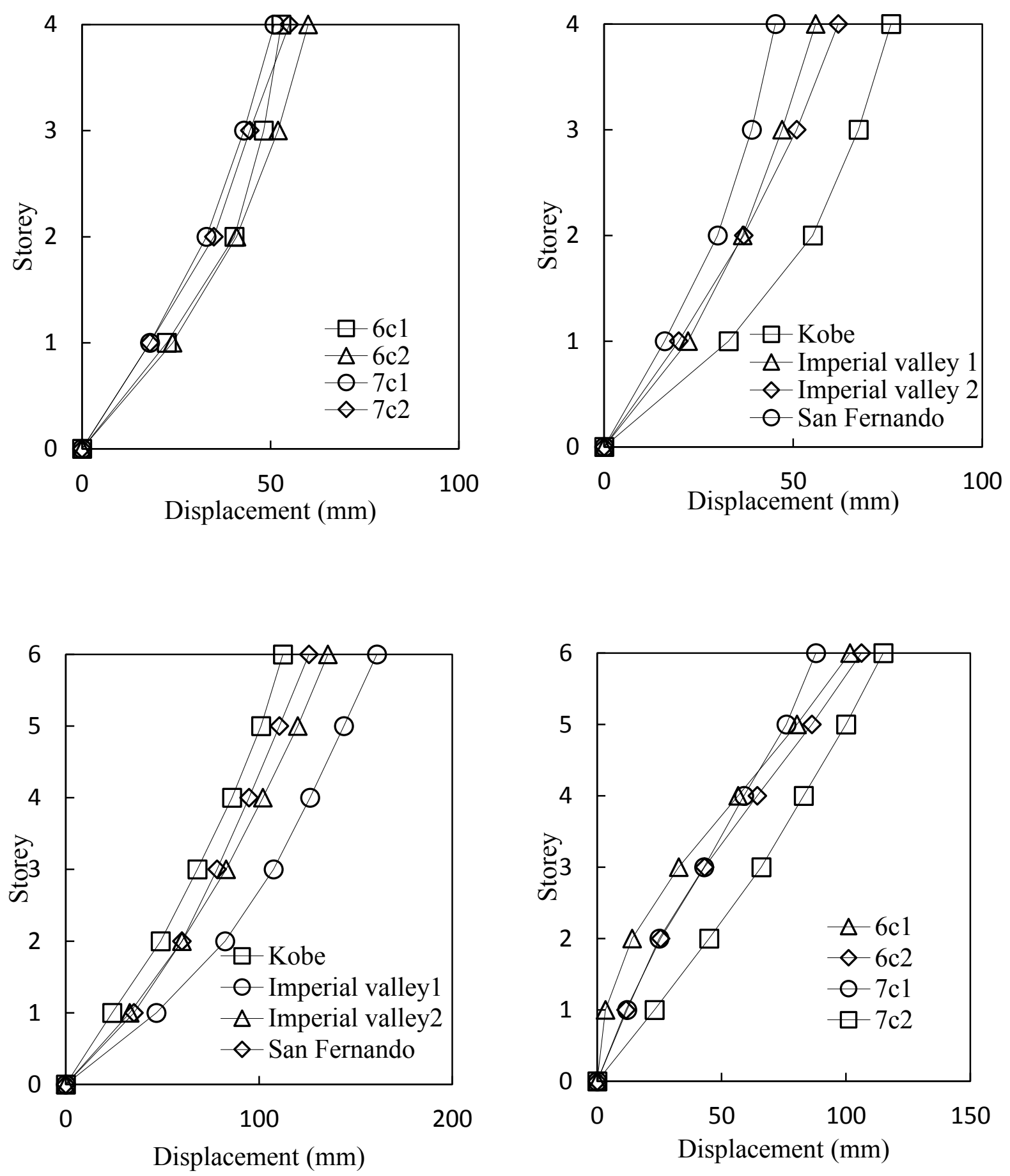

Figure 4.15: Storey displacements at instant of peak top storey displacement 

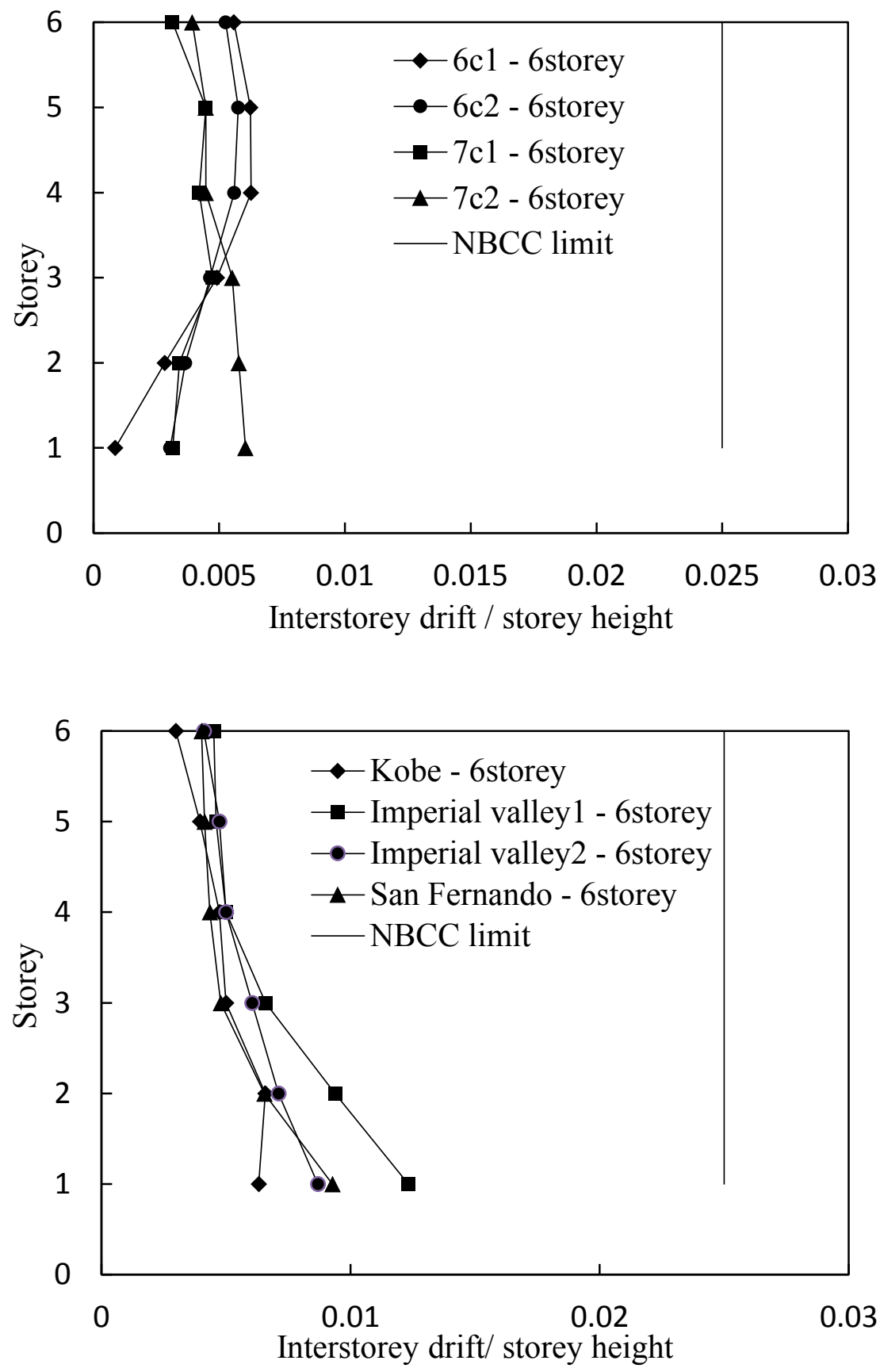

Figure 4.16: Inter-storey drift ratio at instant of peak top storey displacement 

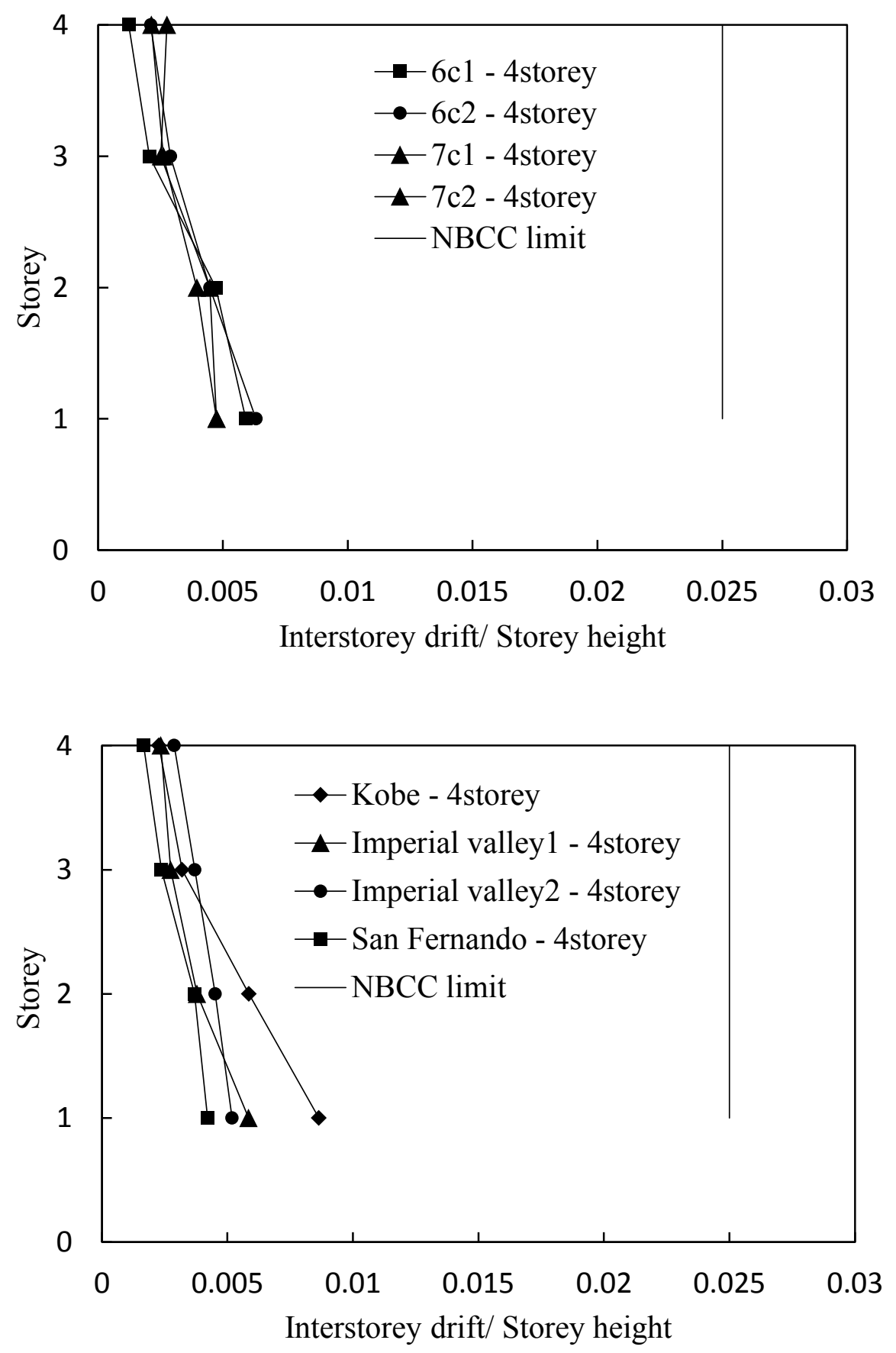

Figure 4.17: Inter-storey drift ratio at instant of peak top storey displacement 

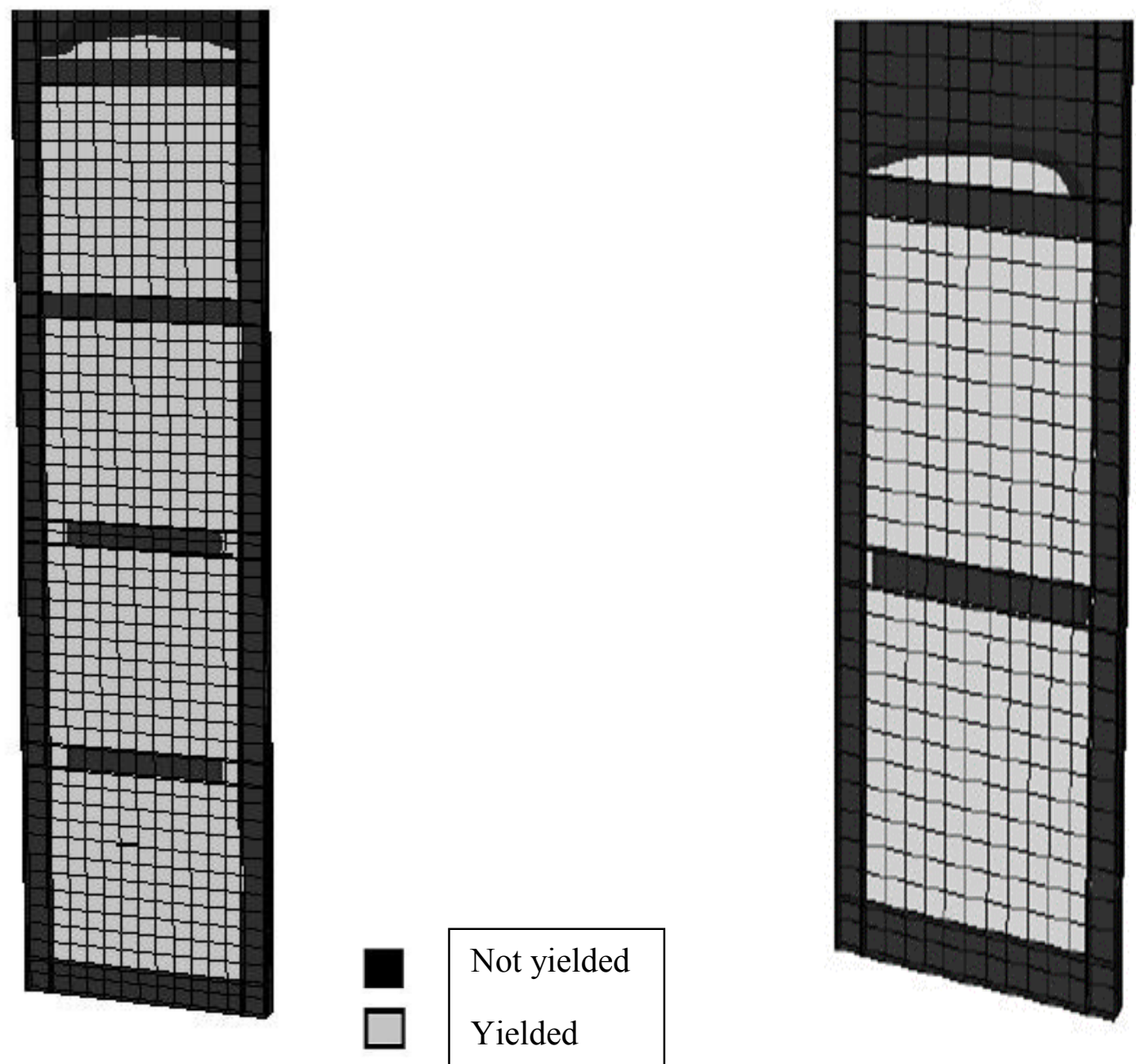

Figure 4.18: Yield pattern of 6-storey (left) and 4-storey (right) C-PSW at peak base shear instant under $7 \mathrm{c} 2$ ground motion

\subsection{Conclusions}

Non-linear time-history analyses were performed in to study the behaviour of C-PSW system. The finite element model used here is a previously validated model, which is able to provide very good representation for the experimental specimen in quasi-static pushover analyses. A 4-storey and a 6-storey C-PSW were assumed to be used in buildings located at Vancouver. Nonlinear seismic analysis is carried out to study its behaviour. Both the C-PSWs performed very well in terms of high shear strength, ductility and stiffness. The C-PSWs were capable in achieving its 
objective of restraining out-of-plane buckling of the steel infill plates resulting in shear yielding rather than formation of tension diagonal fields. This resulted in high shear capacity of the C-PSW. In addition, the C-PSW showed excellent ductility comparable to the conventional ductile steel plates. The boundary steel columns were devoid of yielding which were intended to behave that way. The steel boundary beams however yielded at their ends in the lower stories of the C-PSWs. Some of the important findings of this study are as follows:

(1) The AISC underestimates the shear strength of the C-PSWs. It is observed from the conducted inelastic nonlinear dynamic analyses that the shear strength of a C-PSW is underestimated in the AISC 341-10 due to the fact that, it does not consider any shear contribution from the boundary columns and also the RC-panel. As shown in this study, the boundary columns and RC-panel together can contribute towards a significant amount of shear strength ignored in the current practice.

(2) The capacity design concept for design of vertical boundary elements by Berman and Bruneau (2008) for full yielding of steel infill plates simultaneously in tension diagonal was found to serve well for the C-PSWs in order to maintain its elastic regime.

(3) The inter-storey drifts obtained from the nonlinear time history analyses were within the limits of $0.025 \mathrm{~h}_{\mathrm{x}}$ as recommended by NBCC 2010 .

(4) C-PSWs of the innovative type studied here performed excellently under spectrum compatible ground motions; both simulated and real, showing good ductility comparable to conventional ductile plate walls. The C-PSWs were found to possess high strength and stiffness. Additionally, there is minimal damage associated with this performance in terms of concrete cracking, crushing and primary structural failure. 


\section{FUNDAMENTAL PERIODS OF C-PSWS USING EQUIVALENT SHEAR-FLEXURE CANTILEVER BEAM MODEL}

\subsection{Introduction}

Fundamental period of a structure is an important parameter pertaining to the calculation of the base shear and the lateral forces at each storey. Since, the exact time period of a structure can only be computed once the detailed trial design of the structure is ready; the building codes provide empirical formulae to calculate the approximate time period of the structure based on certain parameters like structure materials, structure type and structure geometry. These code-based empirical approximate time period expressions are generally moderated to provide conservative estimates of the design earthquake forces. This chapter evaluates the current code based formula for determination of fundamental period for 'innovative' C-PSWs. Also, the effectiveness of a simplified equivalent shear-flexure cantilever model to estimate fundamental periods of C-PSWs is investigated in this chapter.

\subsection{Selection of C-PSWs for evaluation of code-based period formula}

In order to evaluate the code based formula for estimating fundamental periods of C-PSWs, a total of eight buildings equipped with C-PSWs as lateral load resisting system were considered. They consisted of two sets of buildings with different symmetrical floor plans equipped with CPSWs of aspect ratio of 1 and 1.5 respectively. For each set of floor plan, 1-storey, 2-storey, 4storey and 6-storey buildings were considered. The buildings for these C-PSWs were chosen to be 
hypothetical office buildings in Vancouver founded on (site class C according to NBCC 2010) and having plan area of $2014 \mathrm{~m}^{2}$ and consisting of two identical shear walls to resist lateral forces in each direction as shown in Figures 5.1 and 4.1. Thus, each shear wall was intended to resist only one half of the design seismic load. The storey height of the buildings were chosen to be $3.8 \mathrm{~m}$. Loads considered were $4.26 \mathrm{kPa}$ for each floor, $1.12 \mathrm{kPa}$ for roof and live loads for all floor as 2.4 $\mathrm{kPa}$. Steel was considered to have yield strength of $350 \mathrm{MPa}$ and young's modulus of 200,000 MPa. For simplicity, torsion was neglected. According to the provisions of NBC 2010 (NRCC 2010) load combination ' $\mathrm{D}+0.5 \mathrm{~L}+\mathrm{E}$ ' (where, $\mathrm{D}=$ dead load, $\mathrm{L}=$ live load and $\mathrm{E}=$ earthquake load) was considered for floors and for the roof, the load combination ' $D+0.25 \mathrm{~S}+\mathrm{E}$ ' (where $\mathrm{S}=$ snow load) was considered. A ductility related force modification factor ' $R_{d}$ ' of 5.0 and an over strength force modification factor ' $R_{0}$ ' of 1.6 was used in the design according to the provisions of NBCC 2010 for the steel plate shear wall component. Figures $5.2-5.5$ represent the detailed dimensions and components for the C-PSWs chosen. Infill plates of $4.8 \mathrm{~mm}$ thickness were used as the minimum practical thickness based on requirements to be bolted with the reinforced concrete panels and handling issues. $13 \mathrm{~mm}$ diameter A325 bolts were selected for connecting the steel infill plate with the RC panel. 


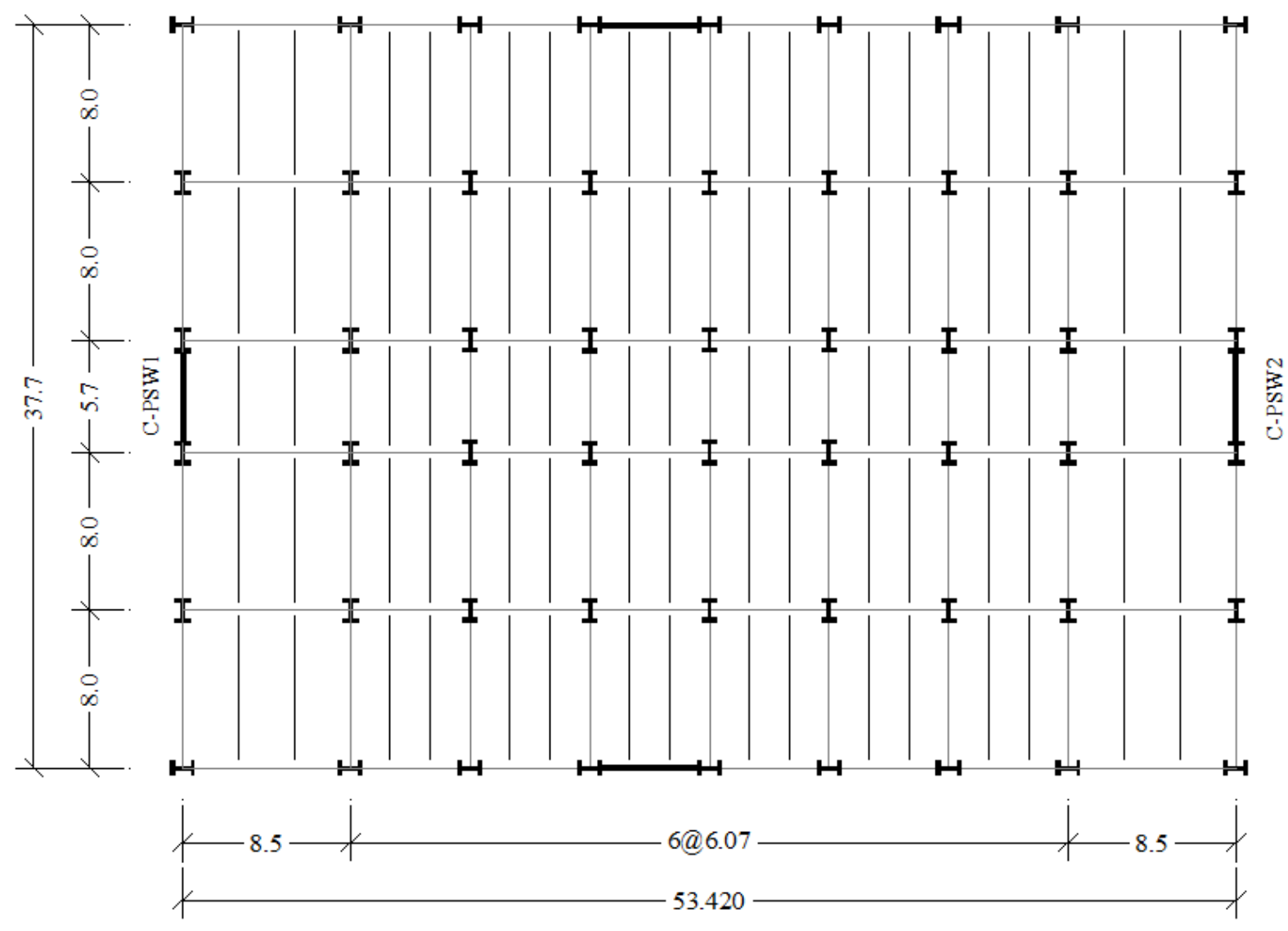

Figure 5.1: Floor plan of buildings with C-PSW of aspect ratio 1.5

As per the requirements in AISC 341-10, minimum concrete wall thickness of $200 \mathrm{~mm}$ was selected. For the bar reinforcement, ratio of 0.0025 was maintained with the bar spacing not exceeding $450 \mathrm{~mm}$. The boundary beams and columns were designed according to the Canadian steel design standard CAN/CSA S16-09 satisfying all the required criteria regarding strength and stiffness. The design philosophy for the vertical and horizontal boundary members were however, followed that of by Berman and Bruneau (2008) and Qu and Bruneau (2009). 

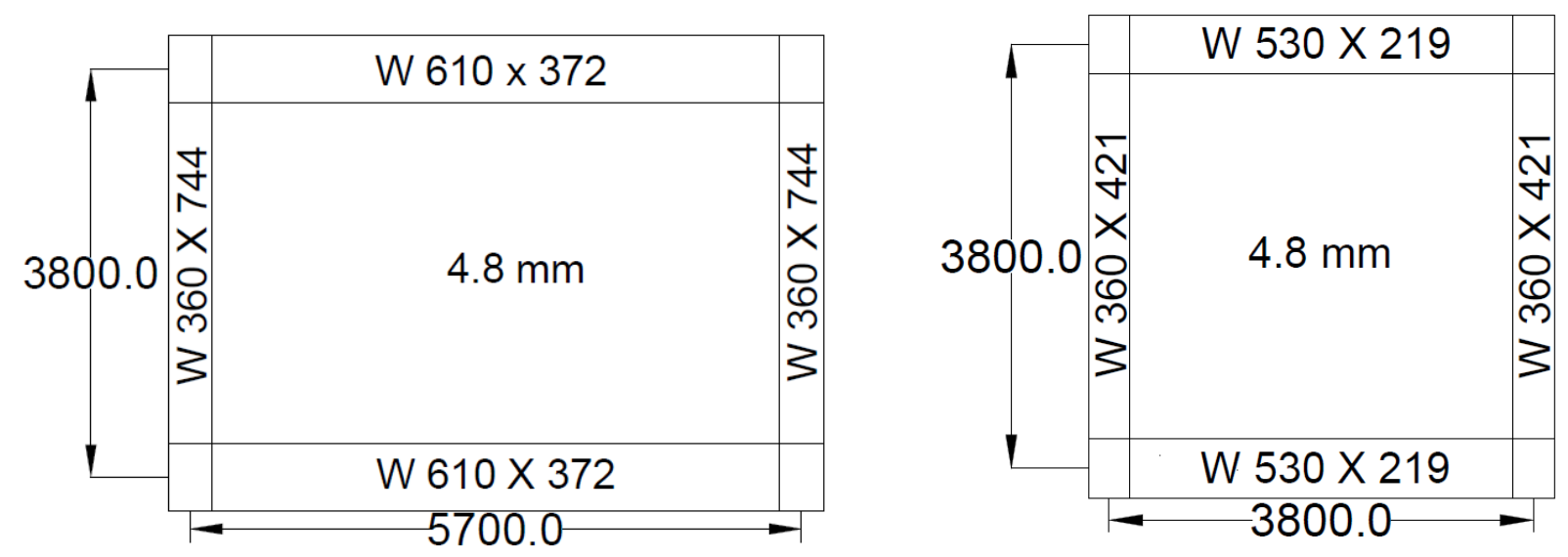

Figure 5.2: 1-Storey specimen of 1 aspect ratio and 1.5 aspect ratio
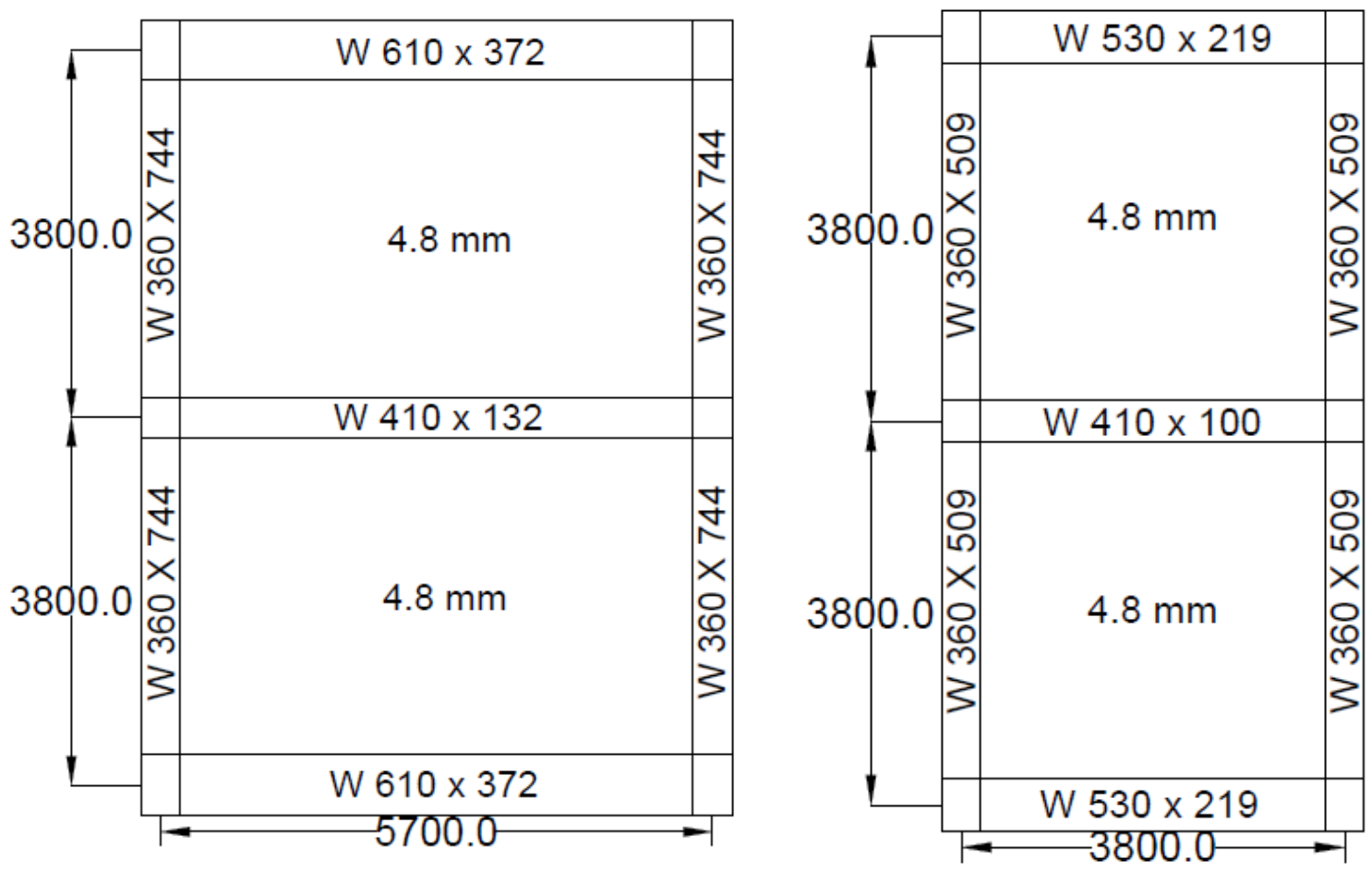

Figure 5.3: 2-Storey specimen of 1 aspect ratio and 1.5 aspect ratio 

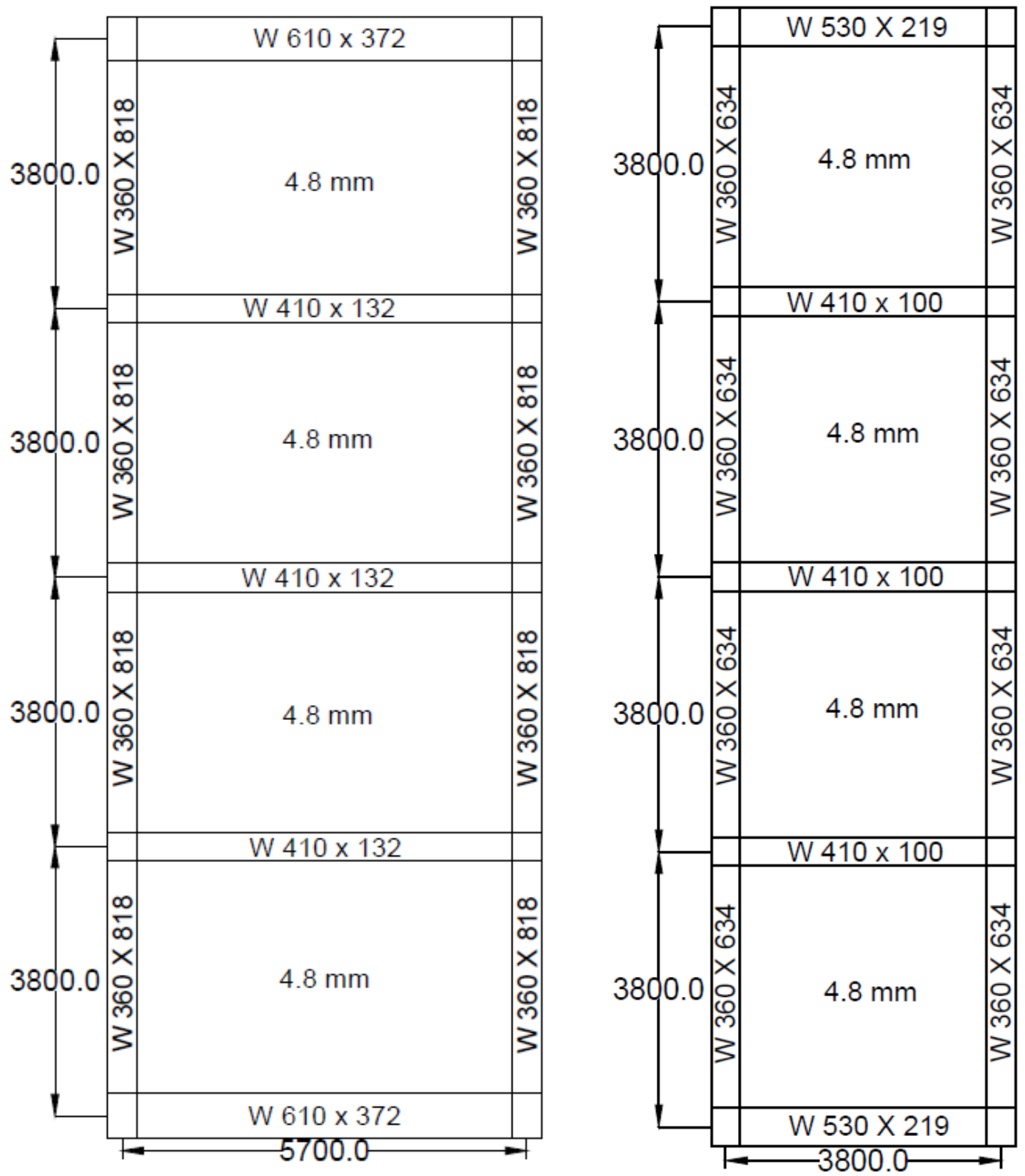

Figure 5.4: 4-Storey specimen of 1 aspect ratio and 1.5 aspect ratio 

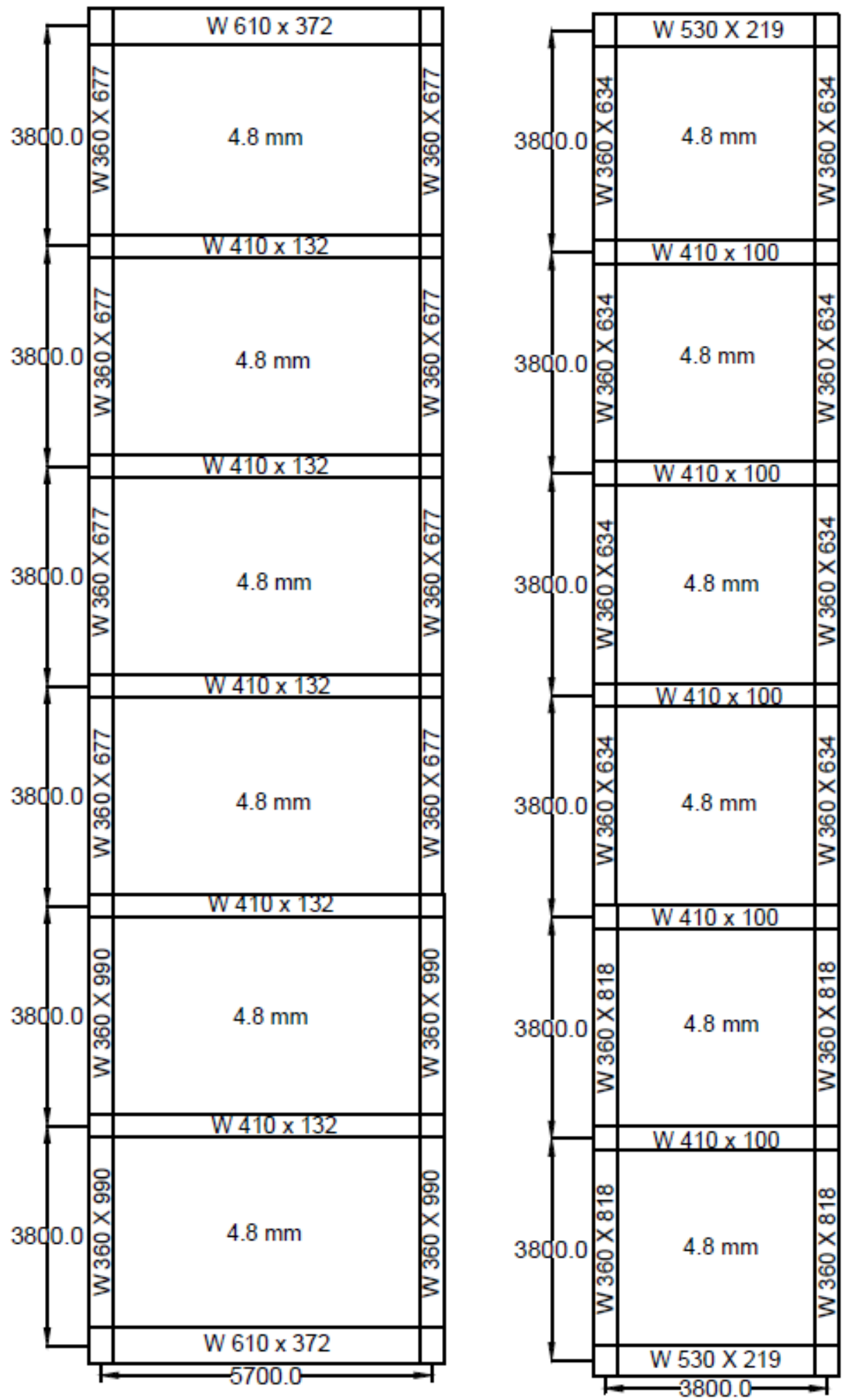

Figure 5.5: 6-Storey specimen of 1 aspect ratio and 1.5 aspect ratio 


\subsection{Evaluation of code period formula for C-PSWs}

The building codes namely the NBCC 2010 and ASCE 7-10 specify upper limits on fundamental periods calculated based on simple methods of structural analysis in order to limit the values of design seismic loads that are too low due to modelling assumptions. NBCC 2010 specifies that, for shear walls, periods calculated by any analytical method should not exceed 2.0 times the value determined by Eq. (5.10). The ASCE 7-10 standard limits the upper limit of fundamental periods as 1.4 times the value for high seismic zones to 1.7 times the value for low seismic zones, as determined by Eq. (5.1).

$$
T=C_{t} h^{x}
$$

Where, ' $T$ ' is the fundamental time period of the structure, ' $h$ ' is the height of the structure above the base, ' $C_{t}$ ' and ' $X$ ' are constants. The NBCC 2010 and ASCE 7-10 recommend values of ' $C_{t}$ ' as 0.05 and ' $x$ ' as 0.75 for shear walls. In this study, the selected eight C-PSWs were analysed to evalaute the code based period formula. ABAQUS/IMPLICIT was used for all the frequency analysis. As explained in Chapter 3, all the C-PSW components (steel boundary members, steel infill plates and the RC panels) were modeled using standard shell elements (ABAQUS element S4R). The bolts connecting the steel infill plate and the reinforced concrete panel at regular intervals were modeled using 2-node linear beam elements (ABAQUS element B31). An eigenvalue extraction technique was used to calculate the natural frequencies and the corresponding mode shapes of C-PSWs. Figure 5.7-5.12 show the fundamental mode shapes of all the selected C-PSWs. As can be seen from the figures, both bending and shear deformation play a significant role in the fundamental mode shapes. C-PSWs with lower width to height ratio can be seen to be governed by bending deformation and vice-versa. 
Figure 5.6 compares the code predicted period formula with the computed fundamental periods obtained from the detailed finite element models. The figure also presents the suggested upper and lower limits by different building codes. It can be observed from the results the computed fundamental period is shorter than the code based fundamental period for only one of the eight cases. The overall results suggest that the code based periods provide conservative estimates of fundamental periods for C-PSWs, leading to higher seismic forces.

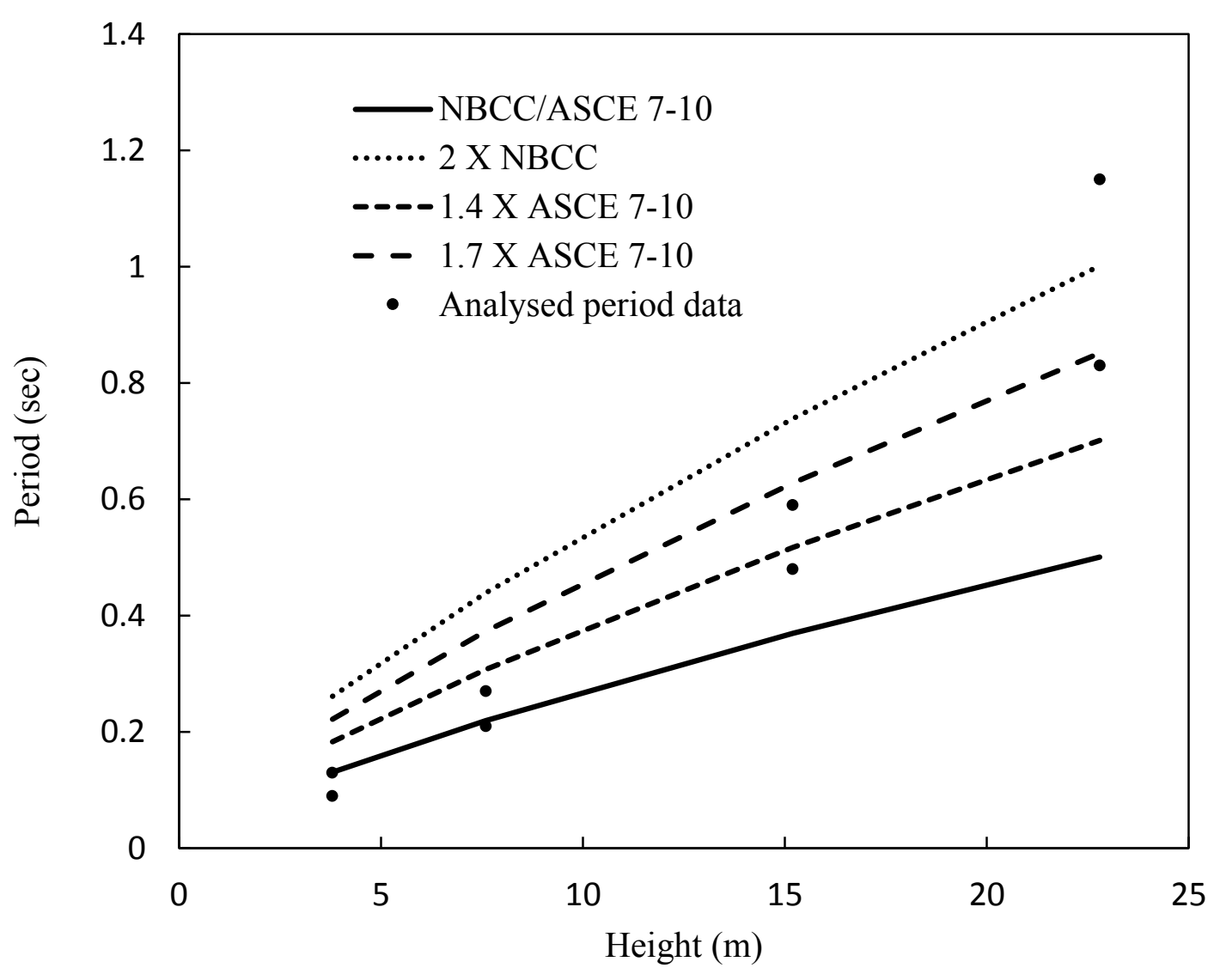

Figure 5.6: Computed and code based periods for C-PSWs 


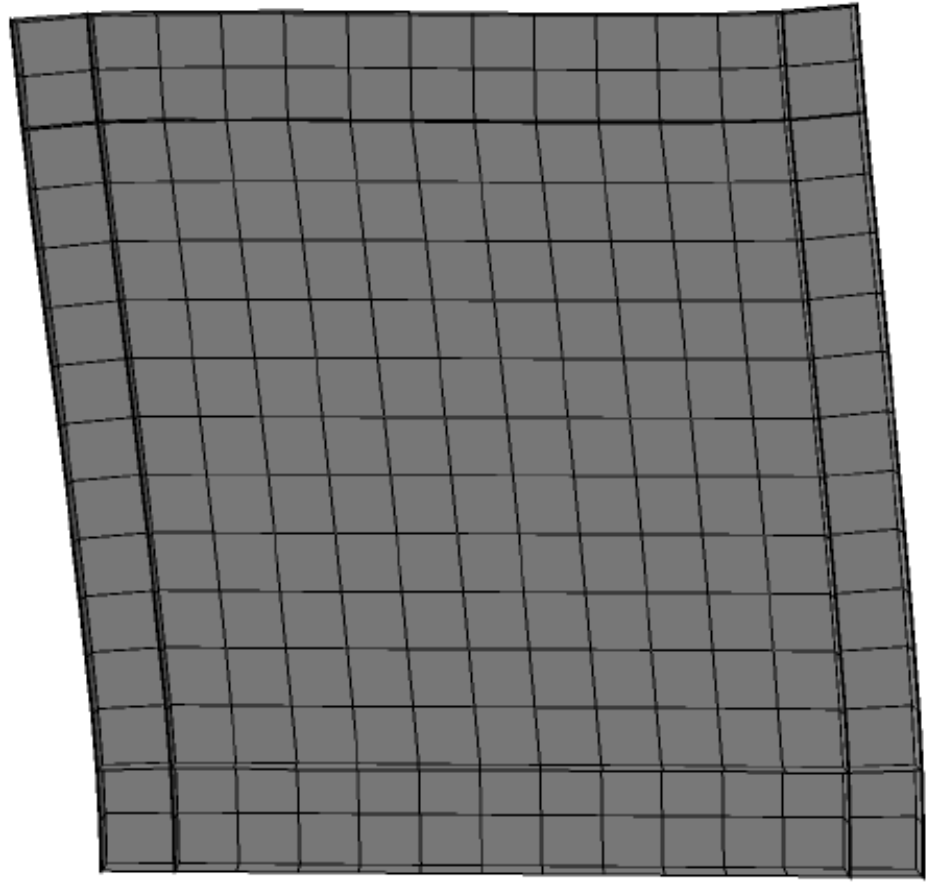

Figure 5.7: Fundamental mode shape of 1 storey 1 aspect ratio C-PSW

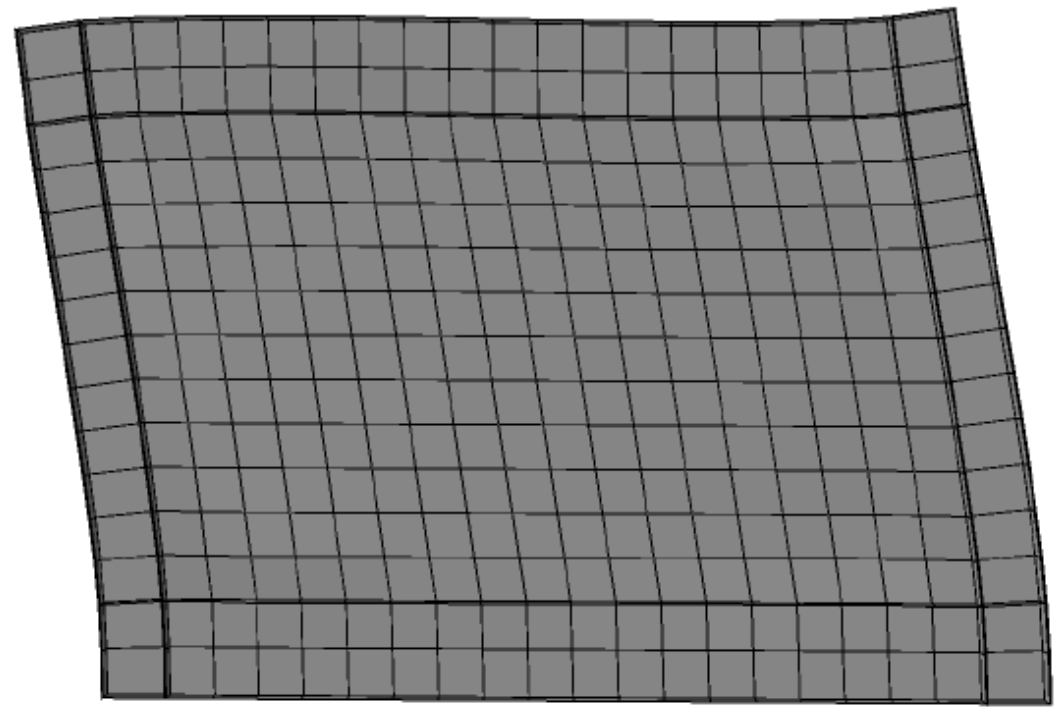

Figure 5.8: Fundamental mode shape of 1 storey 1.5 aspect ratio C-PSW 


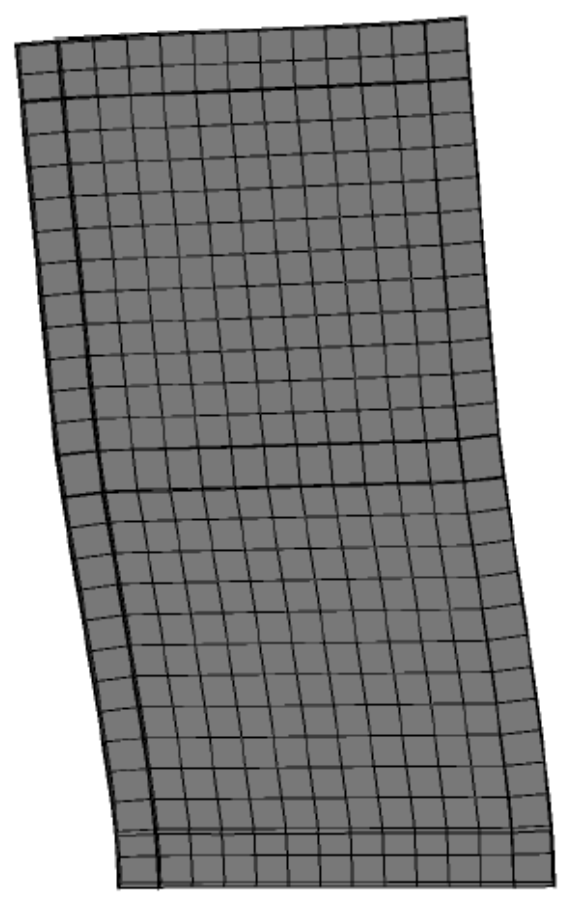

Figure 5.9: Fundamental mode shape of 2 storey 1 aspect ratio C-PSW

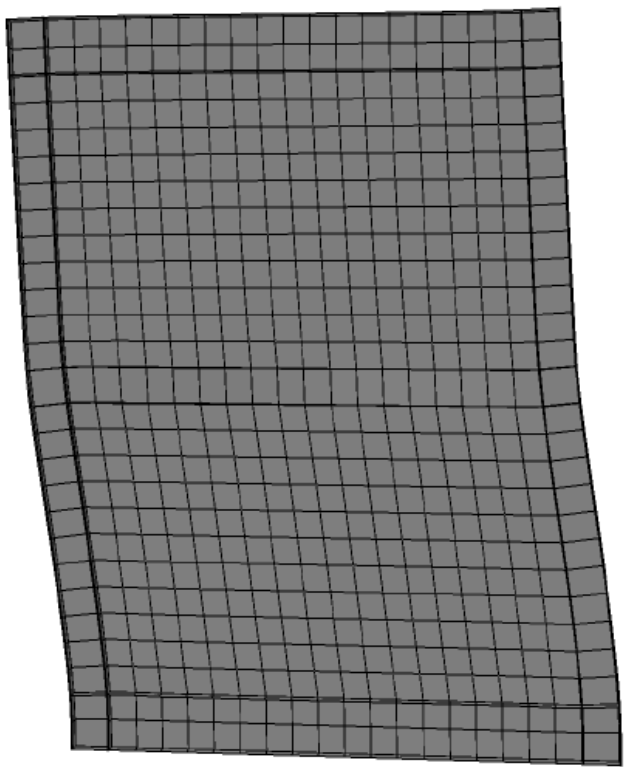

Figure 5.10: Fundamental mode shape of 2 storey 1.5 aspect ratio C-PSW 

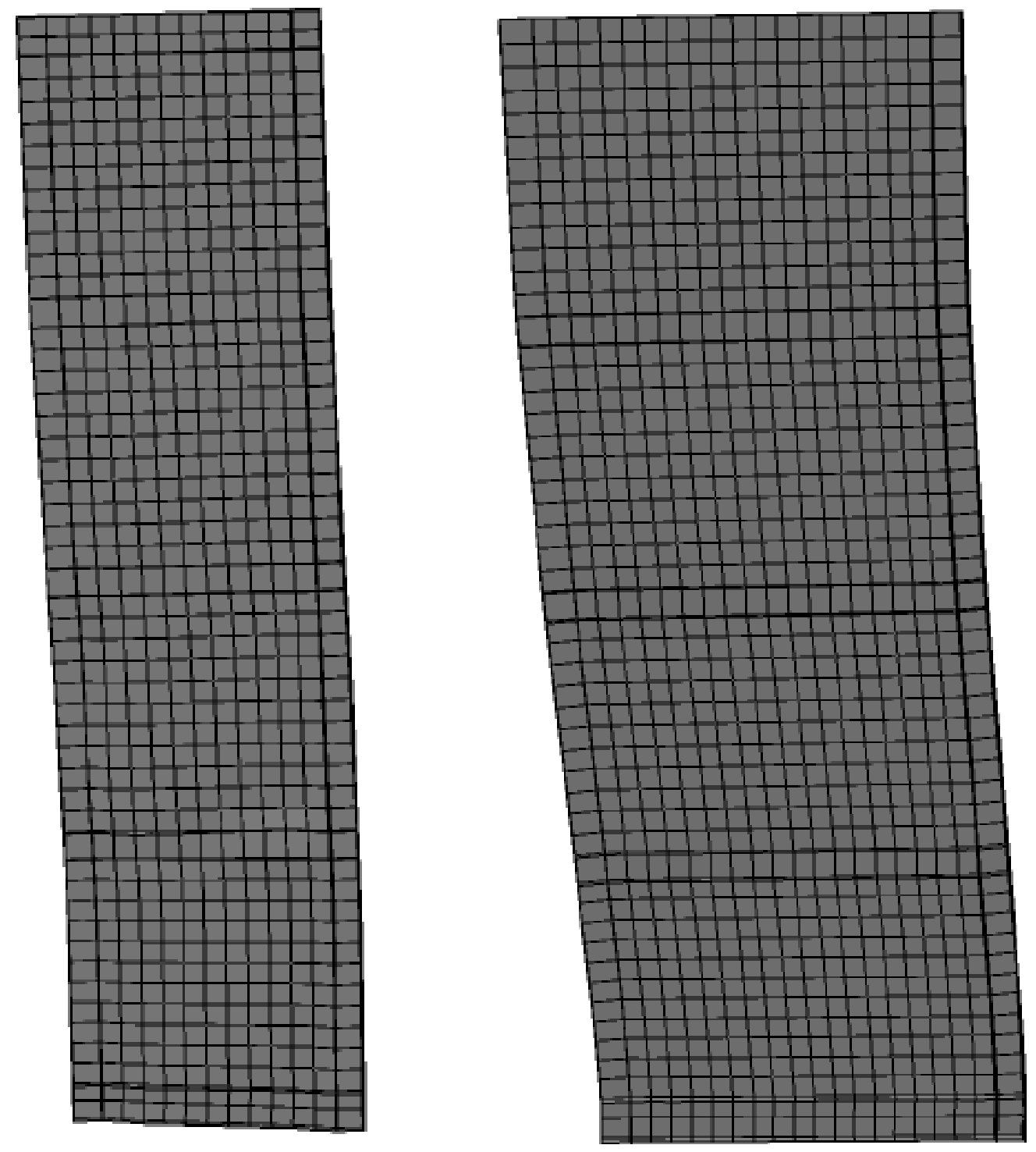

Figure 5.11: Fundamental mode shape of 4 storey 1 and 1.5 aspect ratio C-PSWs 

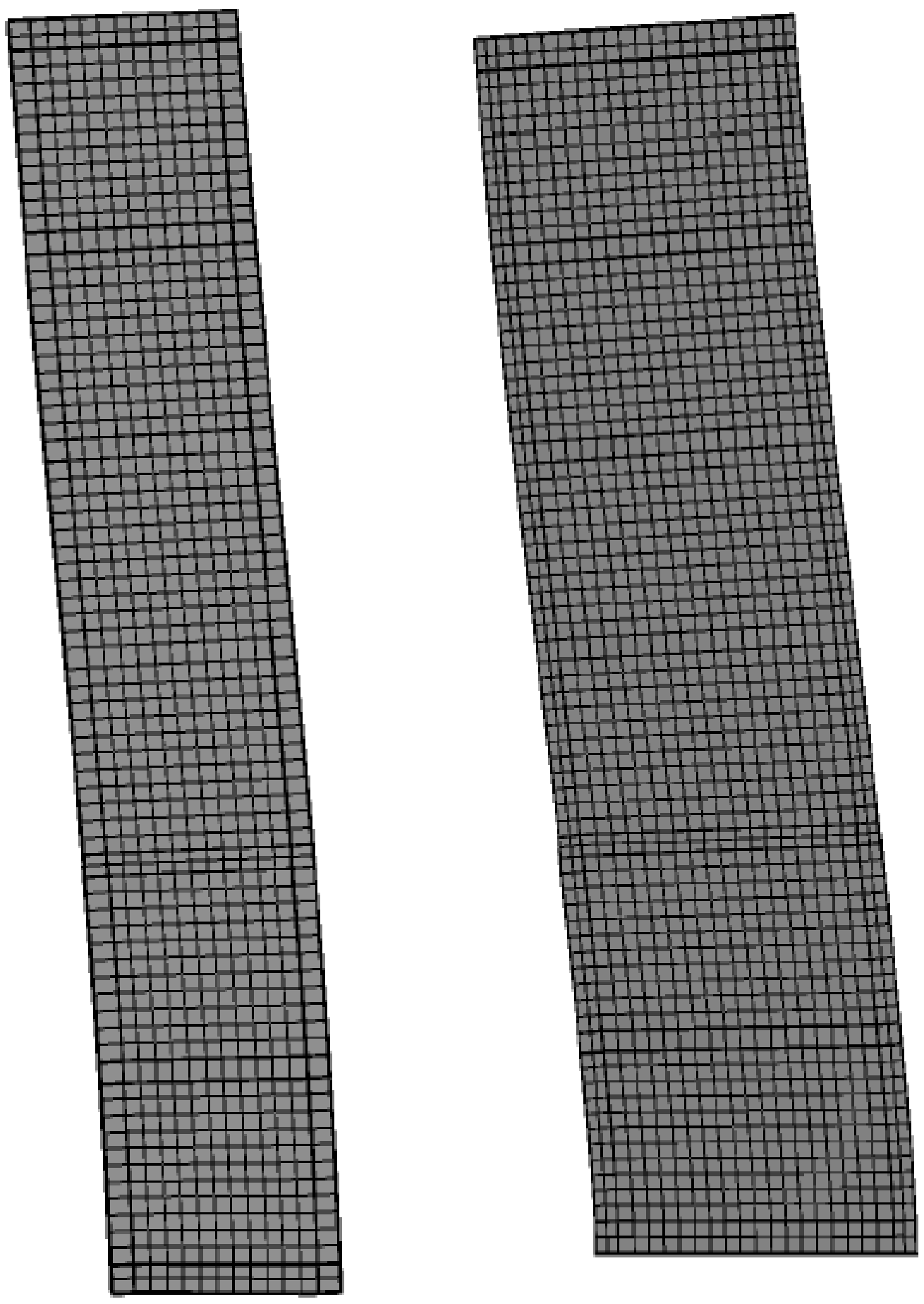

Figure 5.12: Fundamental mode shape of 6 storey 1 and 1.5 aspect ratio C-PSWs 


\subsection{Equivalent shear-flexure cantilever beam model for C-PSWs}

A simple shear-flexure cantilever model was developed to simplify the calculation of the fundamental period of C-PSWs. Generally, in a cantilever beam of length ' $L$ ', the deflection at the tip ' $\Delta$ ' under a point load of ' $P$ ' is given by:

$$
\Delta=\frac{P L^{3}}{3 E I}+\frac{P L}{G K A_{W}}
$$

Where, ' $E$ ' is the modulus of elasticity of the material; ' $G$ ' is the shear modulus; ' $I$ ' is the moment of inertia of the section about the bending axis; ' $K A_{W}$ ' denote the effective shear area of the section. The first term denotes the deformation due to bending and the second term denotes the deformation due to shear. It is evident from the expression that, with the increase in length, the bending deformation will govern over the shear deformation and vice-versa. So, to make a relevant model applicable to low length to depth ratio beams, appropriate shear rigidities were also incorporated in the stiffness input parameters. The C-PSWs studied here being of the 'innovative' type, has no contact between the RC panel edges and the boundary steel columns. Thus, the RC panel is not expected to carry shear force. Hence, no shear rigidity contribution from the RC panels have been considered in the model. In order to provide the equivalent bending stiffness at each storey, the bending rigidities from both the corresponding steel plate shear wall (SPSW) and reinforced concrete panel (RC panel) were considered. The equivalent beam was modeled with two node linear beam elements (ABAQUS element B31) connected in series. Each storey of the C-PSW was represented by a beam element and each floor level was represented by a node where the entire floor mass of the C-PSW is incorporated as point mass as shown in Figure 5.13. The 
linear beam elements at each storey were modeled to possess bending and shear stiffness equivalent to the C-PSW at the corresponding stories.

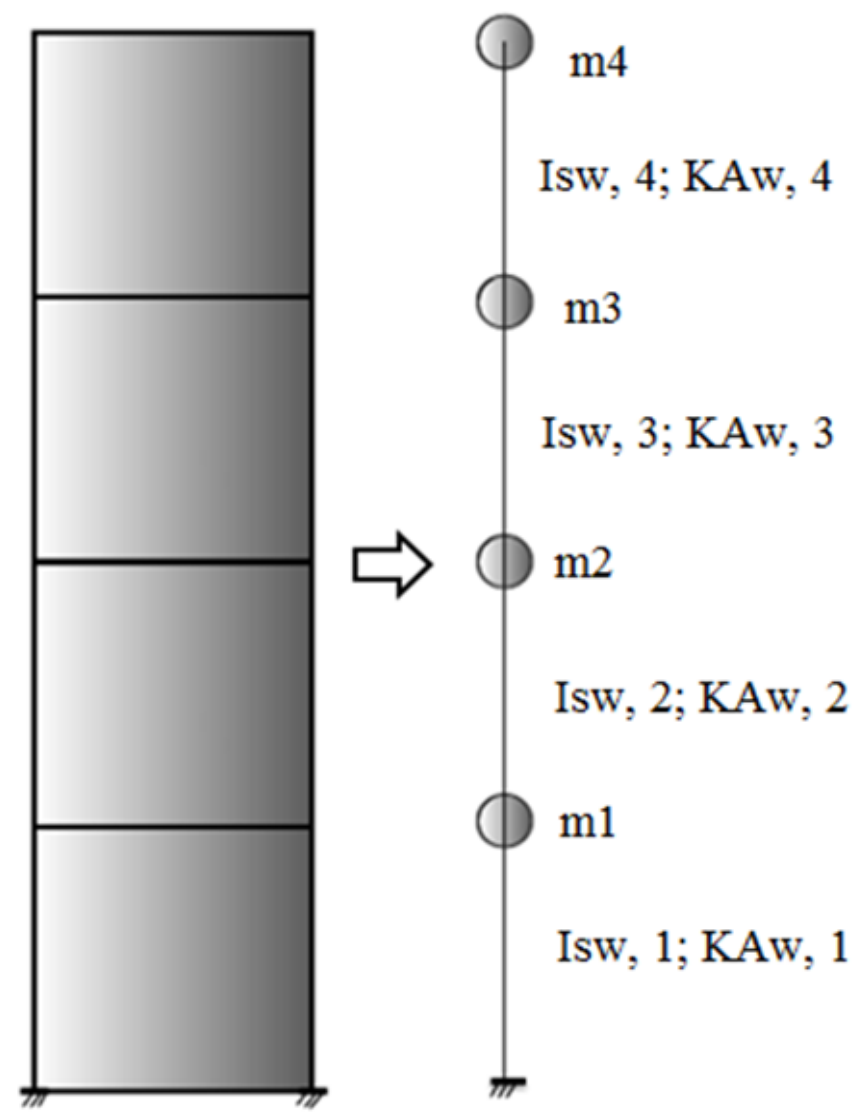

Figure 5.13: Shear-flexure cantilever idealization of C-PSW

\subsection{Bending and shear stiffness of equivalent shear-flexure cantilever beam model}

As stated above, the bending and shear stiffness of the C-PSW at each storey were assigned to each beam element in the corresponding storey in terms of the material properties (elastic modulus and shear modulus) and geometric properties (moment of inertia and effective shear area). 
The following equations (5.3 and 5.4) show the concept of finding out the flexural and shear rigidity of the C-PSW system:

$$
\begin{aligned}
& \left(E_{S} I\right)_{C-P S W}=\left(E_{S} I\right)_{S P S W}+\left(E_{C} I\right)_{\text {RCPanel }} \\
& \left(K A_{W}\right)_{C-P S W}=\left(K A_{W}\right)_{S P S W}
\end{aligned}
$$

Where, ' $E_{S}$ ' is the elastic modulus of steel; ' $E_{C}$ ' is the elastic modulus of concrete; ' $I$ ' represents the moment of inertia of the section; ' $K$ ' 'is the shape factor for shear deformation and ' $A_{W}$ ' represents the cross sectional area of the respective section. The final equivalent cantilever was considered to be made up of steel. So, the material properties for the cantilever were provided that for steel.

\subsubsection{Bending rigidity of equivalent shear-flexure cantilever beam model}

As shown in expression (5.3), the equivalent C-PSW bending rigidity was found out by adding the corresponding bending rigidities of the SPSW and the RC panel. No sliding was assumed to be occurring during bending between the RC panel and the steel infill. According to the theory of solids, it was assumed here that the elongations and contractions of longitudinal fibers (both the steel infill and RC panel) are proportional to the distance from the neutral axis of the combined section. So, the RC panel cross-sectional area was converted to equivalent steel area and then the moment of inertia of the combined section was found out. In order to do so, the RC panel cross-

sectional area was converted to equivalent steel area by reducing it with the modular ratio $\frac{E_{S}}{E_{C}}$; 
where, ' $E_{S}$ ' is the elastic modulus of steel; ' $E_{C}$ ' is the elastic modulus of concrete. The depth of the reduced section was kept the same and the breadth was reduced appropriately in order to satisfy the criteria given by (5.3). The final input parameters to assign bending rigidity in the cantilever model were the elastic modulus for steel and the moment of inertia of the converted cross section about the neutral axis. The moment of inertia for the equivalent C-PSW at any given storey ' $i$ ' was calculated as follows:

$$
I_{S W, i}=\frac{w_{i}\left(L-d_{c, i}\right)^{3}}{12}+2 I_{C, i}+\frac{1}{2} A_{c, i}(L)^{2}
$$

Where, ' $I_{S W, i}$ ' is the moment of inertia of the equivalent C-PSW cross section about neutral axis; ' $I_{C, i}$ ' is the moment of inertia of the column about its neutral axis; ' $A_{C, i}$ ' is the cross sectional area of the columns; ' $L$ ' is the bay width of the C-PSW; ' $d_{c, i}$ ' is the depth of columns.

\subsubsection{Shear rigidity of equivalent shear-flexure cantilever beam model}

The total strain energy stored in a beam due to shear deformation from standard 'Strength of materials' book by Timoshenko S. (1995) is given by:

$$
U=\frac{V^{2} L}{G I^{2}} \int \frac{Q(y)^{2}}{t(y)^{2}} d A
$$

Where, ' $V$ ' is the applied transverse shear load to the section; ' $I$ ' is the moment of inertia of the section about the section neutral axis; ' $t(y)$ ' denotes the width of the section at a depth of $\mathrm{y}$; ' $L$ ' is the length of the beam and ' $Q(y)$ ' represents the first moment of area above or below 
' $y$ ' about the neutral axis. The strain energy stored in the beam based on the applied shear load ' $\mathrm{V}$ ' and shear displacement say, ' $\Delta_{S}$ ' is given by:

$$
U=\Delta_{S} V
$$

So, from expression (5.6) and (5.7), ' $\Delta_{S}$ ' can be found out as follows:

$$
\Delta_{S}=\frac{V L}{G I^{2}} \int \frac{Q(y)^{2}}{t(y)^{2}} d A
$$

Comparing (5.2) and (5.8), we can express the effective shear area as:

$$
K A_{W}=\frac{I^{2}}{\int \frac{Q(y)^{2}}{t(y)^{2}} d A}
$$

It has been assumed that the SPSW and the RC panel are two separate entities contributing towards the shear stiffness of the C-PSW. It was also assumed that no sliding was occurring during deformation in shear. Based on the type of C-PSW designed here, no transfer of shear force was taken into consideration while formulating the equivalent shear rigidity of the C-PSW system. The effective shear area has been calculated separately for the SPSW component and the RC panel in terms of material steel. These are then added to find out the equivalent effective shear area for the C-PSW. To find out the exact shear effective area for a SPSW involves complex integration of up to fourth order polynomials. So, the set of simple formulae developed by Atasoy (2008) has been adopted here to find out the sectional parameter ' $\int \frac{Q(y)^{2}}{t(y)^{2}} d A$ ' called as ' $\beta$ ' by assuming linear 
variation of the parameter $\frac{Q(y)}{t(y)}$, along the continuous regions of the section. The formulae are as follows:

$$
\begin{aligned}
& \beta_{i}=\left(\beta_{1}\right)_{i}+\left(\beta_{2}\right)_{i} \\
& \left(\beta_{1}\right)_{i}=\frac{\left(Q_{1}\right)_{i}{ }^{2}+\left(Q_{2}\right)_{i}{ }^{2}}{w_{c, i}} d_{c, i} \\
& \left(\beta_{2}\right)_{i}=\frac{\left(Q_{3}\right)_{i}{ }^{2}+\left(Q_{4}\right)_{i}{ }^{2}}{2 w_{i}} b_{w} \\
& \left(Q_{1}\right)_{i}=A_{c f, i}\left(0.5 b_{w}+d_{c, i}\right) \\
& \left(Q_{2}\right)_{i}=\left(Q_{1}\right)_{i}+A_{c w, i} 0.5\left(b_{w}+d_{c, i}\right) \\
& \left(Q_{3}\right)_{i}=A_{c, i} 0.5\left(b_{w}+d_{c, i}\right) \\
& \left(Q_{4}\right)_{i}=\left(Q_{3}\right)_{i}+\frac{b w^{2}}{8} w_{i}
\end{aligned}
$$

Where, ' $A_{c w, i}$ ', is the area of each column web at storey $\mathrm{i}$; ' $A_{c f, i}$ ', is the area of the each Column flange at storey $\mathrm{i}$; ' $A_{c, i}$ ', is the area of each column at storey $\mathrm{i}$; ' $w_{i}$ ' is the infill plate thickness at storey $\mathrm{i}$; ' $w_{c, i}$ ', is the web thickness of each column at storey $\mathrm{i}$; ' $d_{c, i}$ ', is the depth of columns; ' $b_{w}$ ', is the width of infill plate. These formulae have been used and validated successfully by Topkaya et al. (2009) and Bhowmick et al. (2011). The effective shear area of the RC Panel component was however neglected, since the RC panel has no interaction with the surrounding boundary columns and is thus not expected to contribute to the shear stiffness of the overall structure. 


\subsection{Fundamental periods of C-PSWs using cantilever beam model}

Eight C-PSWs were considered for validating the equivalent shear-flexure cantilever beam model. All the C-PSWs were considered to have fixed support conditions at the base of their columns. Detailed finite element models of all the C-PSWs were created and an equal number of shear flexure cantilever model were created in ABAQUS to match their fundamental periods. The floor masses at each storey were concentrated on a single node in the cantilever beam model as shown in Figure 5.14.

Table 5.1 lists the values of effective shear area ' $K A_{W}$ ' and moment of inertia ' $I_{S W, i}$ ' calculated for each storey of the C-PSWs concerned. Table 5.2 presents a comprehensive comparison of the fundamental periods obtained from the equivalent shear-flexure cantilever models with that of the detailed finite element models for the selected C-PSWs. Table 5.2 exhibits that the fundamental period obtained from the equivalent shear-flexure beam model is in good agreement with that of the detailed finite element model. It can be observed from the results that the simple cantilever beam over-estimates the fundamental period of the C-PSWs for most of the cases by small margins. However, from a practical point of view, the differences can be considered insignificant. 
Table 5.1: Input parameter values in simple shear-flexure cantilever beam

\begin{tabular}{cccccccc}
\hline $\begin{array}{c}\text { Case } \\
\text { No. }\end{array}$ & $\begin{array}{c}\text { No. of } \\
\text { stories }\end{array}$ & $\begin{array}{c}\text { C-PSW } \\
\text { width }\end{array}$ & $\begin{array}{c}\text { Concerned } \\
\text { stories }\end{array}$ & $\begin{array}{c}\text { Moment } \\
\text { of inertia } \\
\text { 'I' of } \\
\text { SPSW } \\
\left(\mathrm{mm}^{4}\right)\end{array}$ & $\begin{array}{c}\text { Parameter } \\
\text { ' } \beta \text { ' }\end{array}$ & $\begin{array}{c}\text { Effective shear } \\
\text { area ' } K A_{W} \text { ' } \\
\left(\mathrm{mm}^{2}\right)\end{array}$ & $\begin{array}{c}\text { Moment of } \\
\text { inertia } \\
\text { ' } I_{S W, i} \text { ' of } \\
\text { C-PSW } \\
\left(\mathrm{mm}^{4}\right)\end{array}$ \\
\hline 1 & 1 & 3.8 & 1 & $4.02 \mathrm{E}+11$ & $8.20 \mathrm{E}+18$ & 19708 & $4.90 \mathrm{E}+11$ \\
2 & 1 & 5.7 & 1 & $1.60 \mathrm{E}+12$ & $8.87259 \mathrm{E}+19$ & 28861 & $1.92 \mathrm{E}+12$ \\
3 & 2 & 3.8 & 1,2 & $4.87 \mathrm{E}+11$ & $1.18 \mathrm{E}+19$ & 20099 & $5.74 \mathrm{E}+11$ \\
4 & 2 & 5.7 & 1,2 & $1.60 \mathrm{E}+12$ & $8.87259 \mathrm{E}+19$ & 28861 & $1.92 \mathrm{E}+12$ \\
5 & 4 & 3.8 & $1,2,3,4$ & $5.98 \mathrm{E}+11$ & $1.82 \mathrm{E}+19$ & 19648 & $6.84 \mathrm{E}+11$ \\
6 & 4 & 5.7 & $1,2,3,4$ & $1.75 \mathrm{E}+12$ & $1.06 \mathrm{E}+20$ & 28891 & $2.073 \mathrm{E}+12$ \\
7 & 6 & 3.8 & $3,4,5,6$ & $5.98 \mathrm{E}+11$ & $1.82 \mathrm{E}+19$ & 19648 & $6.84 \mathrm{E}+11$ \\
& & & 1,2 & $7.75 \mathrm{E}+11$ & $3.02 \mathrm{E}+19$ & 19888 & $8.60 \mathrm{E}+11$ \\
8 & 6 & 5.7 & $3,4,5,6$ & $1.46 \mathrm{E}+12$ & $7.35 \mathrm{E}+19$ & 29001 & $1.78 \mathrm{E}+12$ \\
& & & 1,2 & $2.11 \mathrm{E}+12$ & $1.54 \mathrm{E}+20$ & 28910 & $2.43 \mathrm{E}+12$ \\
\hline
\end{tabular}


Table 5.2: Comparison of fundamental periods of C-PSWs

\begin{tabular}{lcccc}
\hline $\begin{array}{l}\text { Case } \\
\text { No. }\end{array}$ & No. of stories & $\begin{array}{c}\text { C-PSW } \\
\text { width }\end{array}$ & \multicolumn{2}{c}{ Fundamental Period (seconds) } \\
\cline { 3 - 5 } & & & $\begin{array}{c}\text { Detailed FE } \\
\text { model }\end{array}$ & $\begin{array}{c}\text { Simple shear-flexure } \\
\text { beam model }\end{array}$ \\
\hline 1 & 1 & 3.8 & 0.12 & 0.13 \\
2 & 1 & 5.7 & 0.09 & 0.10 \\
3 & 2 & 3.8 & 0.27 & 0.28 \\
4 & 2 & 5.7 & 0.20 & 0.22 \\
5 & 4 & 3.8 & 0.59 & 0.63 \\
6 & 4 & 5.7 & 0.48 & 0.49 \\
7 & 6 & 3.8 & 1.15 & 1.15 \\
8 & 6 & 5.7 & 0.83 & 0.83 \\
\hline
\end{tabular}

\subsection{Conclusion}

A number of C-PSWs were considered comprising of varying dimensions and heights to find out their fundamental periods. Detailed finite element models of these C-PSWs were created and there fundamental periods were found out using ABAQUS. The fundamental periods obtained from the current code provisions were found to be lower than those obtained from detailed frequency analyses in general. The code formula was found to provide a significantly lower estimate of the fundamental periods of taller C-PSWs. This can lead to conservative estimates of the design seismic forces.

An equal number of equivalent shear-flexure cantilever beam models were created in ABAQUS and analyzed to find out their fundamental periods. The simple cantilever beam was considered to be made up of beam elements connected in series possessing equivalent bending and 
shear stiffness to that of the respective floors of the C-PSWs and the floor mass of the C-PSW was assumed to be concentrated as point mass at the nodes connecting the beam elements resembling the floor level. Some of the other assumptions included no slippage between the SPSW and the $\mathrm{RC}$ panel during deformation under bending or shear. No shear rigidity contribution from the RC panels were considered. It can be concluded from the study that the simple equivalent shearflexure cantilever beam model was quite accurately able to predict the fundamental periods of CPSWs. $75 \%$ of the fundamental periods predicted by the shear-flexure model was found to match very well with that of the detailed finite element model results. The simple cantilever beam model was found to overestimate the fundamental periods of C-PSWs by small margin in general. The maximum error found was about $10 \%$ for the 1 -storey 1.5 aspect ratio specimen. It can be explained that the RC panel, though not in contact with the boundary columns contributes limited shear stiffness to the system resulting in marginally shorter fundamental periods for the detailed finite element models when compared to the simple cantilever beam ones. 


\section{RATIONAL METHOD FOR DETERMINATION OF STUD SPACING AND CONCRETE PANEL THICKNESS FOR C-PSW}

\subsection{Introduction}

Shear studs which are used to connect the still infill plate with the concrete panel should be properly spaced to ensure optimum performance of the composite plate shear wall. Currently there are no guidelines on what would be the minimum or maximum spacing of the shear studs. Another important parameter is the thickness of concrete panel. The concrete panel must be thick enough to ensure global buckling of the steel plate does not occur prior to local buckling of the shear panel. AISC 2010 provides a recommendation of use of minimum of $200 \mathrm{~mm}$ concrete panel when the concrete panel is used in one side of the still infill plate, which is the case in this research. This chapter presents a rational method for determining shear stud spacing and thickness for the reinforced concrete panel. The method is based on classical buckling theory of stiffened plate.

\subsection{Buckling of composite plate shear wall}

The composite plate shear wall can be viewed as a stiffened steel plate shear wall where the concrete panel will act as stiffeners along the shear stud lines both horizontally and vertically. A stiffened steel shear wall can buckle in two modes: (1) global buckling mode of the full stiffened panel, and (2) local buckling mode within the sub panel. In a composite plate shear wall, the concrete panel is selected as to force the buckling of the steel infill plate from a global buckling mode to a localized buckling in the sub-panels (local buckling mode). Global buckling occurs when stiffeners (here concrete panel) have smaller moment of inertia. Also the concrete panel must be connected with the steel infill plate in such a way that steel plate reaches to yield prior to overall 
or local buckling. This requirement will be used to calculate the minimum shear stud spacing of C-PSWs.

\subsubsection{Local buckling mode for spacing of shear studs}

When a plate is subjected to a state of pure shear, the critical shear buckling stress can be obtained as

$$
\tau_{c l}=K_{S l} \frac{\pi^{2} E}{12\left(1-v^{2}\right)\left(\frac{b}{t}\right)^{2}}
$$

Where, ' $K_{S l}$ ' is the buckling coefficient for shear buckling stress; ' $b$ ' is the width of the steel plate; ' $t$ ' is the plate thickness; ' $E$ ' is the modulus of elasticity of steel plate; and ' $\boldsymbol{V}$ ' is the Poisson ratio of steel plate.

Critical stress coefficients, ' $K_{S l}$ ', for plates subjected to pure shear have been evaluated when the plate is clamped (edges restrained from out-of-plane rotation). For finite-length rectangular plate with clamped edges, Moheit (1939) provides following expressions for $K_{S l}$ :

$$
\begin{aligned}
& K_{S l}=5.6+\frac{8.98}{\alpha^{2}} \text { for } \alpha \leq 1 \\
& K_{S l}=8.98+\frac{5.6}{\alpha^{2}} \text { for } \alpha \geq 1
\end{aligned}
$$

Where, $\alpha=\frac{b}{d}, d$ and $b$ are two sides of rectangular plate with side $d$ as shorter side.

When, the plate is simply supported on four edges, Reissner (1932), and Seydel (1933) approximated the following expressions for ' $K_{S l}$ ': 


$$
\begin{aligned}
& K_{S l}=4.0+\frac{5.34}{\alpha^{2}} \text { for } \alpha \leq 1 \\
& K_{S l}=5.34+\frac{4.0}{\alpha^{2}} \text { for } \alpha \geq 1
\end{aligned}
$$

AISC 2010 requires that steel plates of C-PSWs fail is yielding rather than buckling the corresponding critical buckling stress should be greater than the yield stress. One approach to do this is to transform the concrete wall to vertical and horizontal stiffeners along the shear stud lines, as shown in Fig 6.1. Buckling of each sub panel can then be checked using elastic buckling theory considering steel connectors as fixed plate support points (AISC 2010; Choi et al., 2009).

As seen in Figure 6.1, the distance between vertical stiffeners (distance between vertical shear stud lines) is ' $\mathrm{C}_{1}$ ', whereas, the distance between horizontal stiffeners is ' $\mathrm{C}_{2}$ '. The shear studs are assumed to have a diameter of $\mathrm{D}$.

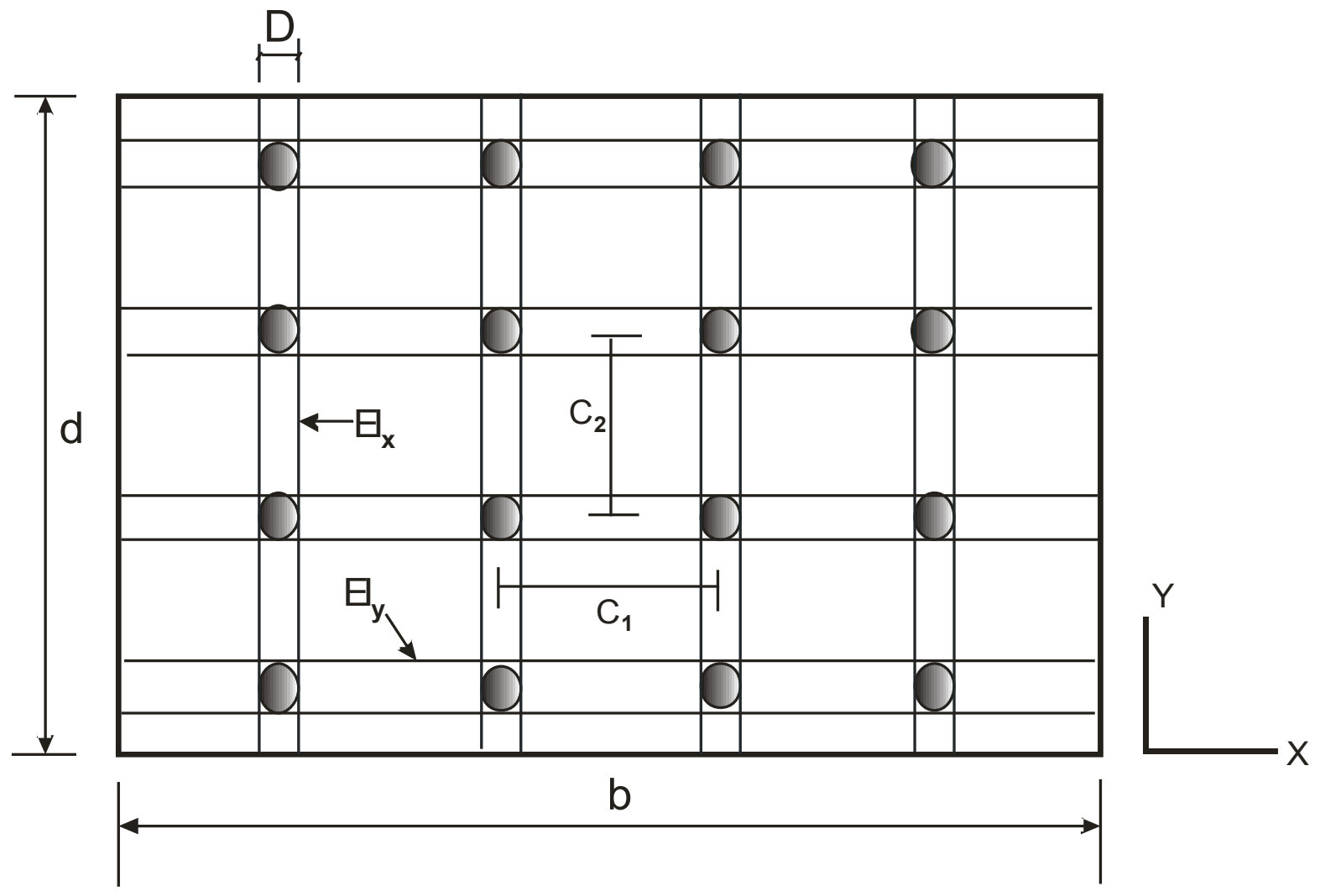

Figure 6.1: Representation of horizontal and vertical stiffeners in C-PSW 
The elastic critical shear buckling stress, ' $\tau_{c r l}$ ', for local buckling of a typical subpanel (surrounded by horizontal and vertical shear stud lines) is obtained as:

$$
\tau_{c r l}=K_{S l} \frac{\pi^{2} E}{12\left(1-v^{2}\right)\left(\frac{c_{1}}{t}\right)^{2}}
$$

For a typical C-PSW, the spacing of vertical and horizontal stiffeners are same, that is $c_{1}=c_{2}=c$ (say). For that case, $\alpha=1$, and $K_{S l}=14.58$. As stated in AISC 2010, shear studs must be spaced in as such that local buckling of each sub panel only occurs once the panel yields in shear. Thus,

$$
\tau_{c r l} \geq \tau_{s y}
$$

Where, ' $\tau_{s y}$ ' is shear yield stress of the steel infill plate, which is equal to $\frac{\sigma_{y}}{\sqrt{3}}$ with $\sigma_{y}$ yield strength of the steel infill plate. Thus equation (6.6) becomes:

$$
\begin{aligned}
& 14.58 \frac{\pi^{2} E}{12\left(1-v^{2}\right)\left(\frac{c}{t}\right)^{2}} \geq \frac{\sigma_{y}}{\sqrt{3}} \\
& c \leq \sqrt{\frac{20.77 E t^{2}}{\sigma_{y}\left(1-v^{2}\right)}}
\end{aligned}
$$

Equation (6.9) defines the maximum shear stud spacing that can be used to avoid any local buckling in the sub panel of C-PSW. For typical values of $E$ and $v$ for steel, ( $E=200,000 \mathrm{MPa}$ and $v=0.3$ ), equation (6.9) becomes: 


$$
c \leq 2136.5 t\left(\sigma_{y}\right)^{-\frac{1}{2}}
$$

For the selected C-PSWs $\left(t=4.8 \mathrm{~mm}\right.$ and $\left.\sigma_{y}=350 \mathrm{MPa}\right)$, the maximum shear stud spacing can be calculated as $548 \mathrm{~mm}$, which is higher than the shear stud spacing $(300 \mathrm{~mm})$ used in this research.

\subsubsection{Reinforced concrete panel thickness requirements}

AISC (2010) recommends that the thickness of the concrete encasement should be calculated to make sure that local buckling occurs in the sub panel instead of global buckling mode of the full C-PSW. The composite panel shall be first transformed into a stiffened plate with the shear stud lines as the horizontal and vertical stiffeners. The overall buckling can then be checked by using elastic buckling theory of stiffened plates or orthotropic plates. Exact solutions for long orthotropic simply supported plates in shear were first obtained by Syedel (1933). The shear stress for closely spaced stiffeners is:

$$
\tau_{c r g}=\frac{K_{S g} \pi^{2}}{d^{2} t}\left(D_{x}\right)^{\frac{3}{4}}\left(D_{y}\right)^{\frac{1}{4}}
$$

Where, ' $K_{S g}$ ' is the global buckling factor, which is a function of ' $D_{x}$ ', ' $D_{y}$ ', ' $c_{1}$ ', ' $c_{2}$ ', as well as the steel plate boundary conditions. The minimum values of ' $K_{S g}$ ' for plate to frame connection with pinned and rigid connections are 3.64 and 6.9 respectively.

$D_{x}=$ flexural stiffness for bending about $\mathrm{x}$-axis

$$
\begin{aligned}
& D_{x}=\frac{E I_{x}}{c_{1}}+\frac{E t^{3}}{12\left(1-v^{2}\right)} \\
& D_{y}=\text { flexural stiffness for bending about } \mathrm{y} \text {-axis }
\end{aligned}
$$




$$
D_{y}=\frac{E I_{y}}{c_{2}}+\frac{E t^{3}}{12\left(1-v^{2}\right)}
$$

To make sure that local buckling mode occurs instead of global buckling, following condition must be satisfied:

$$
\begin{aligned}
& \tau_{c r g}>\tau_{c r l} \\
& \frac{K_{S g} \pi^{2}}{d^{2} t}\left(\frac{E I_{x}}{c_{1}}+\frac{E t^{3}}{12\left(1-v^{2}\right)}\right)^{\frac{3}{4}}\left(\frac{E I_{y}}{c_{2}}+\frac{E t^{3}}{12\left(1-v^{2}\right)}\right)^{\frac{1}{4}}>K_{S l} \frac{\pi^{2} E}{12\left(1-v^{2}\right)\left(\frac{c_{1}}{t}\right)^{2}}
\end{aligned}
$$

To simplify Eq. (6.13), the vertical and horizontal stiffeners are assumed to have the same moment of inertia, $I_{x}=I_{y}=I$ (say). Also, the stiffeners are assumed to be equally spaced, that is $\quad c_{1}=c_{2}=c$ (say). Equation (6.13) becomes as follows:

$$
\begin{aligned}
& \frac{K_{S g} \pi^{2}}{d^{2} t}\left(\frac{E I}{c}+\frac{E t^{3}}{12\left(1-v^{2}\right)}\right)>K_{S l} \frac{\pi^{2} E}{12\left(1-v^{2}\right)\left(\frac{c}{t}\right)^{2}} \\
& \frac{I}{c}>\frac{K_{S l}}{K_{S g}} \frac{d^{2} t^{3}}{12\left(1-v^{2}\right) c^{2}}-\frac{t^{3}}{12\left(1-v^{2}\right)}
\end{aligned}
$$

Using $v=0.3$

$$
I>0.092\left[\frac{K_{S l} d^{2} t^{3}}{K_{S g} c}-c t^{3}\right]
$$

For a concrete panel with thickness ' $h$ ', stud diameter of 'D' and modular ratio of $n\left(=\frac{E_{S}}{E_{c}}\right)$,

Eq. (6.16) becomes: 


$$
\begin{aligned}
& \frac{D h^{3}}{3 n}>0.092\left[\frac{K_{S l} d^{2} t^{3}}{K_{S g} c}-c t^{3}\right] \\
& h>0.65 t\left[\frac{K_{S S} d^{2} n}{K_{S g} c D}-\frac{c n}{D}\right]^{1 / 3}
\end{aligned}
$$

Equation (6.18) can be used to calculate minimum concrete panel thickness required to avoid global buckling of C-PSW. A minimum value of 3.64 can be used for global buckling ' $K_{S g}$ 'to obtain conservative estimate of concrete panel thickness. For the ' $K_{S l}$ ' value, one can conservatively use 14.58 when horizontal and vertical shear studs have same spacing. For the selected C-PSWs, for a given shear stud spacing, ' $C$ ' of $300 \mathrm{~mm}$, the concrete panel thickness is calculated as $155 \mathrm{~mm}$, which is less than the minimum required concrete panel thickness used in this research.

\subsection{Conclusion}

Two equations, one for determination of maximum shear stud spacing and the other one for determination of minimum concrete panel thickness were developed using the concepts of classical buckling theory of stiffened steel plate. The equations showed that the shear stud spacing and the concrete panel thickness used for all the selected C-PSWs in this research meet the requirements. 


\section{SUMMARY AND CONCLUSIONS}

\subsection{Summary}

A non-linear finite element model was developed to study the behaviour of composite plate shear wall system. The finite element model included detailed concrete material model based on available concrete constitutive models in literature. It also included suitable bolt material models based on tension push up tests and bilinear steel model. The finite element model included shell elements and beam elements which were used to model the plate components and the bolts respectively. The validated finite element model was next employed to model a 4-storey and a 6storey C-PSW assumed to be used in buildings in Vancouver to study their nonlinear dynamic seismic behaviour. Nonlinear seismic analyses were carried out under spectrum compatible ground motions which included sets of both real and simulated ground motions. A set of eight C-PSWs as part of office buildings located at Vancouver with different geometry were designed, modelled and analysed to find out their fundamental periods and evaluate the existing code formula. The CPSWs comprised of aspect ratios 1 and 1.5. The detailed and validated finite element model developed was employed for this purpose. The C-PSWs were 1-storey, 2-storey, 4-storey and 6storey structures. A simple shear flexure cantilever formulation was tested for determining the fundamental periods of C-PSWs. For this purpose, the set of eight detailed finite element models of C-PSWs were used. A simple cantilever beam was modelled comprising of beam elements representing the storey levels of the C-PSW and the nodes connecting the beam elements as the storey levels, where the mass at each storey were concentrated. The bending and shear rigidities were found out from some existing formulations and were incorporated in the properties of the 
beam elements. This research also develops equation based on classical buckling theory to determine the maximum shear stud spacing connecting the steel infill and RC panel. It also provides a formulation for the determination of minimum thickness required for the $\mathrm{RC}$ panel.

\subsection{Conclusions}

Some of the important findings of this research are as follows:

- The finite element model developed was found to provide excellent co-relation with the experimental specimen in quasi-static pushover analyses. The model captured all essential behavioral features of the test specimen analysed.

- The 4-storey and 6-storey C-PSW finite element specimens analysed under spectrum compatible dynamic seismic loads were found to provide excellent structural performance in terms of stiffness, ductility, and high shear strength; accompanied by minimal damage in terms of concrete cracking, crushing and primary structural failure.

- It was observed from the seismic analyses that the AISC 341-10 underestimates the shear strength of C-PSWs. The study infers that the boundary columns and RC-panel together can contribute towards a significant amount of shear strength ignored in the current practice.

- The steel column peak bending moment and axial force generated during the nonlinear seismic analyses has been presented comprehensively in this studies. It can be concluded that the steel vertical boundary elements designed according to Berman and Bruneau (2008) capacity design concept serves well for design of columns for C-PSWs. 
- The inter-storey drifts obtained from the nonlinear time history analyses were within the limits of were well within the NBC 2010 limit of $2.5 \%$ of the inter-storey height.

- It can be inferred from the frequency analyses of these C-PSWs that the current code formula predicts periods that are generally shorter than those obtained from detailed finite element analysis.

- The simple shear flexure cantilever was found to overestimate the fundamental periods by small margins. It can be observed from the results that the simple shear-flexure model slightly underestimated the stiffness values and the shear stiffness contribution from the RC panel is minimal.

- Finally, two equations were developed for the determination of shear stud spacing and determination of minimum concrete panel thickness. The equations are simple and easy to use.

\subsection{Scope for future work}

A limited number of C-PSWs have been analysed in this work. More C-PSW systems with varying geometry and parameters need to be tested before final design recommendations can be made. The effect of various geometric and material parameters of the C-PSWs on the overall performance of the structures need to be carried out in a wider scale. Analytical and experimental studies on different forms of C-PSWs can be carried out using other mechanisms other than employing a RC panel to restrain out of plane overall buckling of the steel infill. 
The effect of the type and numbers of bolt connections between the steel infill and the RC panels on the shear contribution of the RC panels to the total shear strength of the C-PSW needs to be studied in a detailed manner. This study can lead to an improved formulation for the shear and bending rigidities of a C-PSW resulting in an improved shear-flexure cantilever model. In addition, more C-PSWs should be analysed to develop an empirical formula for estimation of fundamental periods of C-PSWs.

The Finite element model used in thus study did not include the bond slip at the reinforced concrete panel and the steel plate interface. It is recommended that future analytical research should include non-linear load-slip characteristics of the headed shear studs, obtained from representative push-off tests.

Current design codes provides a strip model to study the behavior of steel plate shear wall. It would be desirable by design engineers to have such a simplified model to accurately predict the inelastic behavior of C-PSW. Therefore, further research should be conducted to achieve this goal.

Future study should investigate use of cold-rolled steel plate as a mean to reduce the demand on boundary members of C-PSWs designed according to capacity design principle. 


\section{REFERENCE}

Abolhassan, A. 2002. Seismic Behaviour and Design of Composite Steel Plate Shear Walls. Structural Steel Educational Council.

AISC 341-10. Seismic Provisions for Structural Steel Buildings. American Institute of Steel Construction, Chicago, Illinois.

Allen, H.G. and Bulson, P.S. 1980. Background to Buckling. McGraw Hill Book Company, U.K.

Amir, A., Hamde, A., Soheil, S. 2012. The Effects of Bolt Spacing on Composite Shear Wall Behaviour. World Academy of Science, Engineering and Technology 702012.

Armaanidis V.I. 2003. A model for the shear strength of Rough Rock Discontinuities under Low Normal Stress. Msc Dissertation, School of Civil Engineering and Geosciences, University of Newcastle upon Tyne, UK.

ASCE. 2010. Minimum Design Loads for Buildings and Other Structures. ASCE/SEI 7-10. American Society of Civil Engineers, Reston, Virginia.

Atasoy, M. 2008. Lateral stiffness of unstiffened steel plate shear walls. MS thesis, Middle East Technical University, Ankara, Turkey.

Beckwith G., Bedenkop D. V. 1973. An investigation of the Load Carrying Capacity of Drilled Cast-in-Place Concrete Piles Bearing on Coarse Granular Soils and Cemented Alluvial Fan Deposits. Report No. AHD-RD-10-122.

Belarbi, H., and T. C. C. Hsu. 1994. Constitutive laws of concrete in tension and reinforcing bars stiffened by concrete. ACI Structural Journal 91(4): 465-474. 
Bergman, S., and Reissner, H. 1932. Über die Knickung von rechteckigen Platten bei Schubbeanspruchung. Z. Flugtech Motorluftschiffahrt, Vol. 23, p. 6.

Berman J.W. and Bruneau M. 2008. Capacity Design of Vertical Boundary Elements in Steel Plate Shear Walls. Engineering Journal. First Quarter: 57-71.

Bhowmick, A.K., Grondin, G. Y., and Driver, R.G. 2011. Estimating Fundamental Periods of Steel Plate Shear Walls. Engineering Structures. 33 (6):1883-1893.

Brost R., Vermeer P. A. 1984. Possibilities and Limitations of Finite Elements for Limit Analysis. Geotechnique. No. 2, Vol. 34, 199-210.

Chang, G.A., and Mander, J.B. 1994. Seismic Energy Based Fatigue Damage Ananlyses of Bridge Columns. Part 1 - Evaluation of Seismic Capacity. NCEER Technical Report No. NCEER-94-0006, State University of New York, Buffalo, N.Y.

Chen, A. C. T., and Chen, W. F. 1975. Constitutive Relations for Concrete. Journal of Engineering Mechanics Division, ASCE, 101(4), 465-481.

Choi, B. J., Kim, K. Y., Kim, C. H., and Kim, T. Y. 2009. Experimental Compression Behavior of Stiffened Steel Plate Concrete (SSC) Structures under Compression Loading. Proceedings of 20th International Conference on Structural Mechanics in Reactor Technology (SMiRT 20), Espoo, Finland, August 9-14, Division 5, Paper 2008.

CSA. 2009. Limit states design of steel structures. CAN/CSA-S16-09, Canadian Standards Association, Toronto, ON. 
Darwin, D., and Pecknold, D. A. 1977. Nonlinear Biaxial Stress-Strain Law for Concrete. Journal of Engineering Mechanics Division, ASCE, 103(2), 229-241.

Driver R.G., Kulak G.L., Kennedy D.J.L. and Elwi A.E. 1997. Seismic behaviour of steel plate shear walls. Structural Engineering Report No. 215. Department of Civil and Environmental Engineering, University of Alberta, Canada.

Driver R.G., Kulak G.L., Kennedy D.J.L. and Elwi A.E. 1998a. Cyclic test of a Four- Storey Steel Plate Shear Wall. ASCE Journal of Structural Engineering, Vol. 124, No. 2, 112-120.

Driver R.G., Kulak G.L., Kennedy D.J.L. and Elwi A.E. 1998b. FE and Simplified Models of Steel Plate Shear Wall. ASCE Journal of Structural Engineering, Vol. 124, No. 2, 121-130.

Gail, A., Karen, A., Bernie, D. Engineering seismology toolbox.

Hansen, B. 1958. Line ruptures regarded as narrow rupture zones. Basic equations based on kinematic considerations. Proc. Conf. Earth Pressure Probl. Brussels.

Hibbitt, Karlsson, and Sorensen. 2011. ABAQUS/Standard User's Manual. Version 6.11, HKS Inc., Pawtucket, RI.

Hilber, H.M., Hughes, T.J.R., and Taylor, R.L. 1978. Collocation, dissipation and 'overshoot' for time integration schemes in structural dynamics. Earthquake Engineering and Structural Dynamics, 6: 99-117. 
Hsu, L. S. and Hsu, T. C. T. 1994. Stress-Strain Behaviour of Steel-Fiber High-Strength Concrete under Compression. Proceeding of ACI Structures Journal, 91(4), 448-457.

Hsu, L.S. and Hsu C.T.T. 1994. Complete stress-strain behaviour of high-strength concrete under compression. Magazine of Concrete Research, 46(169): 301-312.

Hsu. T. T. C., and Zhang, 1996. Tension stiffening in reinforced concrete membrane elements. ACI Structural Journal 93(1): 108-115.

Hsu, T. T. C., and Zhu, R. R. H. 2002. Softened membrane model for reinforced concrete elements in shear. ACI Structural Journal 99(4): 460-469.

Isobata, O. 1978. On an Anisotropic Constitutive Model of Concrete for the FEM Nonlinear Stress Analysis. Transactions of Architectural Institute of Japan, 265, 11-18.

Jankowiak and Lodygowski. 2005. Identification of parameters of concrete damage plasticity constitutive model. Foundations of Civil and Environmental Engineering. No. 6.

Kotsovos, M. D., and Newman. J. B. 1978. Generalized Stress-Strain Relations for Concrete. Journal of Engineering Mechanics Division, ASCE, 104(4), 845-856.

Kotsovos, M. D., and Newman. J. B. 1979. Mathematical Description of Deformational Behaviour of Concrete under Complex Loading. Magazine of Concrete Research, 131(107), 7790.

Kulak, G. L., 2005. High Strength Bolting for Canadian Engineers. Canadian Institute of Steel Construction. 
Kupfer, H. B., and Gerstle, K. 1978. Behaviour of Concrete under Biaxial Stresses. Journal of Engineering Mechanics Division, ASCE, 99(4), 853-866.

Lamontagne, M., Halchuk, S., Cassidy, J. F. and Rogers. G. C. 2008. Significant Canadian Earthquakes of the Period 1600-2006. Seismological Research Letters Volume 79, Number 2 March/April 2008.

Lanhui, G., Ran L., Qin R. and Sumei Z. 2012. Cyclic behaviour of SPSW and CSPSW in composite frame. Thin-Walled Structures 51 (2012) 39-52.

Lanhui, G., Qin, R., Xinbo M. and Sumei Z. 2013. Analysis of composite steel plate shear walls connected with frame beams only. Institution of Civil Engineers.

Lee, J., and Fenves, G. L. 1998. Plastic-Damage Model for Cyclic Loading of Concrete Structure. Journal of Engineering Mechanics, ASCE, 124(8), 892-900.

Lubell S., Prion H. G. L., Ventura C. E. and Rezai M. April, 2000. Unstiffened steelplate- shear wall performance under cyclic loading. Journal of Structural Engineering 126(4): 453-460.

Lubliner, J., Oliver, J., Oller, S. and Onate, E. 1989. A Plastic-Damage Model for Concrete. International Journal of Solids and Structures, 25(3), 299-326.

Mansour, M., Lee, J. and Hsu, T. T. C. 2001. Cyclic stress-strain curves of concrete and steel bars in membrane elements. ASCE Journal of Structural Engineering 127(12): 1402-1411. 
Moheit, W. 1939. Schubbeulung rechteckiger Platten mit eingespannten Rändern. Thesis, Technische Hochschule Darmstadt, Leipzig, Germany.

Naumoski, N., Saatcioglu, M., and Amiri-Hormozaki, K. 2004. Effects of Scaling of earthquake excitations on the dynamic response of reinforced concrete frame buildings. $13^{\text {th }}$ World Conference on Earthquake Engineering. 2917: 15.

NRCC. 2010. National Building Code of Canada (NBCC). Canadian Commission on Building and Fire Codes, National Research Council of Canada, Ottawa, ON.

Pang, X.D., and Hsu, T. T. C. 1995. Behaviour of reinforced concrete membrane elements in shear. ACI Structural Journal 92(6): 665-679.

PEER. 2010. NGA Strong Motion Database. Pacific Earthquake Engineering Research Center.

Popovics, S. 1973. Numerical Approach to the Complete Stress-Strain Curve of Concrete. Cement and Concrete Research 3(5): 583-599.

Qu, B., Bruneau, M. 2008. Capacity Design of Intermediate Horizontal Boundary Elements in Steel Plate Shear Walls. ASCE Journal of Structural Engineering.

Rahai, A. and Hatami, F.2009. Evaluation of composite shear wall behaviour under cyclic loadings. Journal of Constructional Steel Research, 65:1528-1537.

Rollins K. M. 1997. Drilled Shaft Side Friction in Gravelly Soils. Report No. UT-90.02. 
Seydel, E. 1933. Über das Ausbeulen von rechteckigen isotropen oder orthogonalanisotropen Platten bei Schubbeanspruchung. Ing. Arch., Vol. 4, p. 169.

Syed S.Q. 2012. Seismic Probabilistic Fragility Assessment of Reinforced Concrete Shear Wall Structures in Nuclear Power Plants. North Carolina State University.

Thorburn L.J., Kulak G.L. and Montgomery C.J. 1983. Analysis of Steel Plate Shear Walls. Department of Civil Engineering, University of Alberta, Edmonton, Alberta: Structural Engineering Report No. 107.

Timler P.A., and Kulak G.L. 1983. Experimental Study on Steel Plate Shear Walls. Structural Engineering Report o. 114, Department of Civil Engineering, University of Alberta, Edmonton, Canada.

Timoshenko, S. 1955. Strength of materials. Part 1. Elementary theory and problems. Third Ed. D. Van Nostrand Co. Inc., Princeton. N. Y.

Topkaya, C. and Kurban, C. O. 2009. Natural periods of steel plate shear wall systems. Journal of Constructional Steel Research, 65(3): 542-551.

Tremblay, R., Léger, P., and Tu., J. 2001. Inelastic seismic response of concrete shear walls considering P-delta effects. Canadian Journal of Civil Engineering. 28: 640-655.

Wan T. Tsai. 1988. Uniaxial Compressional Stress-Strain Relation of Concrete. J. Struct. Eng., 114(9), 2133-2136.

Zhao and Astaneh-A. 2004. Cyclic behaviour of traditional and innovative composite shear wall. $13^{\text {th }}$ World Conference on Earthquake Engineering. 
Zhao, Q. and Astaneh-Asl, A. 2004. Cyclic Behaviour of Traditional and Innovative Composite Shear Walls. Journal of Structural Engineering, 130: 271-284.

Zhao, Q. and Astaneh-Asl, A. 2007. Seismic Behaviour of Composite Shear Wall Systems and Application of Smart Structures Technology. Steel Structures 7: 69-75 